\author{
Universidade de São Paulo \\ Faculdade de Medicina de Ribeirão Preto \\ Departamento de Clínica Médica
}

Márcio Eloi Colombo Filho

\title{
DETECÇÃO DE SÍNDROME DE FRAGILIDADE EM IDOSOS VIA PLATAFORMA WEB/MOBILE
}


Márcio Eloi Colombo Filho

\title{
Detecção de Síndrome de Fragilidade em idosos via plataforma web/mobile
}

\author{
Versão Original
}

Dissertação apresentada à Faculdade de

Medicina de Ribeirão Preto - USP para obtenção do Título de Mestre em Investigação Biomédica.

Área de concentração: Clínica Médica

Orientador: Prof. Dr. Anderson Marliere Navarro 
Autorizo a reprodução e divulgação total ou parcial deste trabalho, por qualquer meio convencional ou eletrônico, para fins de estudo e pesquisa, desde que citada a fonte.

\section{FICHA CATALOGRÁFICA}

Colombo Filho, Márcio Eloi

Detecção de Síndrome de Fragilidade em idosos via plataforma web/mobile. Ribeirão Preto, 2018.

85 p.: il.; $30 \mathrm{~cm}$

Dissertação de Mestrado, apresentada à Faculdade de Medicina de Ribeirão Preto/USP. Área de concentração: Clínica Médica.

Orientador: Marliere Navarro, Anderson.

1. Mobile. 2. Web. 3. Geriatria. 4. Síndrome de Fragilidade. 


\section{FOLHA DE APROVAÇÃO}

MÁRCIO ELOI COLOMBO FILHO

Dissertação apresentada à Faculdade de

Medicina de Ribeirão Preto - USP para obtenção do Título de Mestre em Investigação Biomédica.

Área de concentração: Clínica Médica

Orientador: Prof. Dr. Anderson Marliere Navarro

Aprovado em:

Banca Examinadora

Prof. Dr.

Instituição:

Assinatura:

Prof. Dr.

Instituição:

Assinatura:

Prof. Dr.

Instituição:

Assinatura: 


\section{Agradecimentos}

Primeiramente à Deus que, por amor, nos deu o dom da vida e tudo nesse mundo.

À Márcio e Regina, meus pais, que me criaram com tanto amor e carinho e que me proveram com tudo que pavimentou meu caminho até aqui.

Ao Prof. Dr. Anderson Marliere Navarro pela oportunidade e orientação neste projeto.

À Dra. Karina Pfrimer, Dr. Paulo Fernandes Formiguieri, Prof. Dr Eduardo Ferriolli e a todos que participaram do grupo Gerontopole pelo suporte na construção e execução deste projeto.

À Jurek Kirakowski por fornecer acesso ao questionário WAMMI e pelo suporte durante o tempo em que eu estava coletando as respostas.

À todas as pessoas que colaboraram com a minha trajetória. 


\section{RESUMO}

Colombo Filho, M. E. Detecção de Síndrome de Fragilidade em idosos via plataforma web/mobile [dissertação]. Ribeirão Preto: Universidade de São Paulo, Faculdade de Medicina de Ribeirão Preto, 2018. $85 f$.

O Ministério da Saúde define os idosos como "pessoas com idade igual ou superior a 60 (sessenta) anos". A população brasileira ganhou 4,8 milhões de idosos de 2012 a 2017, superando a marca dos 30,2 milhões. Em estudos 6,9\% dos idosos foram identificados como frágeis e $47 \%$ apresentaram fragilidade intermediária. As divisões de Nutrição e Metabolismo do departamento de Ciências da Saúde e de Geriatria do departamento de Clínica Médica do Hospital das Clínicas de Ribeirão Preto, investiram na identificação de idosos frágeis na comunidade, uma adaptação do projeto francês Gerontopole de Toulouse. No entanto o protocolo inicial foi feito em fichas de papel, a informação em papel está disponível somente a um profissional ao mesmo tempo, possui baixa mobilidade e está sujeito a ilegibilidade, ambiguidade, perda de dados, dificuldade de pesquisa coletiva, falta de padronização, dificuldade de acesso, e requer amplos espaços para arquivamento. Neste trabalho foi desenvolvida uma plataforma web / mobile para avaliação e diagnóstico de fragilidade em idosos. Foi utilizada a arquitetura de projetos MVC, e as linguagens PHP, JavaScript, CSS3 e HTML5. O sistema possui as funcionalidades de cadastro, edição e deleção para todas as escalas, pacientes e usuários, também é possível gerar relatórios das escalas. Os usuários avaliaram o sistema no teste de usabilidade WAMMI resultando na pontuação 75 de 100 . A maior parte das recomendações de usabilidade e segurança da Sociedade Brasileira de Informática em Saúde foram atendidas pelo software desenvolvido.

Palavras-chave: Mobile; Web; Geriatria; Síndrome de Fragilidade. 


\begin{abstract}
Colombo Filho, M. E. Detection of Fragility Syndrome in the elderly via web/mobile platform [dissertation]. Ribeirão Preto: University of São Paulo, Medicine School of Ribeirão, 2018. 85f.

The Ministry of Health defines the elderly as "persons aged 60 or over (60)". The Brazilian population gained 4.8 million elderly people from 2012 to 2017, surpassing the mark of 30.2 million. In studies $6.9 \%$ of the elderly were identified as fragile and $47 \%$ presented intermediate frailty. The Nutrition and Metabolism and Geriatrics divisions of the Clinical Medicine Department of the Hospital das Clínicas of Ribeirão Preto invested in the identification of fragile elderly in the community, an adaptation of the French Gerontopole project in Toulouse. However the initial protocol was made in paper chips, paper information is available only to a professional at the same time, has low mobility and is subject to illegibility, ambiguity, loss of data, difficulty in collective research, lack of standardization, difficult to access, and requires ample space for archiving. In this project a web / mobile platform was developed to evaluate and diagnose frailty in the elderly. The MVC project architecture was used, along with the languages PHP, JavaScript, CSS3 and HTML5. The system has the registration, editing and deletion features for all scales, patients and users, it is also possible to generate reports of scales. The users evaluated the system in the WAMMI usability test resulting in a score of 75 out of 100. Most of the usability and security recommendations of the Brazilian Society of Health Informatics were met by the software developed.
\end{abstract}

Keywords: Mobile; Web; Geriatrics; Frailty Syndrome. 


\section{LISTA DE FIGURAS}

Figura 1 - Fluxo de atendimento e aplicação das escalas no protocolo. ....................19

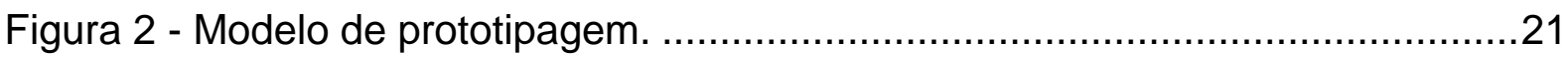

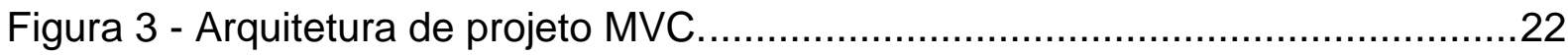

Figura 4 - Tela de cadastro de usuário no sistema. ..........................................25

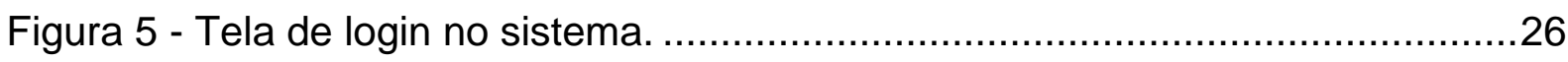

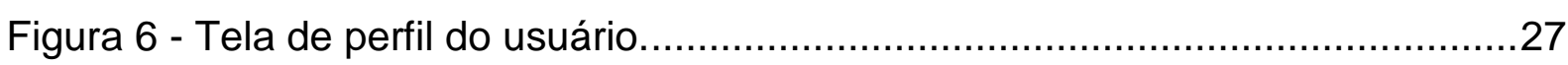

Figura 7 - Tela de gerenciamento de usuários, janela de confirmação de deleção...28

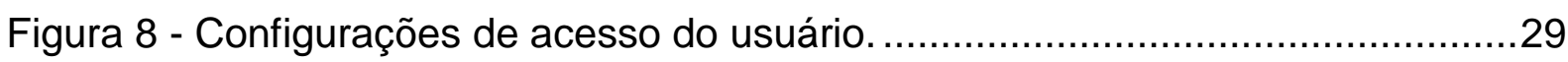

Figura 9 - Tela de cadastro de pacientes, guia de dados gerais............................30

Figura 10 - Tela de cadastro de pacientes, guia de cadastro de endereço do

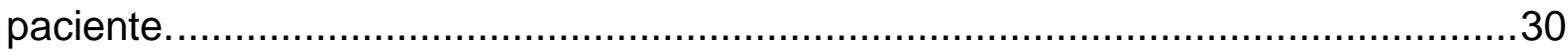

Figura 11 - Tela de cadastro de pacientes, guia de cadastro de foto do paciente. ...31

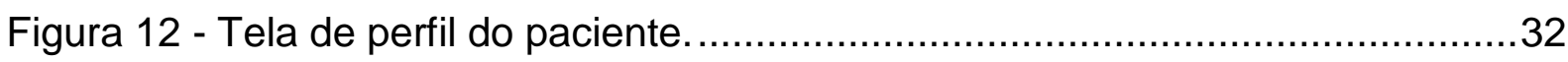

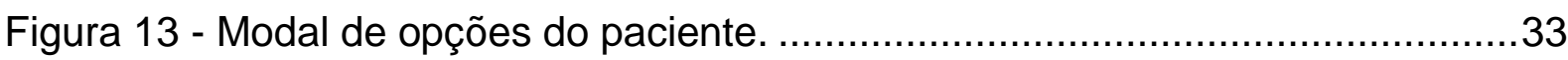

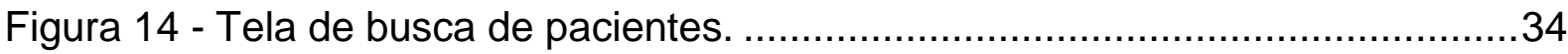

Figura 15 - Novo atendimento, seleção do tipo de escala......................................36

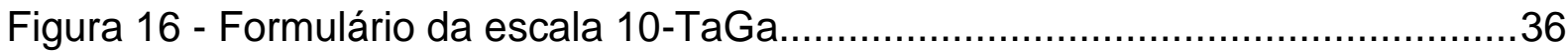

Figura 17 - Lista de atendimentos passados do paciente, janela de operações do

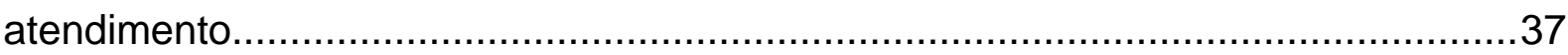

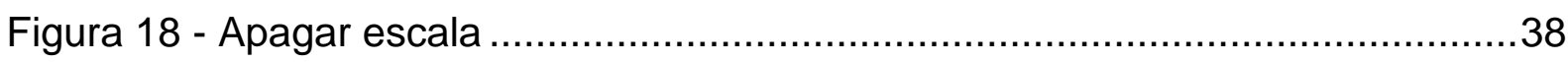

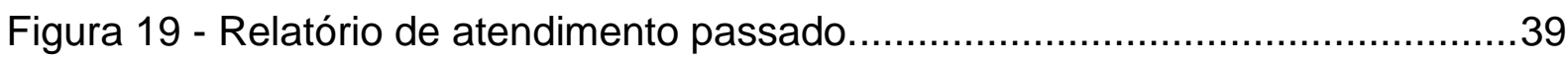

Figura 20 - Tela de atendimentos passados, busca de escala. ..............................40

Figura 21 - Modelo Entidade Relacionamento do banco de dados..........................41

Figura 22 - As dez respostas com maior divergência.............................................43

Figura 23 - As dez respostas com menor divergência .......................................... 44

Figura 25 - Quantidade de artigos por categoria ...............................................49 


\section{LISTA DE TABELAS}

Tabela 1 - Escalas do teste de usabilidade WAMMI ..........................................23

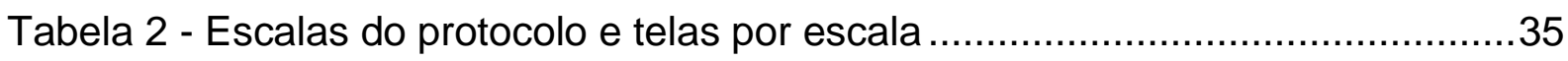

Tabela 3 - Pontuações das escalas de usabilidade .............................................42

Tabela 4 - Conjunto de dados das avaliações...................................................... 42

Tabela 5 - Respostas de campo aberto sobre interesse ou utilidade ........................45

Tabela 6 - Respostas de campo aberto sobre melhores aspectos..........................46

Tabela 7 - Respostas de campo aberto sobre possíveis falhas ..............................47

Tabela 8 - Como o usuário classifica sua habilidade e conhecimento de Internet ....48

Tabela 9 - Pontuação das escalas por habilidade e conhecimento de Internet........48

Tabela 10 - Adequação às normas da Sociedade Brasileira de Informática em Saúde 


\section{LISTA DE ABREVIATURAS E SIGLAS}

TACO

IBGE

CEP

CID-10

GPS

PDF
Tabela Brasileira de Composição de Alimentos - NEPA/Unicamp

Instituto Brasileiro de Geografia e Estatística

Código de Endereçamento Postal

Classificação Internacional de Doenças

Global Positioning System (Sistema de Posicionamento Global)

Portable Document Format (Formato Portátil de Documento) 


\section{SUMÁRIO}

1. INTRODUÇÃO

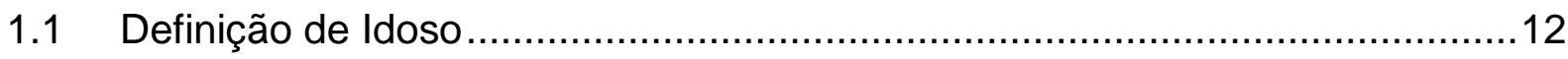

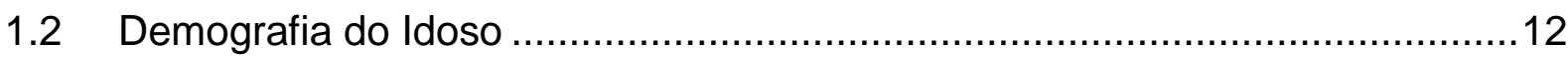

1.3 Dados de Hospitalização do Idoso ........................................................13

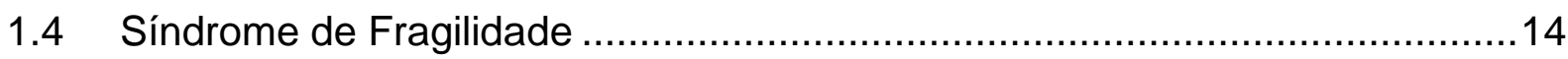

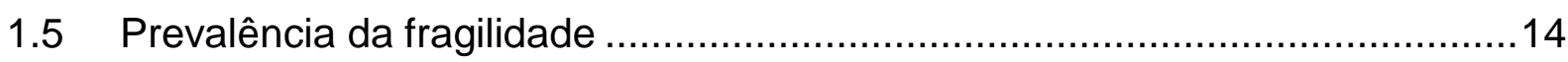

1.6 Gerontopole (Toulouse e Ribeirão Preto) …….........................................16

1.7 Armazenamento de dados (papel $x$ digital) …..............................................17

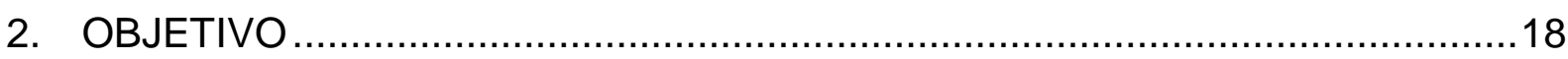

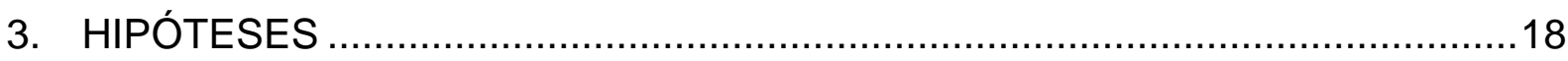

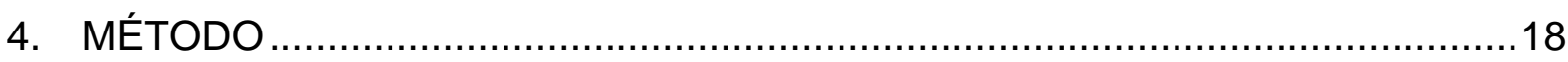

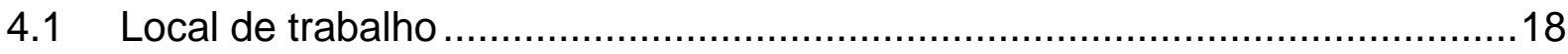

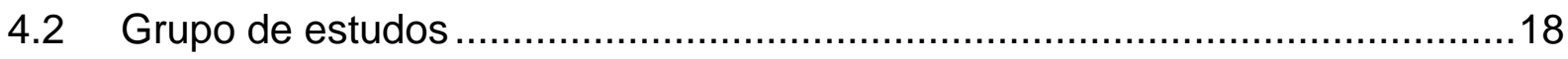

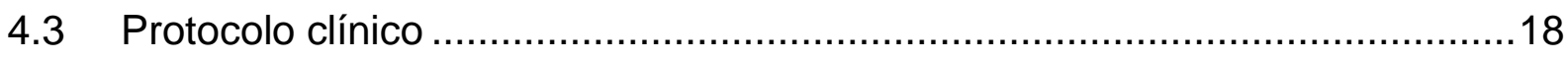

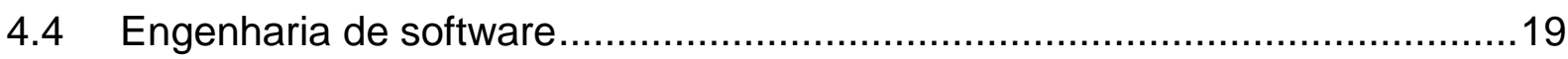

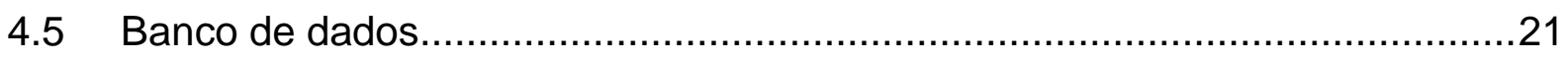

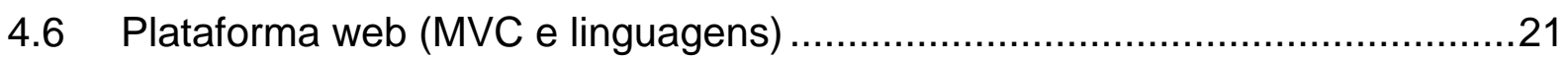

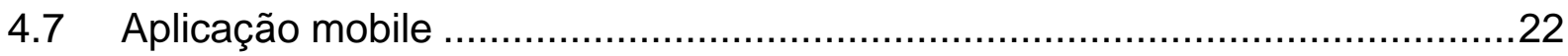

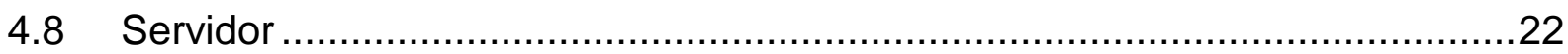

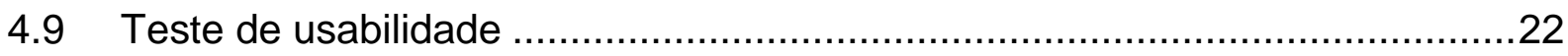

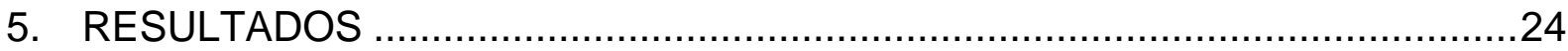

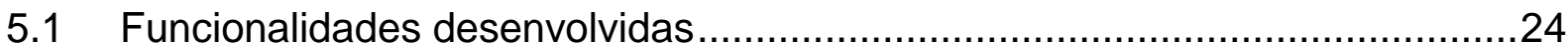

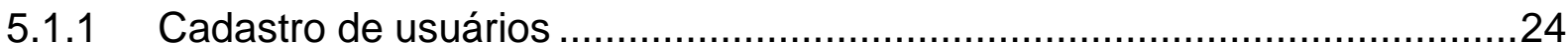

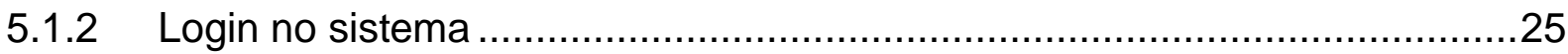

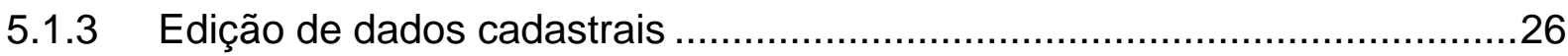

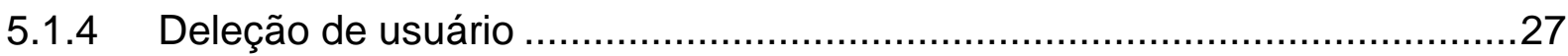

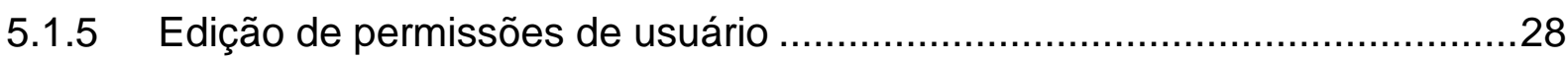

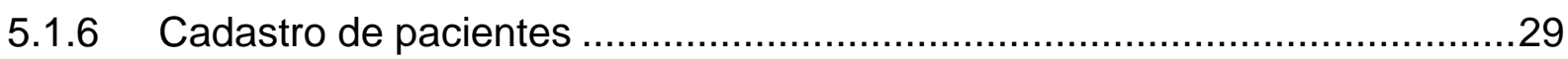

5.1.7 Edição dos dados de pacientes ..........................................................

5.1.8 Deleção dos dados de pacientes ..........................................................32

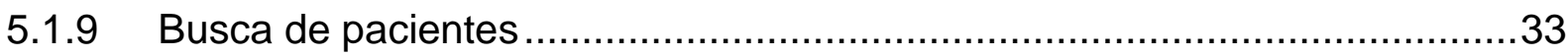

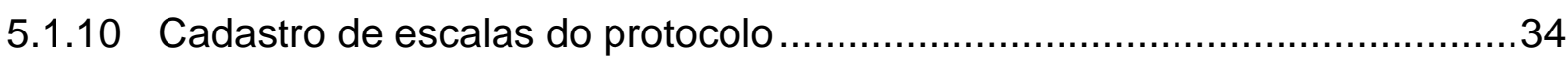

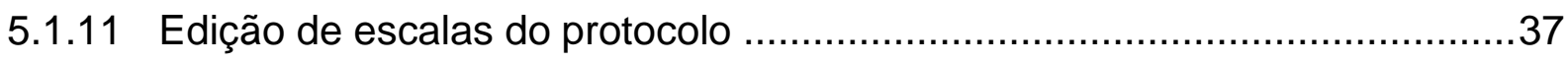




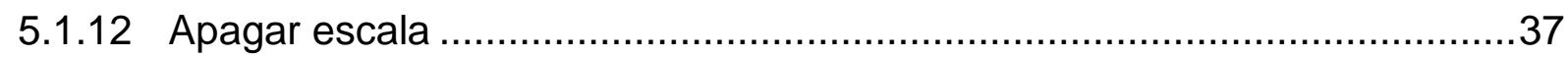

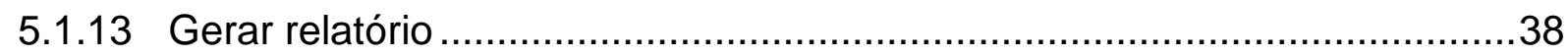

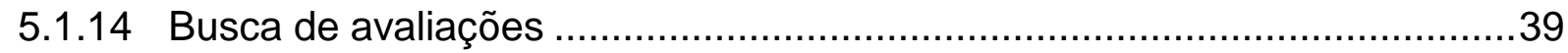

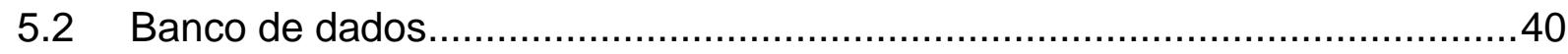

5.3 Resultados do teste de usabilidade WAMMI ............................................. 41

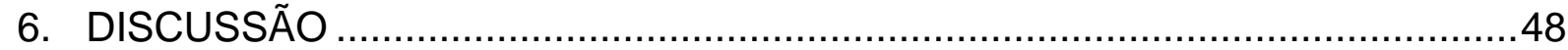

6.1 Tecnologia no tema Síndrome de Fragilidade .........................................48

6.2 Normas da Sociedade Brasileira de Informática em Saúde ............................50

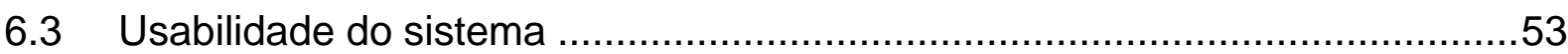

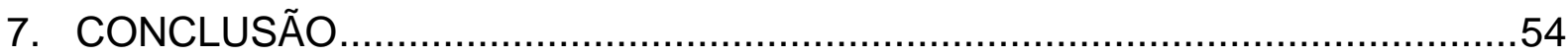

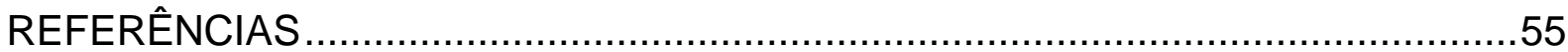

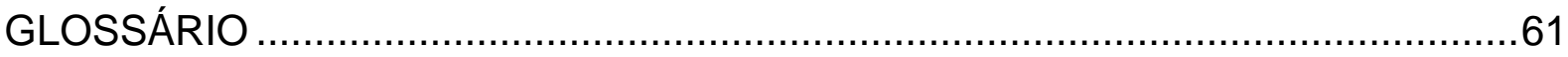

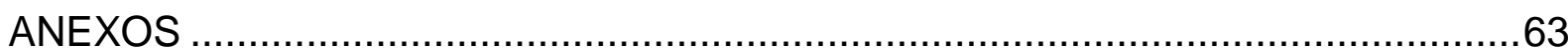




\section{INTRODUÇÃO}

\subsection{Definição de Idoso}

A Organização Mundial da Saúde (OMS), define o idoso como sendo todo indivíduo humano com 60 anos de idade ou mais. Entretanto, para efeito de formulação de políticas públicas, essa definição pode variar segundo a legislação de cada país. A OMS reconhece que, independentemente da idade mínima adotada, é importante levar em conta que a idade cronológica não é um marcador preciso para as alterações que acompanham o envelhecimento, podendo haver grandes variações quanto a condições de saúde, nível de participação na sociedade e nível de independência entre as pessoas idosas, em diferentes contextos (1).

Os fenômenos do envelhecimento e da velhice e a determinação de quem é considerado idoso, muitas vezes, são definidas pelas restritas modificações que ocorrem no corpo, na dimensão física. Mas é desejável que se perceba que, ao longo dos anos, são processadas mudanças também na forma de pensar, de sentir e de agir dos seres humanos que passam por esta etapa do processo de viver (2). É importante ressaltar que o ser humano idoso tem várias dimensões: biológica, psicológica, social, espiritual e outras, que necessitam ser consideradas para aproximação de um conceito que o abranja e que o perceba como ser complexo (3).

No Brasil, o Ministério da Saúde define no Estatuto do Idoso em seu Art. 1.ำ das Disposições Preliminares que: "É instituído o Estatuto do Idoso, destinado a regular os direitos assegurados às pessoas com idade igual ou superior a 60 (sessenta) anos" (4)

\subsection{Demografia do Idoso}

A população brasileira está envelhecendo, a faixa etária idosa é o segmento populacional que cresce mais rapidamente no país, um reflexo, dentre outros fatores, do aumento da expectativa de vida devido aos avanços que o sistema de saúde vem conquistando no decorrer dos anos (4).

Segundo o Instituto Brasileiro de Geografia e Estatística (IBGE), em 1991 a população com 60 anos ou mais no país contabilizava 10,7 milhões de pessoas 
(7,3\% da população total). No Censo de 2000 foram contabilizados cerca de 14 milhões de idosos (8,6\% da população total). Em 2009 o número de idosos subiu para 21,7 milhões de pessoas. Já em 2011, os idosos somavam 23,5 milhões dos brasileiros, mais que o dobro do registrado em 1991. Somente na comparação entre 2009 e 2011, o grupo aumentou 7,6\%, ou seja, mais 1,8 milhão de pessoas (5). Nos últimos anos a população brasileira manteve a tendência de envelhecimento e ganhou 4,8 milhões de idosos de 2012 a 2017, superando a marca dos 30,2 milhões. Os 4,8 milhões de novos idosos em cinco anos correspondem a um crescimento de $18 \%$ desse grupo etário. As mulheres são maioria expressiva nesse grupo, com 16,9 milhões (56\% dos idosos), enquanto os homens idosos são 13,3 milhões (44\% do grupo) (6).

As previsões mais conservadoras indicam que, em 2020, o Brasil será o sexto país do mundo em número de idosos, com um contingente superior a 30 milhões de pessoas (7).

\subsection{Dados de Hospitalização do Idoso}

No Brasil, em 1996, 15,8\% do total de hospitalizações no âmbito do Sistema Único de Saúde (SUS) - autorização de internação hospitalar (AIH) de tipo 1 -, correspondentes a 1,5 milhão de internações, ocorreram entre pessoas com 60 ou mais anos de idade, com um gasto de 659 milhões de dólares americanos. Naquele ano, os idosos representaram $7,9 \%$ da população do país, mas consumiram $27,2 \%$ do total gasto com internações hospitalares públicas (8). No ano de 2001, ocorreram 2.153.094 internações (AlH de tipo 1) entre idosos brasileiros, no âmbito do SUS. A soma de recursos pagos para todas essas $A l H$ foi de $R \$ 1$ 1.140.167.000. Acrescentando-se as $\mathrm{AlH}$ de tipo 5 a esses números, verifica-se que o número de internações entre idosos eleva-se para 2.237.923; e os recursos pagos, para cerca de 1,2 bilhão de reais, correspondendo a um aumento de 3,8\% e 6,2\%, respectivamente (9). Os idosos, que representavam $8,5 \%$ da população geral, responderam por $18,3 \%$ das hospitalizações. A taxa de internação hospitalar entre a população SUS-dependente, no âmbito do Sistema Único de Saúde na faixa etária de 60 anos ou mais $(15,2 \%)$ foi mais de duas vezes superior à verificada na faixa etária de 20-59 anos (7,2\%) (10). 


\subsection{Síndrome de Fragilidade}

O termo fragilidade tem surgido como um conceito muito importante em geriatria e gerontologia, aumentando na mesma proporção em que aumenta o número de idosos, e elevando o risco de eventos adversos à saúde como queda, incapacidades, institucionalização e mortalidade, repercutindo em impactos na vida dos idosos, seus familiares, cuidadores e toda a sociedade (11).

No entanto, ainda não existe um consenso sobre a definição de fragilidade. Há cerca de 30 anos é reconhecida por diferentes autores, a existência de um quadro de fragilidade que atingia alguns idosos, cujo conceito vem se modificando com o passar do tempo. Inicialmente a fragilidade foi definida apenas pela natureza funcional, ou seja, era considerado frágil o idoso com variáveis graus de dependência (12).

Na última década, a fragilidade tem sido definida como uma síndrome de declínio de energia, fundamentada em alterações que ocorrem com o envelhecimento, como sarcopenia, desregulação neuroendócrina e disfunção imunológica, que predispõe os idosos a redução acentuada da massa muscular e a um estado inflamatório crônico, que, caso associado a fatores extrínsecos de diversas naturezas, como doenças, imobilidade, diminuição da alimentação, entre outros, ocasiona um ciclo de redução de energia, aumentando a dependência e susceptibilidade a agressores, manifestando-se por velocidade de marcha reduzida, perda de peso, fadiga, diminuição da força de preensão e baixo nível de atividade física(13).

Segundo Vieira (14), os idosos fragilizados são aqueles que apresentam maior número de fatores associados e podem estar relacionados com maior ocorrência de doenças crônicas, quedas, sintomas depressivos, limitações em atividades instrumentais da vida diária, redução da autoeficácia, hospitalização e idade mais avançada.

\subsection{Prevalência da fragilidade}

A incidência e prevalência da síndrome da fragilidade variam principalmente pela falta de um consenso acerca da definição. Pelos critérios de Fried aplicados no 
Cardiovascular Health Study, 6,9\% dos idosos do foram identificados como frágeis ( $7,3 \%$ das mulheres e $4,9 \%$ dos homens), $46 \%$ como não frágeis e $47 \%$ como portadores de fragilidade intermediária (15). Em outros estudos a prevalência de frágeis encontrada varia entre oito e $37 \%(16,17,18)$.

A prevalência da fragilidade também sofre influência da localidade geográfica estudada, fatores socioeconômicos como educação parecem contribuir para esta diferença. Nos países europeus foi encontrada uma variação entre 5,8 a 27,3\%, sendo maior nos países do sul (19). Nos Estados Unidos (EUA) já se observaram variações entre 7 e 12\%; e de 21 a 48\% na América Latina e Caribe (18).

A baixa escolaridade, a qual é considerada um bom indicador do nível socioeconômico, é um importante preditor da evolução da síndrome da fragilidade. Estudos prévios têm demonstrado que o nível socioeconômico está associado com fragilidade prevalente e incidente. O possível mecanismo que explica esta associação é o estado inflamatório, que talvez seja a maior alteração fisiológica da fragilidade e que também resulta de déficit nutricional, menor acesso a cuidados médicos e alta prevalência de doenças crônicas, condições estas que também tem associação com o nível socioeconômico (20).

Esta síndrome tem prevalência crescente com a idade, sendo maior entre aqueles que têm 80 anos ou mais $(17,21)$. No estudo de Fried a prevalência da fragilidade foi de $23,1 \%$ no grupo de 90 anos ou mais e de 3,2\% entre 65 e 70 anos (15). Em diversos estudos, idosos classificados como frágeis apresentam associação com sexo feminino, viuvez, dependência nas atividades de vida diária, depressão, comorbidades e uso de várias medicações $(17,21)$. No estudo de Espinoza fragilidade foi um preditor de mortalidade. Estes dados sugerem que fragilidade implica em desfechos negativos (22).

Constatou-se que mulheres frágeis tiveram uma maior prevalência de doenças crônicas como osteoartrite, doença coronariana, hipertensão arterial sistêmica (HAS), câncer e doença pulmonar obstrutiva crônica (DPOC) quando comparadas com pré-frágeis e não frágeis. A relação entre fragilidade e doenças crônicas é complexa, somente $7 \%$ dos idosos considerados frágeis não tem nenhuma das 9 doenças crônicas mais comuns, ao passo que existe uma tendência estatisticamente significativa do aumento da prevalência da fragilidade em pessoas 
portadoras de várias doenças. Nos estágios avançados de muitas doenças o desenvolvimento de características da fragilidade é evidente (23). O termo fragilidade primária ou secundária tem sido utilizado para caracterizar fragilidade na ausência ou presença de doenças crônicas respectivamente. O número de idosos com fragilidade primária é muito pequeno (24).

\subsection{Gerontopole (Toulouse e Ribeirão Preto)}

Preocupados com os cuidados da população com mais de 60 anos, profissionais da Universidade de São Paulo (USP) de Ribeirão Preto investiram na identificação de idosos frágeis na comunidade, no projeto denominado Gerontopole, adaptação do projeto original francês Gerontopole de Toulouse (25).

A equipe é formada por médicos, fisioterapeutas, nutricionistas, farmacêuticos, enfermeiros e terapeutas ocupacionais, ligados ao Hospital das Clínicas (HCRP) e Faculdades da USP em Ribeirão Preto. Esse grupo tria os idosos atendidos nos Núcleos de Saúde da Família (NSF), vinculados à Faculdade de Medicina de Ribeirão Preto (FMRP) da USP (25).

Os idosos que aceitarem participar são encaminhados para "avaliação complementar na Clínica de Fragilidade", que fica no ambulatório do Centro de Saúde Escola no bairro Sumarezinho. Lá, investigam os fatores de risco para "perda de autonomia e independência, caracterização de fragilidade e dimensionamento dos prejuízos funcionais" de cada idoso individualmente (25).

Com essas informações, a equipe elabora um relatório técnico dos riscos e condições encontradas com recomendações específicas aos profissionais do NSF. E para o paciente, entrega o Plano de Cuidados em Saúde, com orientações de reparo dos riscos identificados, como por exemplo o controle da obesidade. Os idosos com necessidades específicas (quedas de repetição, risco social, alterações de humor ou cognição) são encaminhados para avaliação complementar também específicas: psicológicas, gerontológicas ou de enfermagem (25). 


\subsection{Armazenamento de dados (papel $\mathrm{x}$ digital)}

A informação do prontuário em papel está disponível somente a um profissional ao mesmo tempo, possui baixa mobilidade e está sujeito a ilegibilidade, ambiguidade, perda frequente da informação, multiplicidade de pastas, dificuldade de pesquisa coletiva, falta de padronização, dificuldade de acesso, fragilidade do papel, além de requerer amplos espaços nos serviços de arquivamento (26).

Com a evolução da tecnologia, especialmente da Internet, a possibilidade de compartilhar as informações de saúde tornou-se viável. A informação digital possui disponibilidade de ser acessada e atualizada, onde e quando o usuário precisar. Todos os dados armazenados têm maior legibilidade, acurácia e exatidão. $\mathrm{O}$ uso de software dispõe ferramentas como sistemas de alerta e de apoio à decisão, reduzindo a possibilidade de erro, e trazendo assim maior segurança ao paciente (26). A possibilidade de backups, e a própria natureza digital, tornam os dados resistentes a qualquer tipo de dano físico (danos por fogo, água, eletricidade, deterioração do papel, ação humana).

A criptografia do banco de dados, e a restrição de acesso através de login/senha, tornam a versão digital muito mais segura contra a violação de privacidade. É possível também exibir o conteúdo de forma dinâmica, exibindo apenas as informações permitidas ao usuário que as acessa.

Outros benefícios estão ligados à pesquisa clínica, e a facilidade que o banco de dados digital fornece nos usos secundários da informação para fins epidemiológicos e estatísticos.

Estudos demonstram que a migração para o registro digital é também vantajosa em termos econômicos, enfatizando a necessidade de impulsionar o uso desse sistema em detrimento do uso de impressão (27).

O uso de um aplicativo mobile apresenta algumas vantagens em relação a um aplicativo em desktop. A mobilidade, e economia de espaço físico tornam o smartphone/tablet mais adequado para o uso a beira do leito hospitalar. A integração de gadgets no smartphone permitem uma maior variedade de funcionalidades, o uso de GPS para registro (check-in) de visitas domiciliares é um exemplo de como essas ferramentas podem ser exploradas. 


\section{OBJETIVO}

Desenvolver uma plataforma web e aplicativo mobile para a identificação de fragilidade em pacientes idosos.

\section{HIPÓTESES}

O uso de uma plataforma web e móvel para a aplicação dos protocolos de identificação de fragilidade terá aprovação dos usuários quanto à usabilidade e eficiência no processo de atendimento, além de maior acessibilidade e maior segurança dos dados.

\section{MÉTODO}

\subsection{Local de trabalho}

O trabalho foi desenvolvido na Faculdade de Medicina de Ribeirão Preto (FMRP). Após a etapa de desenvolvimento, o sistema foi testado e utilizado no ambulatório do Centro de Saúde Escola (CSE) de Ribeirão Preto.

\subsection{Grupo de estudos}

O protocolo clínico foi previamente desenvolvido e padronizado num esforço conjunto da Divisão de Nutrição e metabolismo do departamento de Ciências da Saúde e divisão de Geriatria do departamento de Clínica Médica do Hospital das Clínicas de Ribeirão Preto (HCRP). O mesmo grupo participou na transformação do protocolo em ferramenta digital.

\subsection{Protocolo clínico}

O fluxo do protocolo (Figura 1) se inicia com o médico do Núcleo de Saúde da Família aplicando a triagem GFST (Gérontopôle Frailty Screening Tool) (28) adaptada para português (Anexo A). Após a identificação são agendadas consultas no Centro de Saúde e Escola de Ribeirão Preto, uma vez por semana. A primeira avaliação consiste na coleta de dados antropométricos e aplicação do TaGA (Tenminute Targeted Geriatric Assessment) (29) (Anexo B). Posteriormente é realizada 
avaliação por uma escala clínica multiprofissional por um geriatra (Anexo C), seguida de uma escala nutricional por um nutricionista (Anexo D) e uma escala de avaliação física por um fisioterapeuta (Anexo E). Dentre os testes contidos nas escalas destacam-se: Timed Up and Go (TUG) Test (30), TUG Dupla Tarefa (31), Teste de Sentar e Levantar da Cadeira (32), Testes de Equilíbrio Unipodálico (33), Teste de Trendelemburg (34), Teste com monofilamentos (Estesiometria) (35), Teste de Força muscular (36), Teste de Marcha (37), AIVDs - Escala de Lawton \&Brody (38) e ABVDs - Índice de Katz (39), Addenbrooke's Cognitive Examination (40) e MINI (Mini International Neuropsychiatric Interview) (41). No final dos atendimentos os profissionais que participaram se reúnem para discussão do caso, definição de diagnósticos e definição de metas para o paciente.

Figura 1 - Fluxo de atendimento e aplicação das escalas no protocolo.

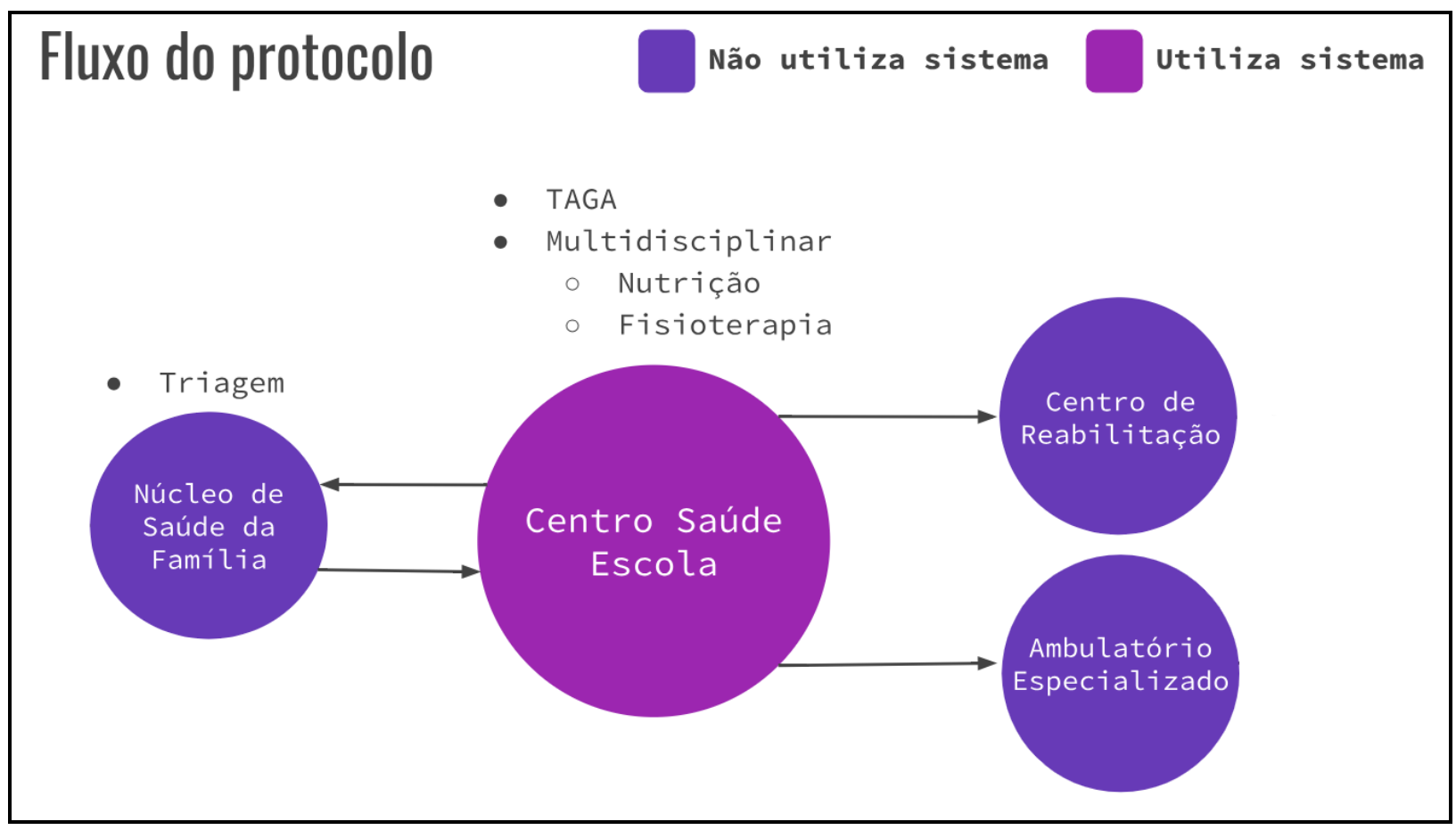

Fonte: autoria própria.

\subsection{Engenharia de software}

O desenvolvimento do sistema foi orientado por um documento de requisitos de software. O documento foi criado e revisto diversas vezes por meio de reuniões 
com profissionais de saúde envolvidos no projeto. O modelo de processo de software utilizado no desenvolvimento deste trabalho foi a prototipagem. Este modelo é recomendado quando o cliente define um conjunto de objetivos gerais para o software, mas não identifica detalhadamente requisitos de entrada, processamento ou saída, ou mesmo, quando o desenvolvedor não está seguro sobre a eficiência de um algoritmo, da adaptabilidade de um sistema operacional ou da forma que a interação homem/máquina deve assumir. O paradigma de prototipagem, conforme ilustrado na Figura 2, começa com a comunicação. $O$ engenheiro de software e 0 cliente encontram-se e definem os objetivos gerais do software, identificando as necessidades conhecidas e verificam as áreas que necessitam de mais definições. Uma iteração de prototipagem é planejada rapidamente e a modelagem ocorre. $\mathrm{O}$ projeto rápido concentra-se na representação daqueles aspectos do software que estarão visíveis para o cliente (exemplo: layout da interface, entre outros). O projeto rápido leva à construção de um protótipo, que é implantado e depois avaliado pelo cliente. O feedback é usado para refinar os requisitos do software. A iteração ocorre à medida que o protótipo é ajustado para satisfazer às necessidades do cliente e, ao mesmo tempo, permite ao desenvolvedor entender melhor o que precisa ser feito (42). 
Figura 2 - Modelo de prototipagem.

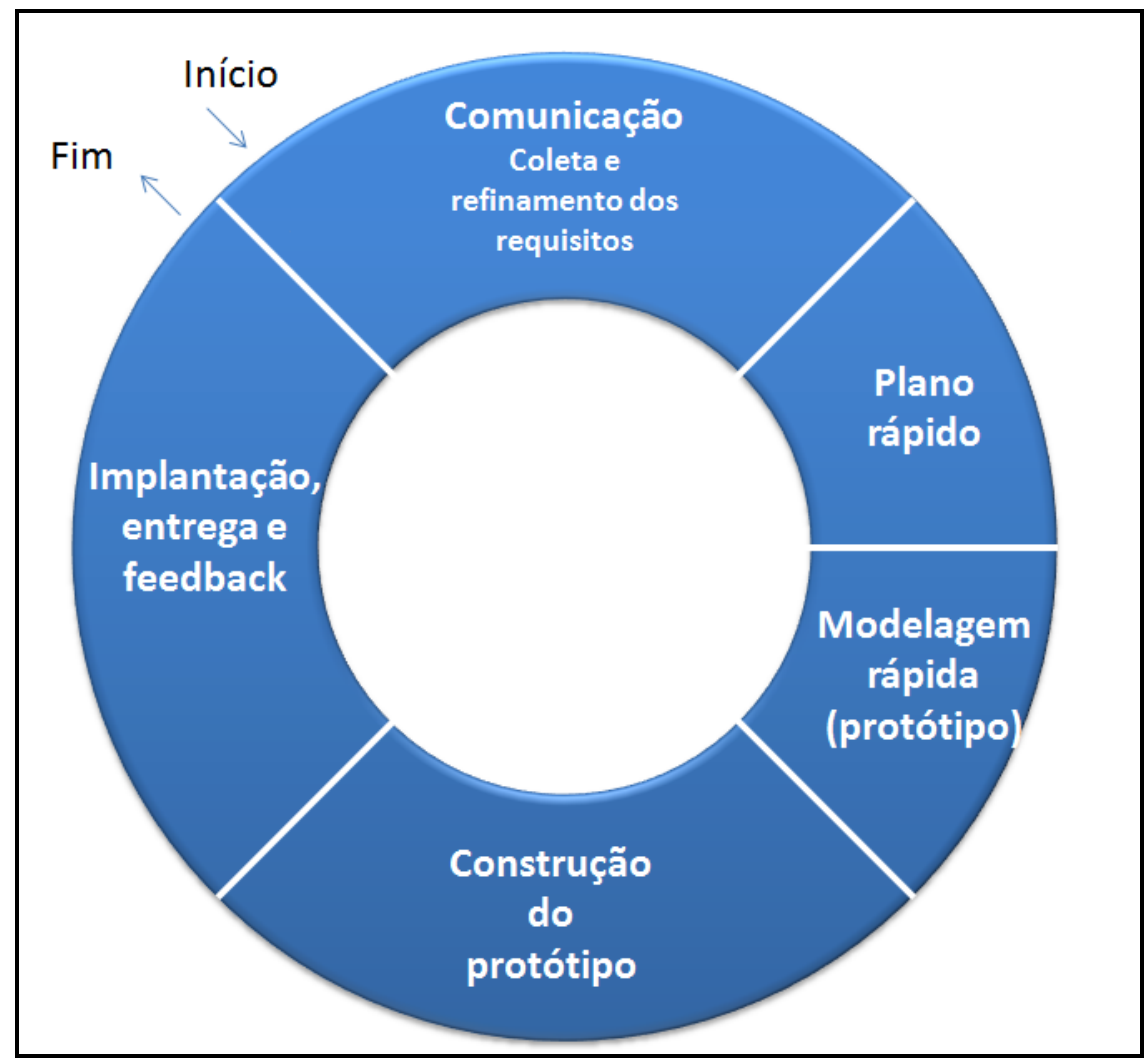

Fonte: autoria própria.

\subsection{Banco de dados}

O Modelo Entidade Relacionamento, um modelo conceitual de dados de alto nível (43), do banco de dados foi feito baseando-se nos requisitos coletados durante a parte de engenharia do software, para composição dos diagramas foi utilizada a ferramenta DBDesigner 4 (44), o banco de dados utilizado foi o MySQL (45).

\subsection{Plataforma web (MVC e linguagens)}

Na programação da plataforma foi utilizada a arquitetura de projeto MVC (46), a qual separa as funções de interação com o usuário e de interação com o banco de dados em diferentes camadas (Figura 3). Na parte de Front-End do sistema foram utilizadas as linguagens HTML 5 (47) para estruturação da página, juntamente com Javascript (48) e JQuery (49) para execução de funções, e CSS 3 (50) para layout e efeitos visuais. Na camada de Back-End foi utilizada a linguagem PHP 5.6 (51) e o 
framework Codeigniter (52). Todos os códigos foram desenvolvidos na IDE (integrated development environment) Netbeans (53).

Figura 3 - Arquitetura de projeto MVC.

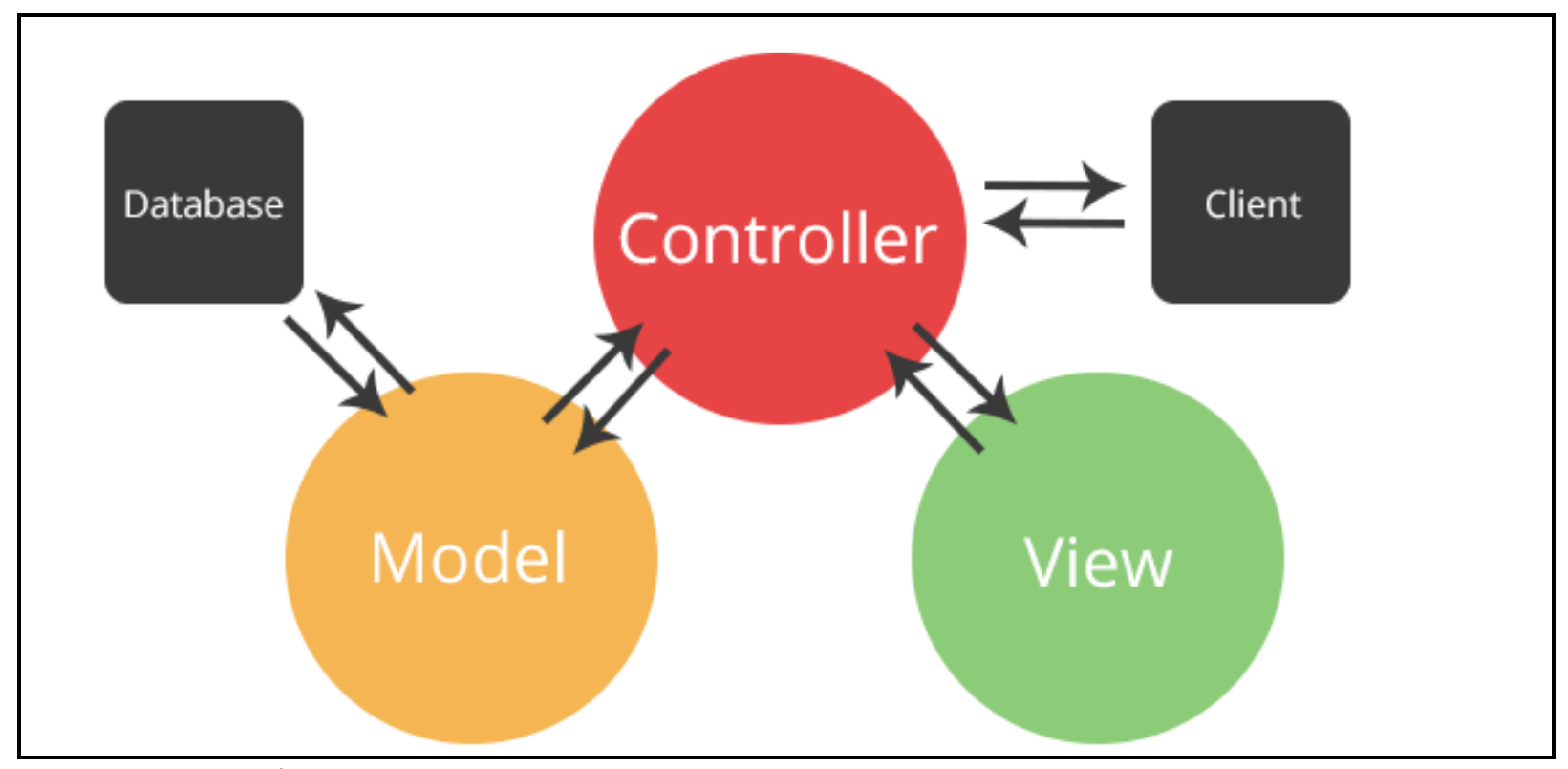

Fonte: autoria própria.

\subsection{Aplicação mobile}

No desenvolvimento da aplicação mobile foi utilizada a linguagem Android (54) nativa. Foi desenvolvida uma Webview (55) para acessar o sistema web de uma aplicação móvel, essa tecnologia foi escolhida para o desenvolvimento ágil da ferramenta.

\subsection{Servidor}

A plataforma e os dados colhidos estão armazenados em um servidor web da Faculdade de Medicina de Ribeirão Preto.

\subsection{Teste de usabilidade}

Para testar a usabilidade do sistema foi utilizado o questionário WAMMI. Estudos feitos utilizando a ferramenta concluem que o WAMMI possui resultados 
que correlacionam bem com a avaliação de usabilidade baseada no usuário e com os dados de avaliação heurística baseados em especialistas (56). Existem fortes indicativos de que incluir o WAMMI no loop de teste e design melhora a usabilidade do site (56).

O teste divide atributos do sistema em escalas e gera uma pontuação global, as escalas estão representadas na Tabela 1.

Tabela 1 - Escalas do teste de usabilidade WAMMI

\begin{tabular}{|c|c|}
\hline Escala & Descrição \\
\hline Atratividade & $\begin{array}{l}\text { Um site atraente é visualmente agradável, e também oferece muito interesse } \\
\text { direto para os entrevistados, seja pelas funcionalidades ou informações. }\end{array}$ \\
\hline Controlabilidade & $\begin{array}{l}\text { Se um site tiver uma boa controlabilidade, os entrevistados provavelmente } \\
\text { sentirão que podem navegar com facilidade e fazer o que quiserem. Baixa } \\
\text { pontuação geralmente significa um site mal organizado que interrompe a } \\
\text { maneira como normalmente se espera fazer as coisas. }\end{array}$ \\
\hline Eficiência & $\begin{array}{l}\text { Quando os respondentes dão uma classificação de alta eficiência eles } \\
\text { sentem que podem localizar e fazer o que Ihes interessa de maneira eficiente } \\
\text { e econômica. Eles sentem que o site responde em uma velocidade razoável. }\end{array}$ \\
\hline Utilidade & $\begin{array}{l}\text { Um site que com alta utilidade corresponde às expectativas dos } \\
\text { entrevistados sobre seu conteúdo e estrutura. Um site com pouca utilidade } \\
\text { pode ser enganoso quanto ao layout e conteúdo. }\end{array}$ \\
\hline Aprendizabilidade & $\begin{array}{l}\text { Quando a capacidade de aprendizagem é alta, os entrevistados sentem que } \\
\text { podem começar a usar o site com o mínimo de apresentações. Tudo é fácil } \\
\text { de entender desde o início. Quando a capacidade de aprendizagem é baixa, } \\
\text { os entrevistados acham que o site pode estar usando conceitos ou } \\
\text { terminologias que não são familiares. Mais explicações são necessárias. }\end{array}$ \\
\hline $\begin{array}{l}\text { Pontuação global de } \\
\text { usabilidade }\end{array}$ & $\begin{array}{l}\text { A Usabilidade Global centraliza os conceitos de que um site deve facilitar o } \\
\text { acesso dos entrevistados ao que eles precisam ou desejam do site, que } \\
\text { existe um nível de organização bom e compreensível e que o site "fala a } \\
\text { língua dos entrevistados" e atende às suas necessidades. }\end{array}$ \\
\hline
\end{tabular}


O teste também possui questões de texto abertas para o usuário opinar sobre aspectos do sistema avaliado, assim o proprietário do sistema pode ter um retorno de situações mais específicas e que envolvam questões não abordadas nas perguntas fechadas.

O usuário que está avaliando o sistema também classifica sua própria experiência e habilidade no uso de páginas na internet, assim é possível segmentar as opiniões e pontuações pela experiência do usuário, além de traçar o perfil dos mesmos.

O teste foi aplicado nos usuários que utilizaram o sistema no CSE de Ribeirão Preto durante o período de 02 de abril até 12 de novembro no ano de 2018.

\section{RESULTADOS}

\subsection{Funcionalidades desenvolvidas}

\subsubsection{Cadastro de usuários}

Um administrador do sistema pode adicionar novos usuários preenchendo os campos: nome, e-mail, senha, CPF, tipo de profissional, número de registro do profissional (Figura 4). 
Figura 4 - Tela de cadastro de usuário no sistema.

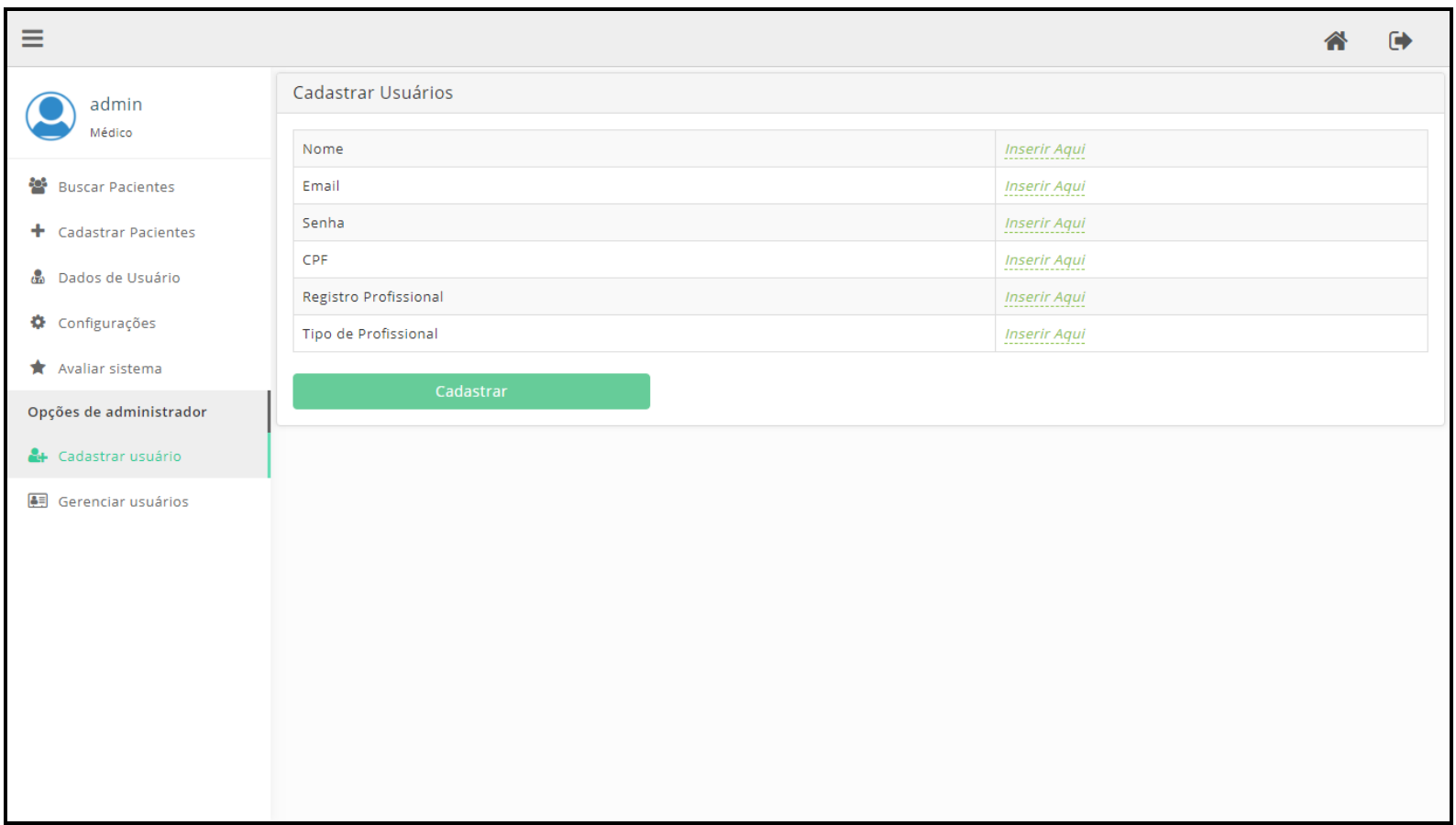

Fonte: autoria própria.

\subsubsection{Login no sistema}

Um usuário cadastrado pode ter acesso ao sistema após digitar seu e-mail e senha nos campos indicados na tela de login e clicar no botão de acesso (Figura 5). 
Figura 5 - Tela de login no sistema.

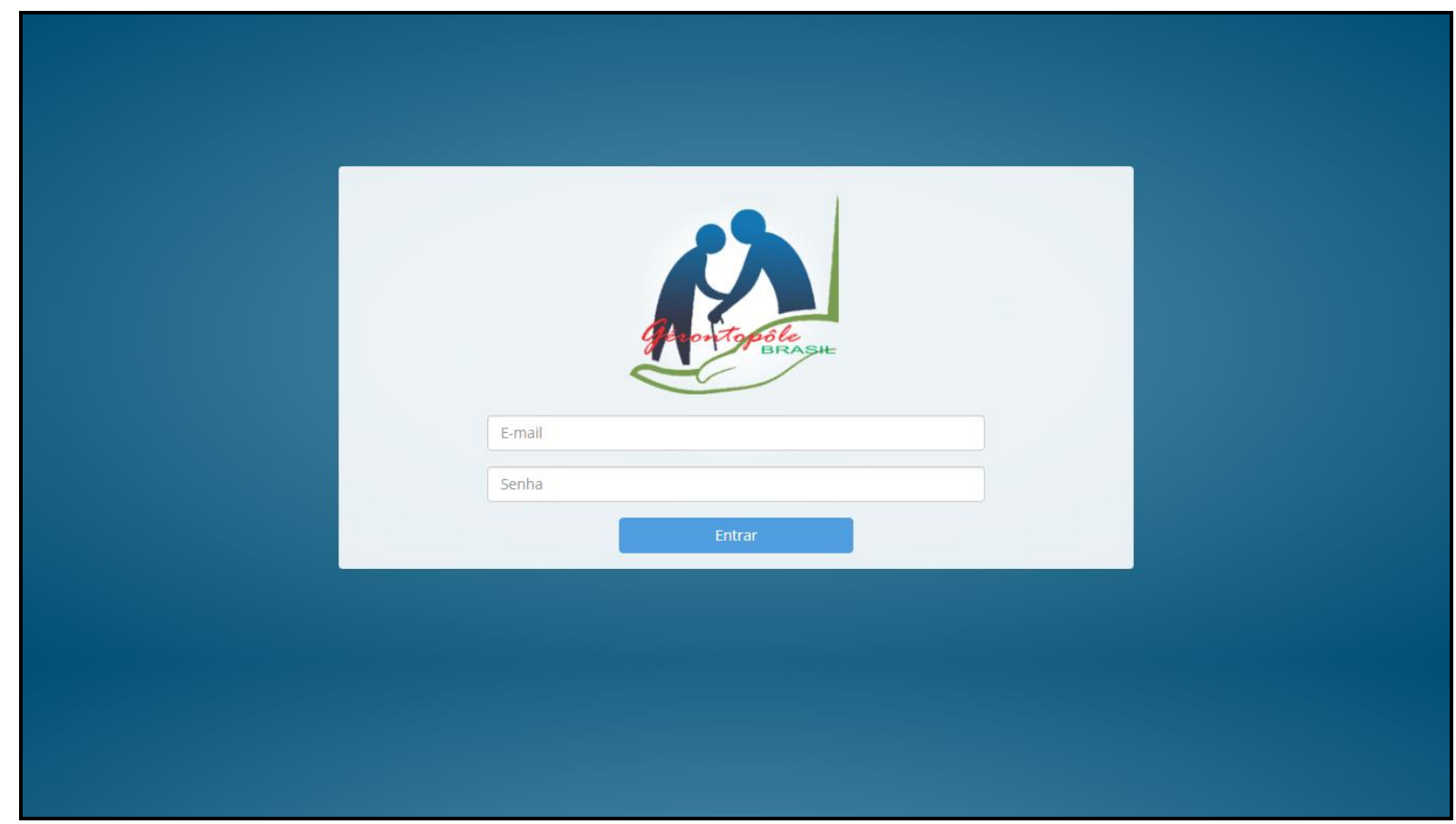

Fonte: autoria própria.

\subsubsection{Edição de dados cadastrais}

Um usuário pode ter seus campos de dados cadastrais editados tanto por um administrador do sistema quanto por ele mesmo (Figura 6). 
Figura 6 - Tela de perfil do usuário.

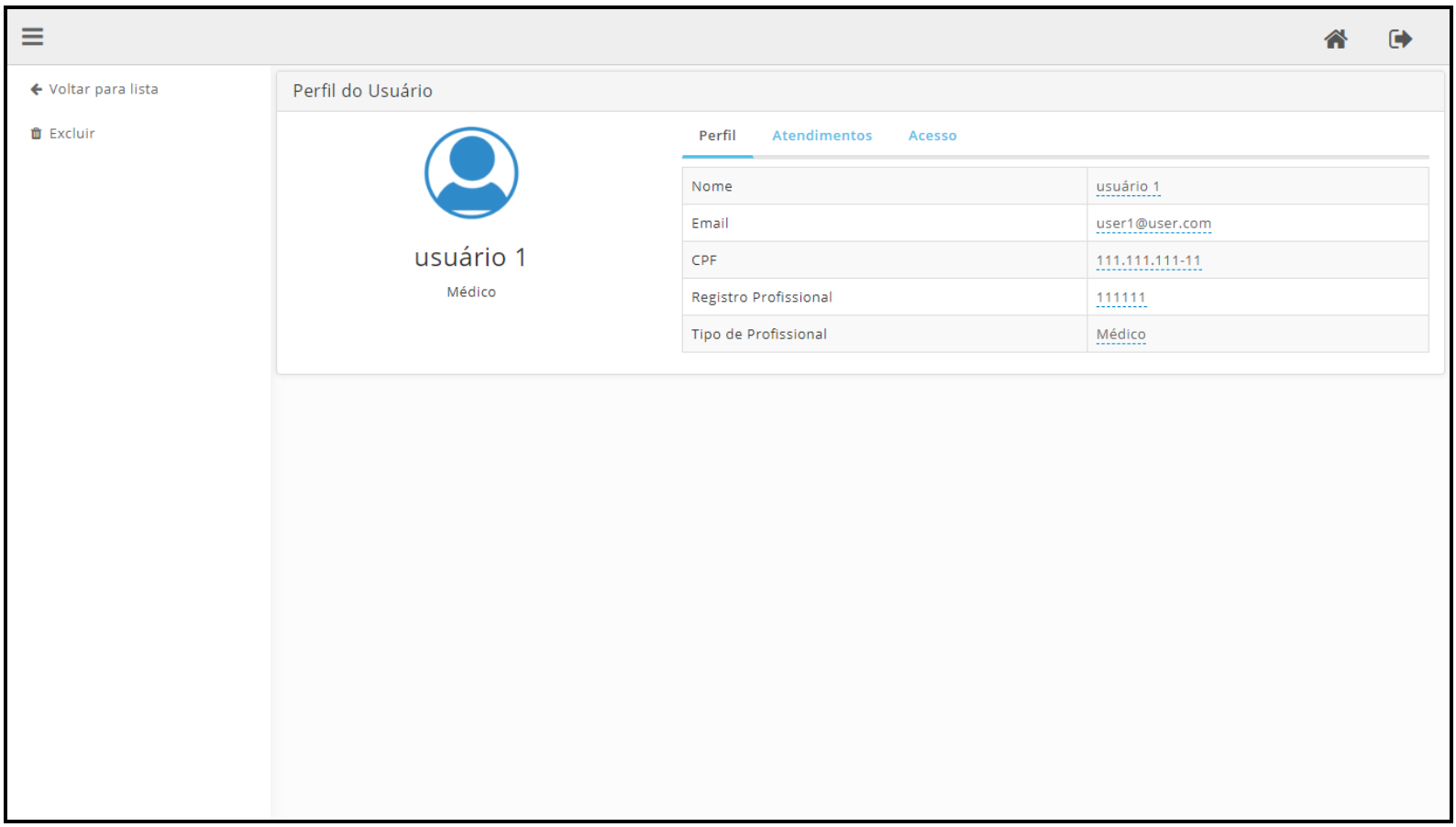

Fonte: autoria própria.

\subsubsection{Deleção de usuário}

Um usuário pode ter seu acesso ao sistema removido permanentemente por um administrador (Figura 7). As ações que esse usuário efetuou no sistema e o registro dessas ações permanecem armazenados. 
Figura 7 - Tela de gerenciamento de usuários, janela de confirmação de deleção.

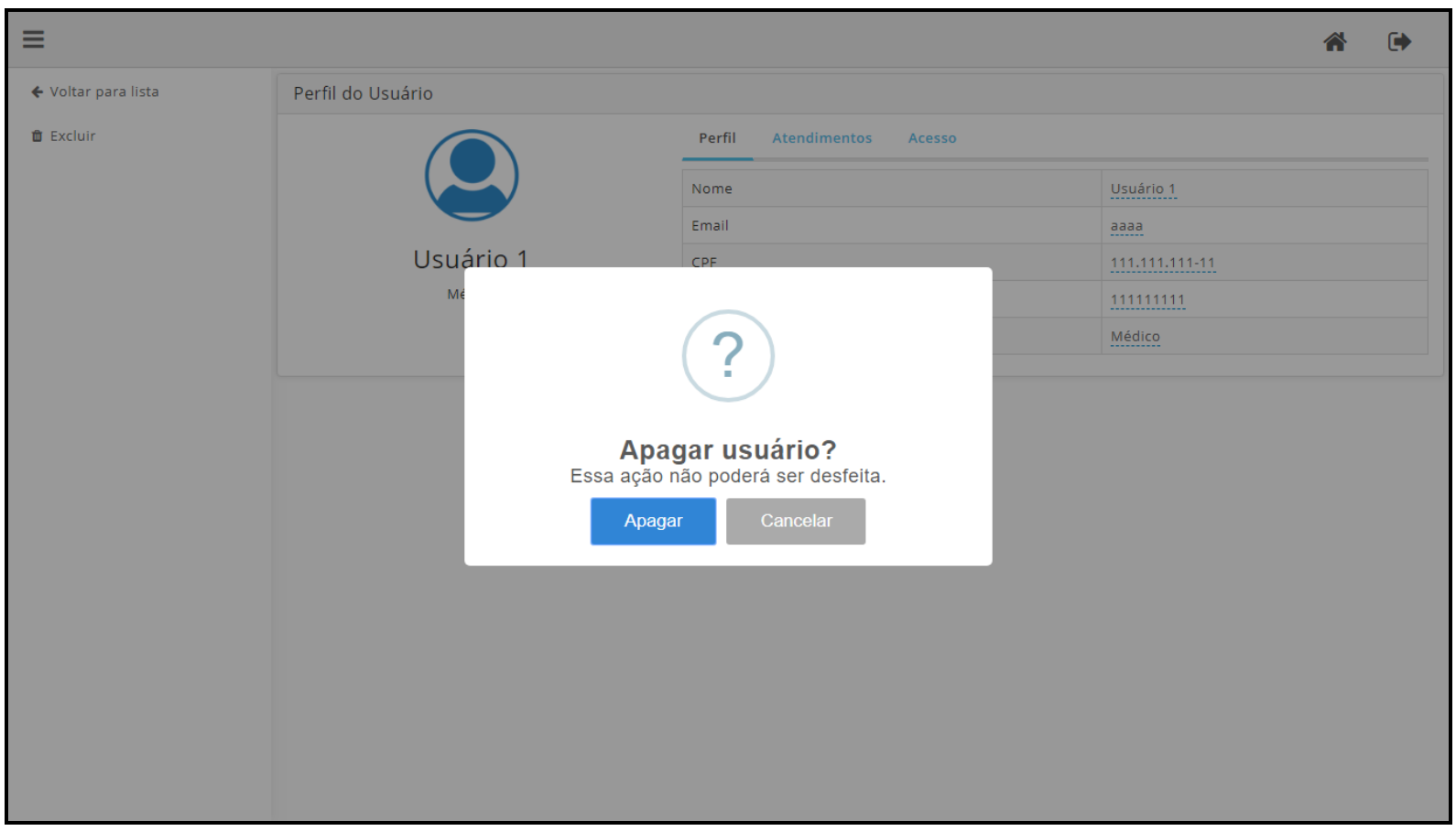

Fonte: autoria própria.

\subsubsection{Edição de permissões de usuário}

Um administrador do sistema pode conceder a outro usuário permissão de administrador (Figura 8), fazendo com que esse usuário tenha acesso a todas as funcionalidades antes restritas. 
Figura 8 - Configurações de acesso do usuário.

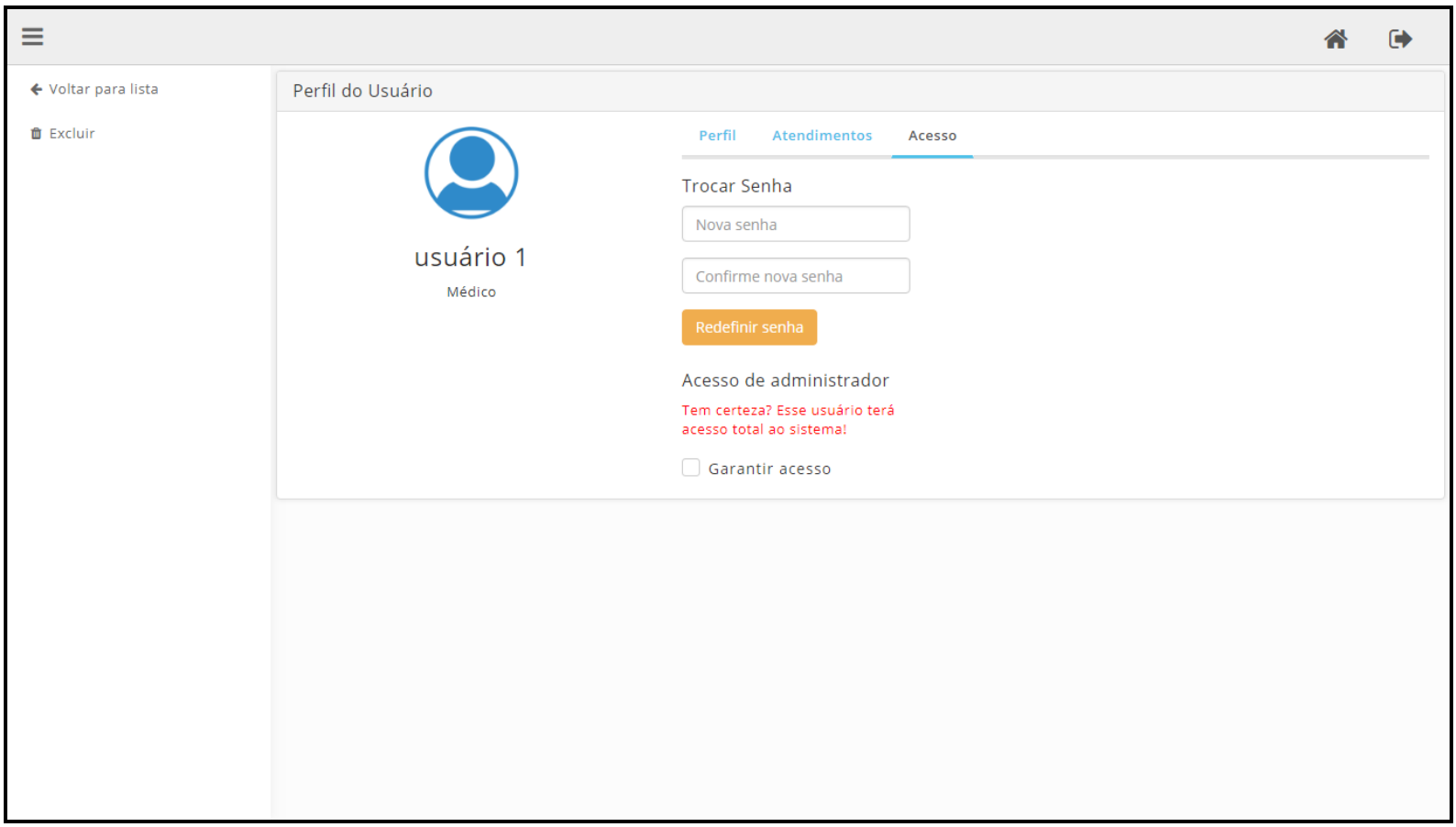

Fonte: autoria própria.

\subsubsection{Cadastro de pacientes}

Um usuário do sistema pode cadastrar um novo paciente, o processo de cadastro possui três etapas. Na primeira etapa (Figura 9) devem ser preenchidos os campos obrigatórios: nome, data de nascimento, número de registro Hygia, sexo e telefone. A segunda etapa (Figura 10) consiste no cadastro do endereço do paciente, nela devem ser preenchidos os campos obrigatórios: estado, cidade, rua, bairro e número. $\mathrm{Na}$ segunda etapa existem os campos opcionais CEP e complemento, ao preencher o CEP é possível buscar os dados do endereço e preencher os campos automaticamente. A terceira e última etapa (Figura 11) é adicionar uma foto do paciente, essa etapa é opcional. 
Figura 9 - Tela de cadastro de pacientes, guia de dados gerais.

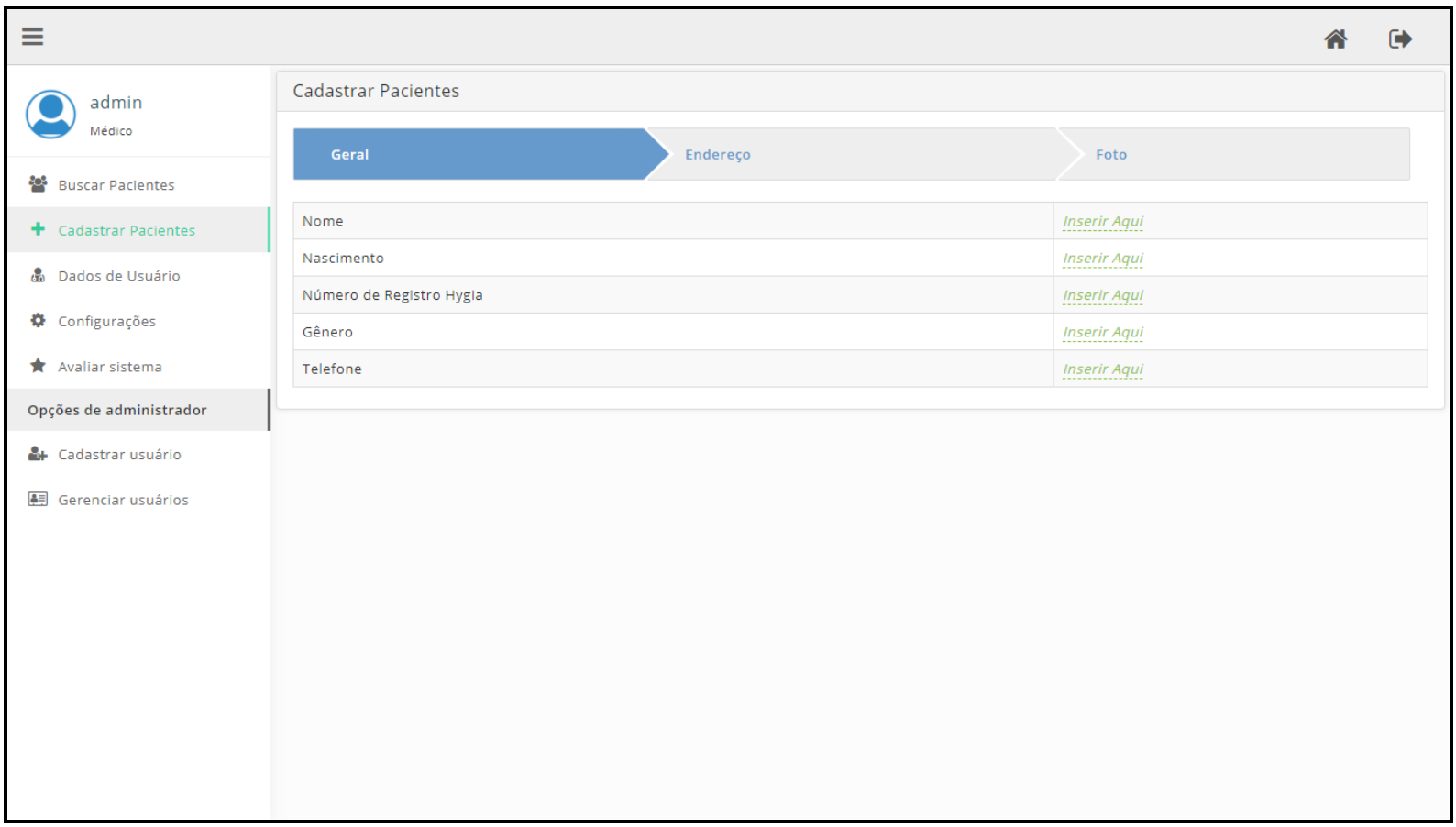

Fonte: autoria própria.

Figura 10 - Tela de cadastro de pacientes, guia de cadastro de endereço do paciente.

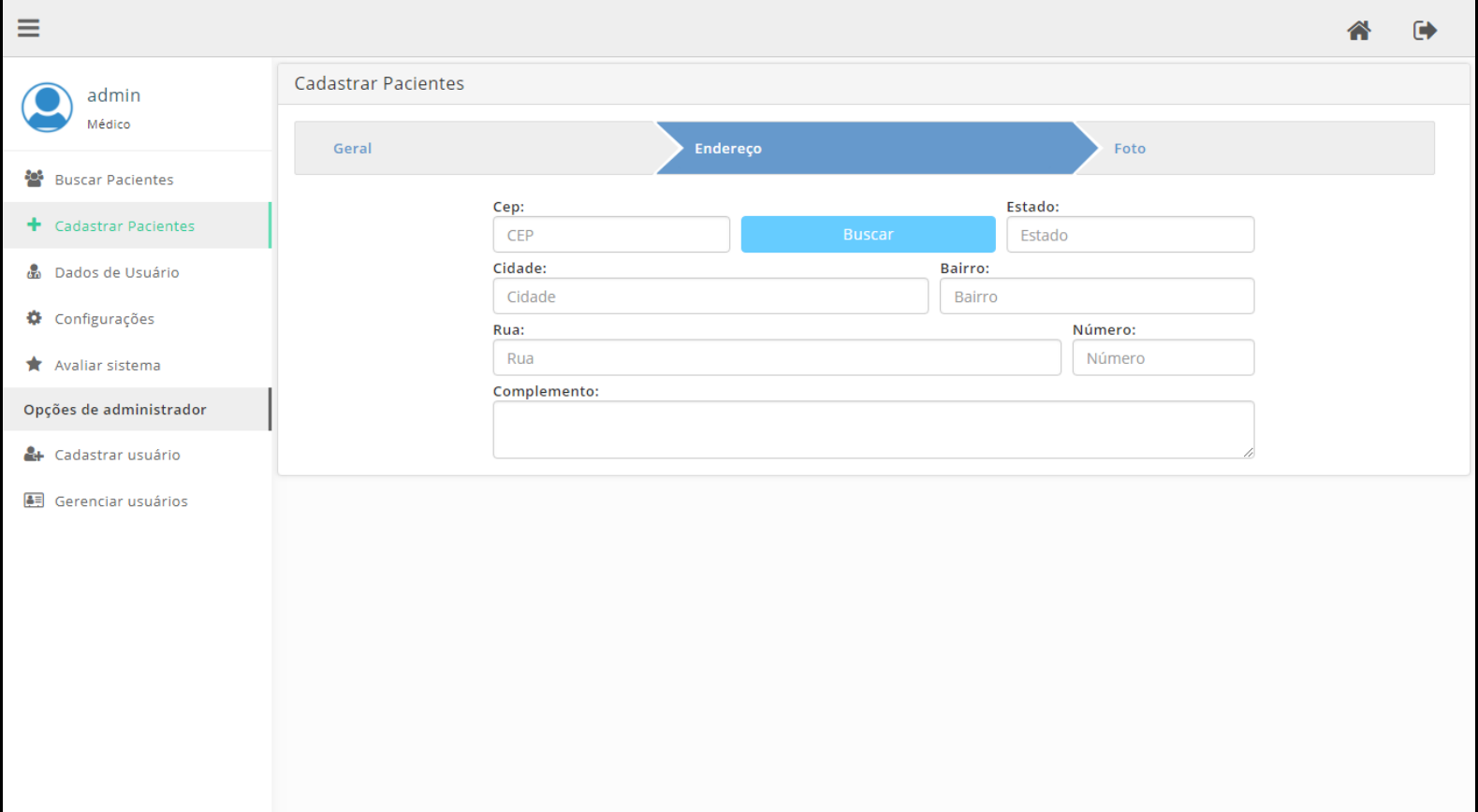

Fonte: autoria própria. 
Figura 11 - Tela de cadastro de pacientes, guia de cadastro de foto do paciente.

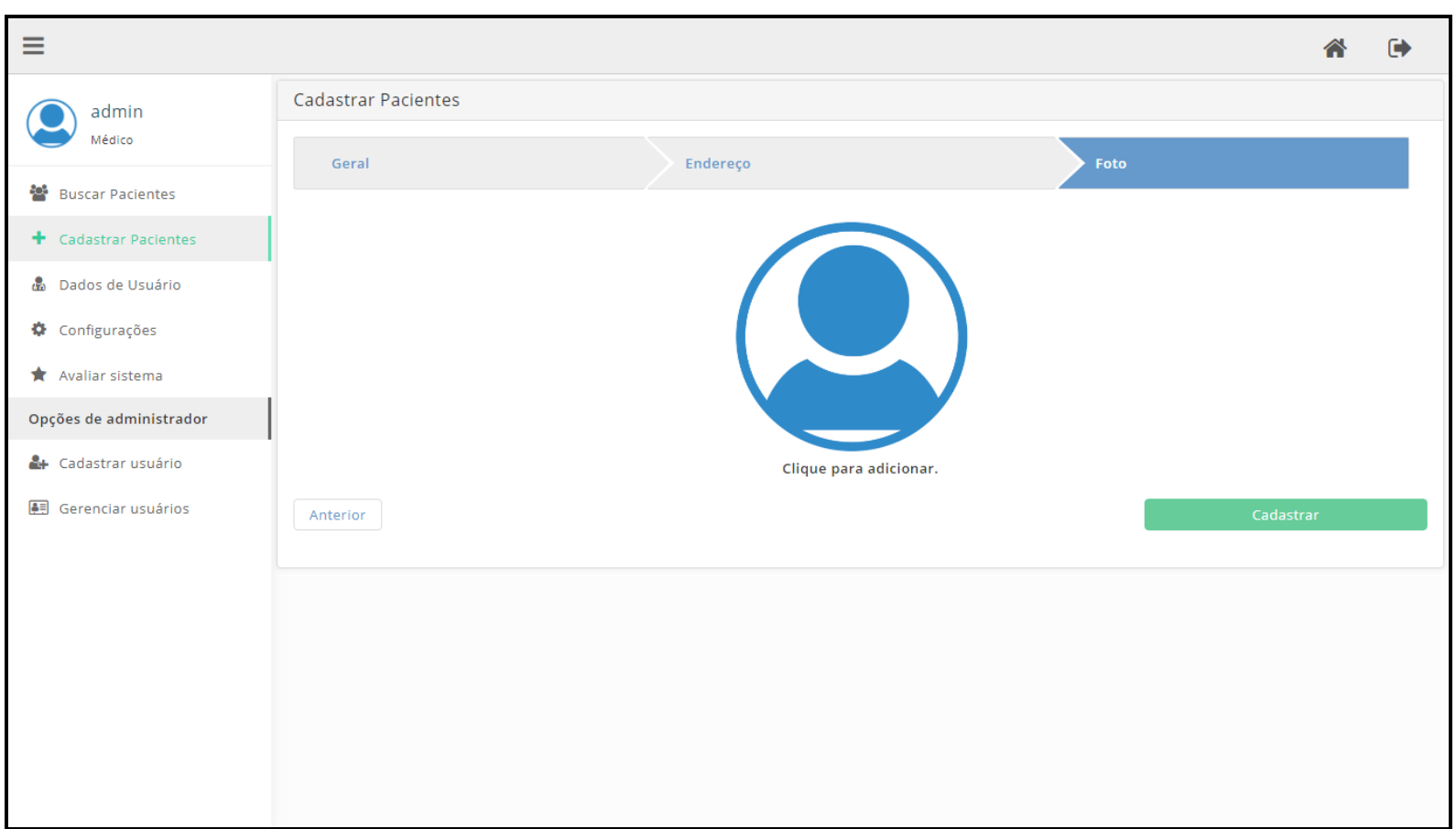

Fonte: autoria própria.

\subsubsection{Edição dos dados de pacientes}

Um usuário do sistema pode editar os dados cadastrais de pacientes (Figura 12). 
Figura 12 - Tela de perfil do paciente.

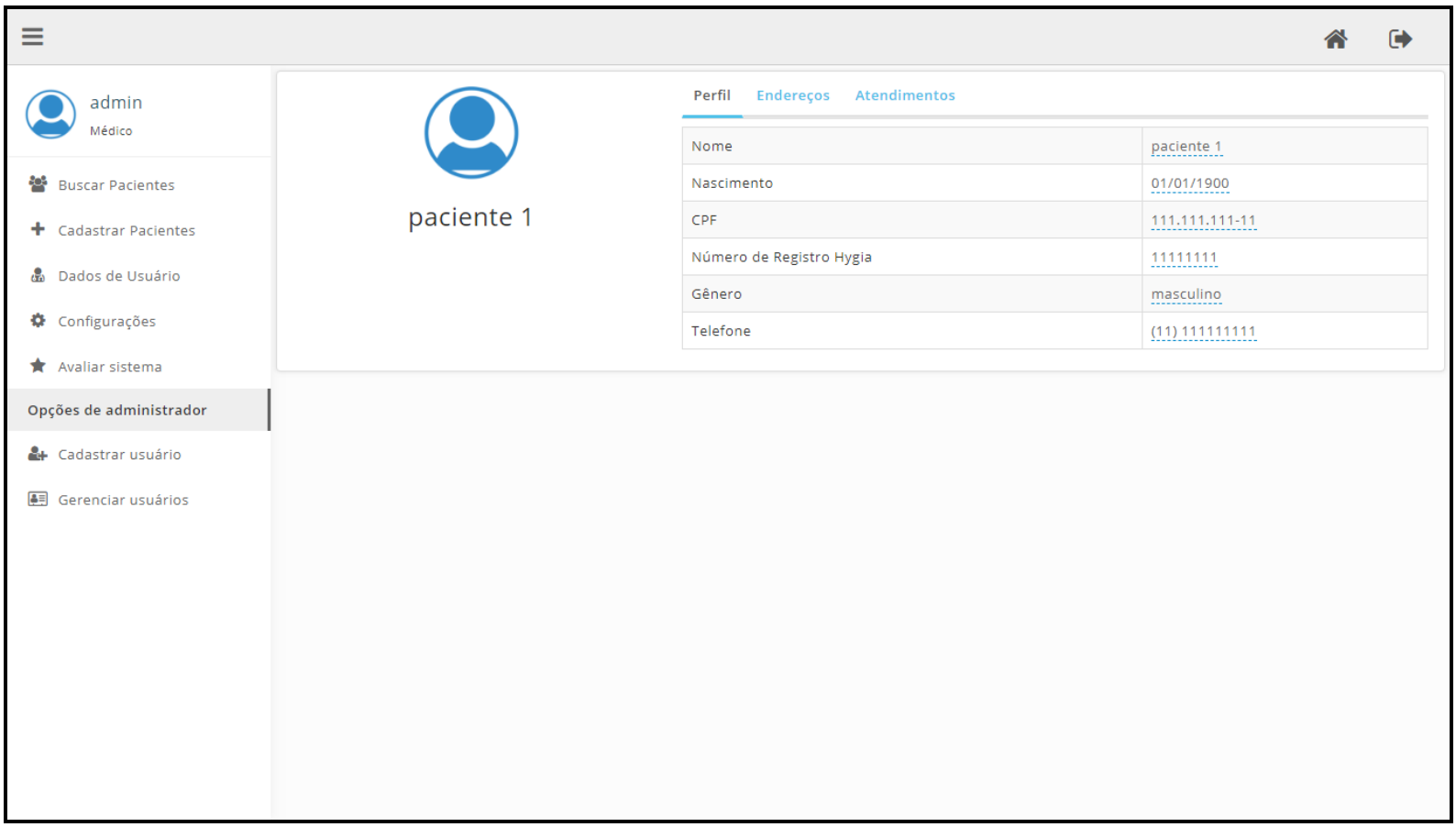

Fonte: autoria própria.

\subsubsection{Deleção dos dados de pacientes}

Um paciente pode ter seu cadastro removido do sistema permanentemente por um administrador do sistema (Figura 13). As escalas do paciente permanecem salvas no sistema e o registro das ações envolvendo um paciente permanecem armazenados. 
Figura 13 - Modal de opções do paciente.

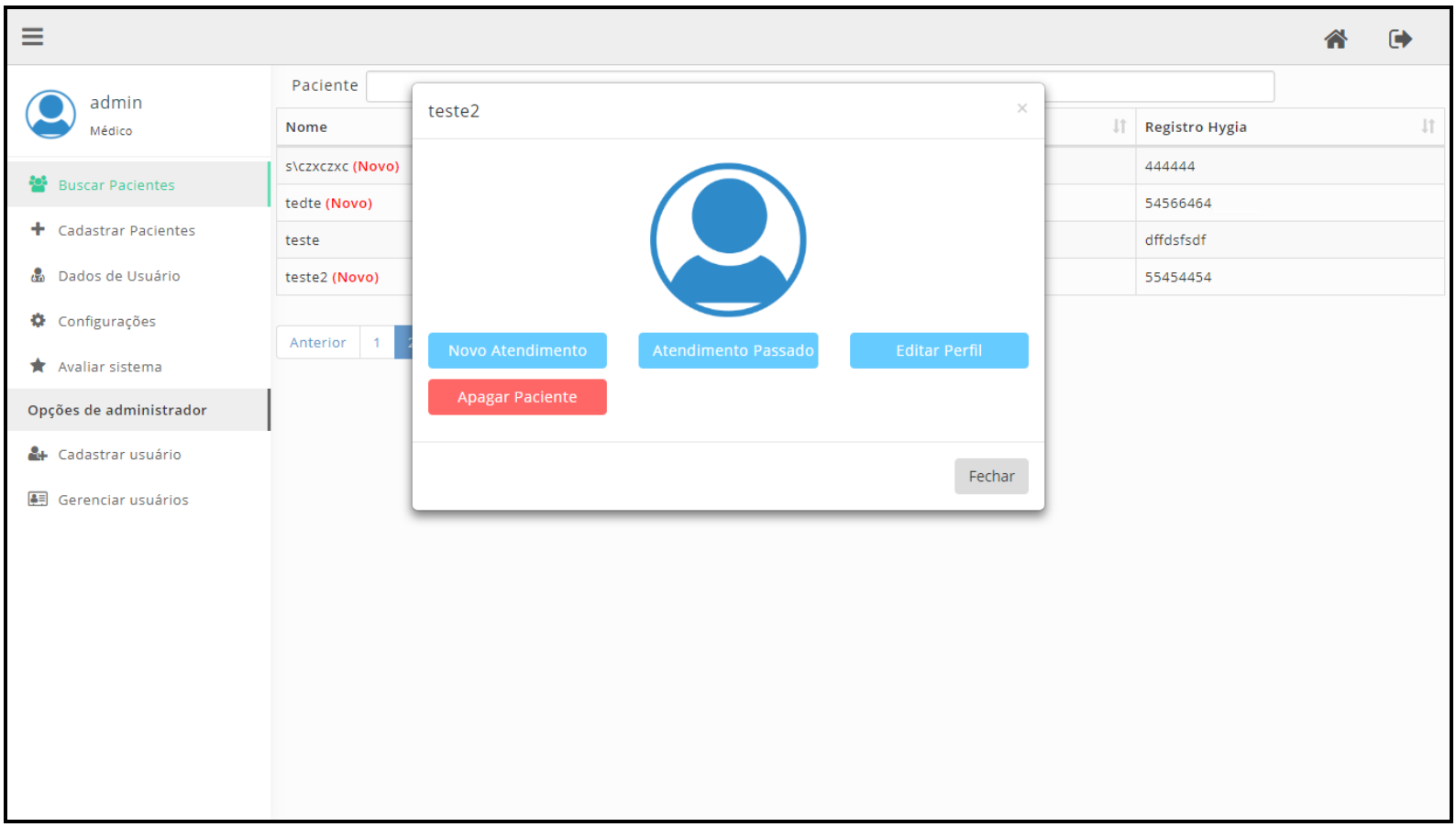

Fonte: autoria própria.

\subsubsection{Busca de pacientes}

Um usuário pode efetuar uma busca entre os pacientes cadastrados (Figura 14) utilizando como chave: nome, idade, ou registro Hygia. As chaves podem ser inseridas parcialmente e a busca retorna uma lista de resultados que contém a chave digita em seu registro. 
Figura 14 - Tela de busca de pacientes.

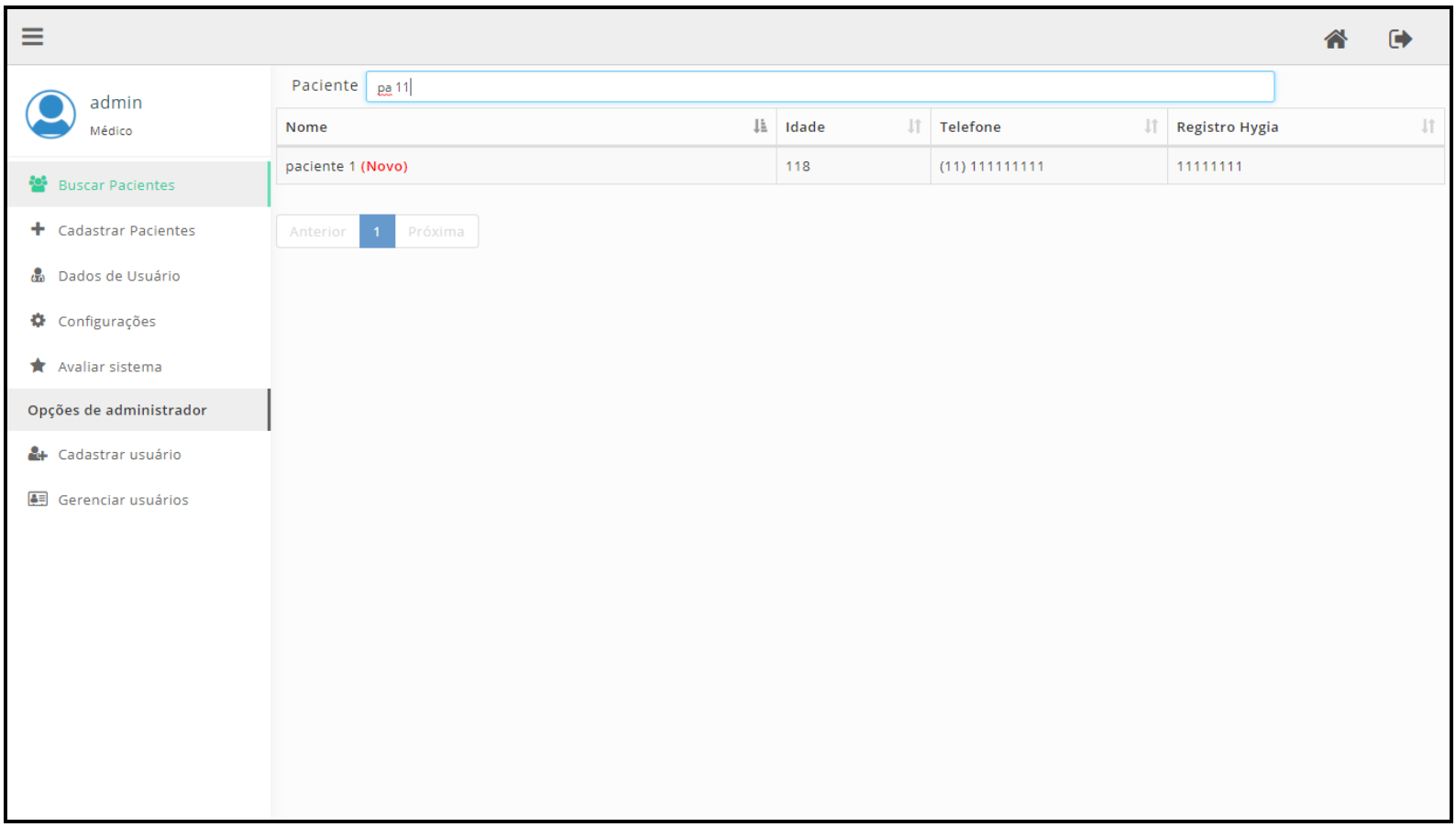

Fonte: autoria própria.

\subsubsection{Cadastro de escalas do protocolo}

As avaliações feitas são separadas em escalas (Figura 15), um usuário pode iniciar uma avaliação de um paciente e salvá-la (Figura 16). A Tabela 2 exibe as escalas do protocolo e as telas contidas em cada escala. 
Tabela 2 - Escalas do protocolo e telas por escala

\begin{tabular}{ll}
\hline Escalas & Avaliações \\
\hline Escala de Triagem & Triagem inicial, Lista de medicamentos de uso contínuo, Morbidades \\
& Conhecidas, Exames nos últimos 6 meses. \\
10 - TaGa & Cotidiano, Funcionalidades, Cognição, Autopercepção, Nutrição / Marcha, \\
& Resultados. \\
Multiprofissional & Fatores de risco social 1, Fatores de risco social 2, Fatores de risco social 3, \\
& Medicações 1, Medicações 2, Morbidades, Fatores de risco, CAGE / \\
& Autopercepção, Nutrição 1, Nutrição 2, Nutrição 3, Atividades Diárias, Gênito / \\
& Urinário, Psiquiátrico, Sono, Pele e Visão, Sensorial, Gastrointestinal 1, \\
& Gastrointestinal 2, Cardiovascular, Osteoarticular, Avaliação do observador 1- \\
& 10, Avaliações finais 1, Avaliações finais 2. \\
& Resumo da Triagem, Composição Corporal, Recordatório Alimentar, Perfil \\
& Social, Alterações na Deglutição, Problemas na Deglutição, Diagnóstico. \\
Escala Nutricional & Estado geral de dor, Articular e Periarticular 1, Articular e Periarticular 2, \\
Escala & Muscular, Amplitude de Movimento, Relato de Queda, Mobilidade, Olhos, \\
Fisioterapêutica & Estesiômetro, Timed GetUp and Go, Avaliação da marcha 1, Avaliação da \\
& marcha 2, Velocidade de marcha, Qualidade da marcha, Força muscular, \\
& Resultados.
\end{tabular}


Figura 15 - Novo atendimento, seleção do tipo de escala.

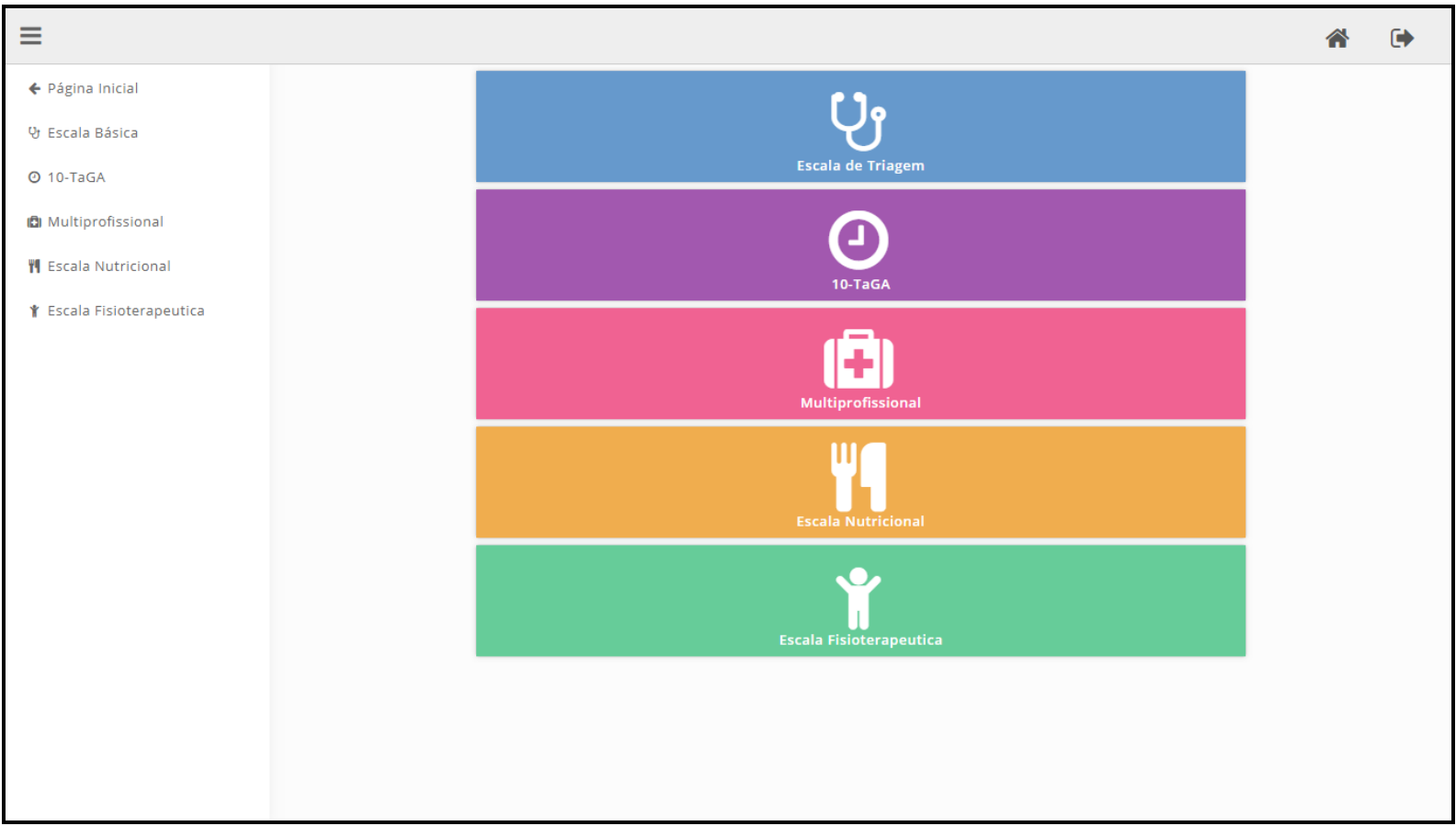

Fonte: autoria própria.

Figura 16 - Formulário da escala 10-TaGa.

\begin{tabular}{|c|c|c|c|c|c|c|}
\hline$\equiv$ & & & & 回 & న & $\hookrightarrow$ \\
\hline$\leftarrow$ voltar para escalas & \multicolumn{3}{|c|}{ Cotidiano } & & $>$ & \\
\hline Cotidiano & \multirow{2}{*}{$\begin{array}{l}\text { Suporte Social } \\
\text { Mora com quem? }\end{array}$} & & & & & \\
\hline Funcionalidade & & Familiar ou cuidador & - & & & \\
\hline Cognição & $\begin{array}{l}\text { Se ficasse de cama, com que } \\
\text { frequência contaria com laguém para }\end{array}$ & Sempre ou quase sempre & - & & & \\
\hline Auto Percepção & Uso do sistema de saúde & & & & & \\
\hline Nutrição / Marcha & Últimos 6 meses: & Pronto atendimento & - & & & \\
\hline \multirow[t]{5}{*}{ Resultados } & Quedas & & & & & \\
\hline & Último ano: & Até 1 queda & . & & & \\
\hline & Medicaçōes de uso continuo & & & & & \\
\hline & Número de medicamentos: & De 5 a 9 & v & & & \\
\hline & Escolaridade & Nenhuma & $v$ & & & \\
\hline
\end{tabular}

Fonte: autoria própria. 


\subsubsection{Edição de escalas do protocolo}

Avaliações salvas podem ser editadas por um usuário (Figura 17).

Figura 17 - Lista de atendimentos passados do paciente, janela de operações do atendimento.

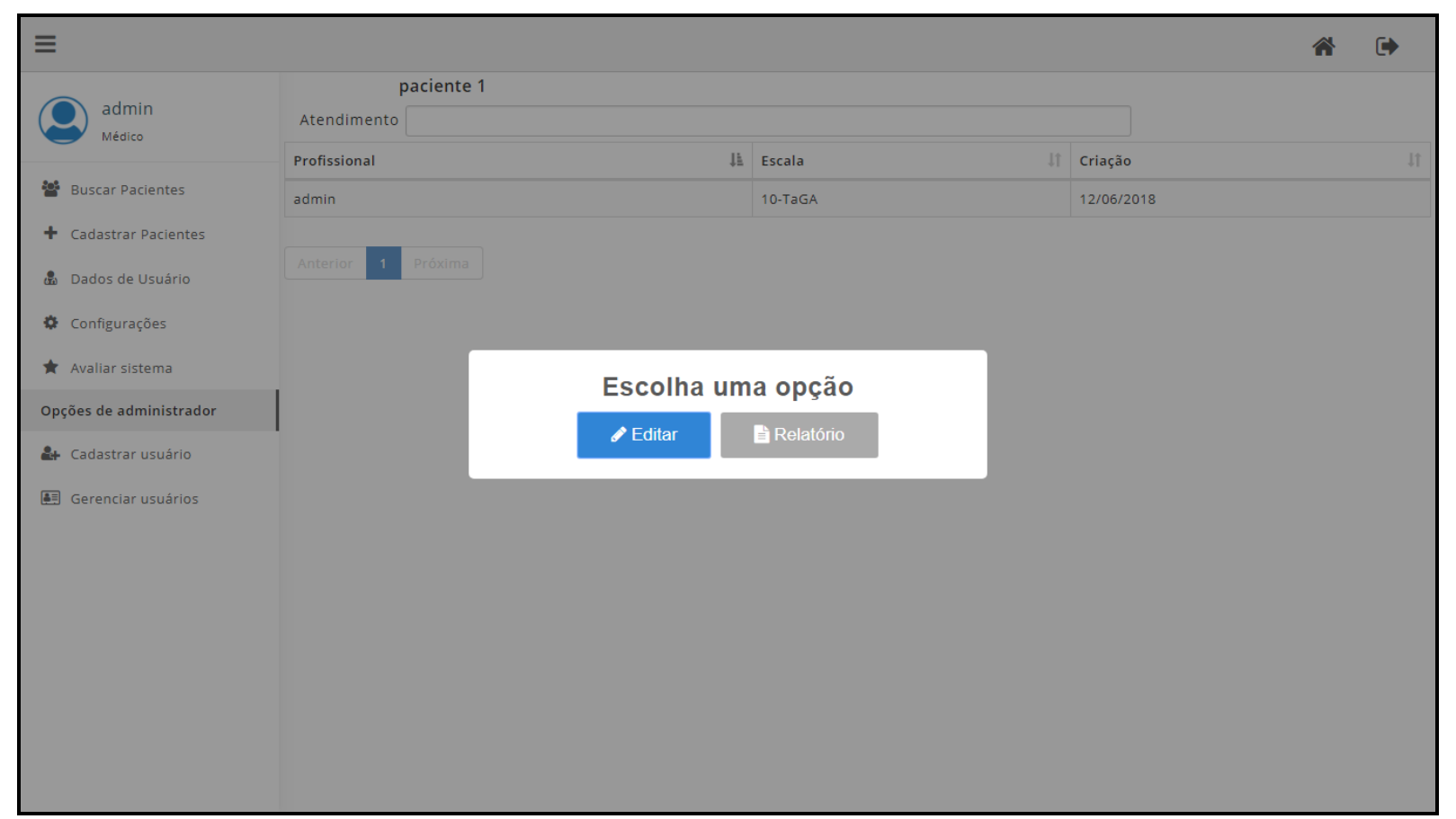

Fonte: autoria própria.

\subsubsection{Apagar escala}

Uma escala pode ter seu cadastro removido do sistema permanentemente por um administrador do sistema (Figura 18). 
Figura 18 - Apagar escala

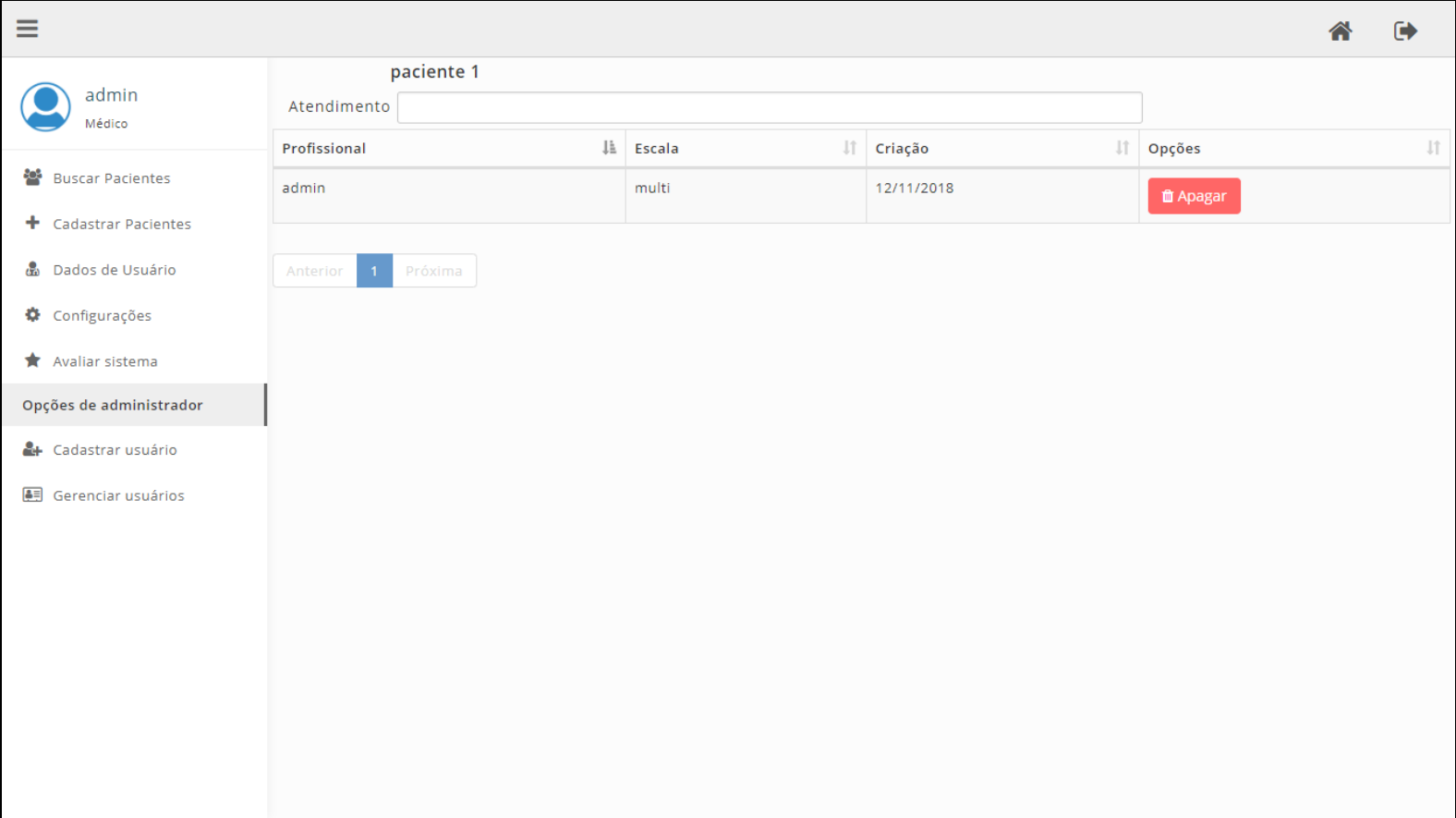

Fonte: autoria própria.

\subsubsection{Gerar relatório}

Um usuário pode gerar um relatório de uma avaliação selecionada, o relatório possui um formato pronto para impressão e pode ser também salvo no formato PDF (Figura 19). 
Figura 19 - Relatório de atendimento passado.

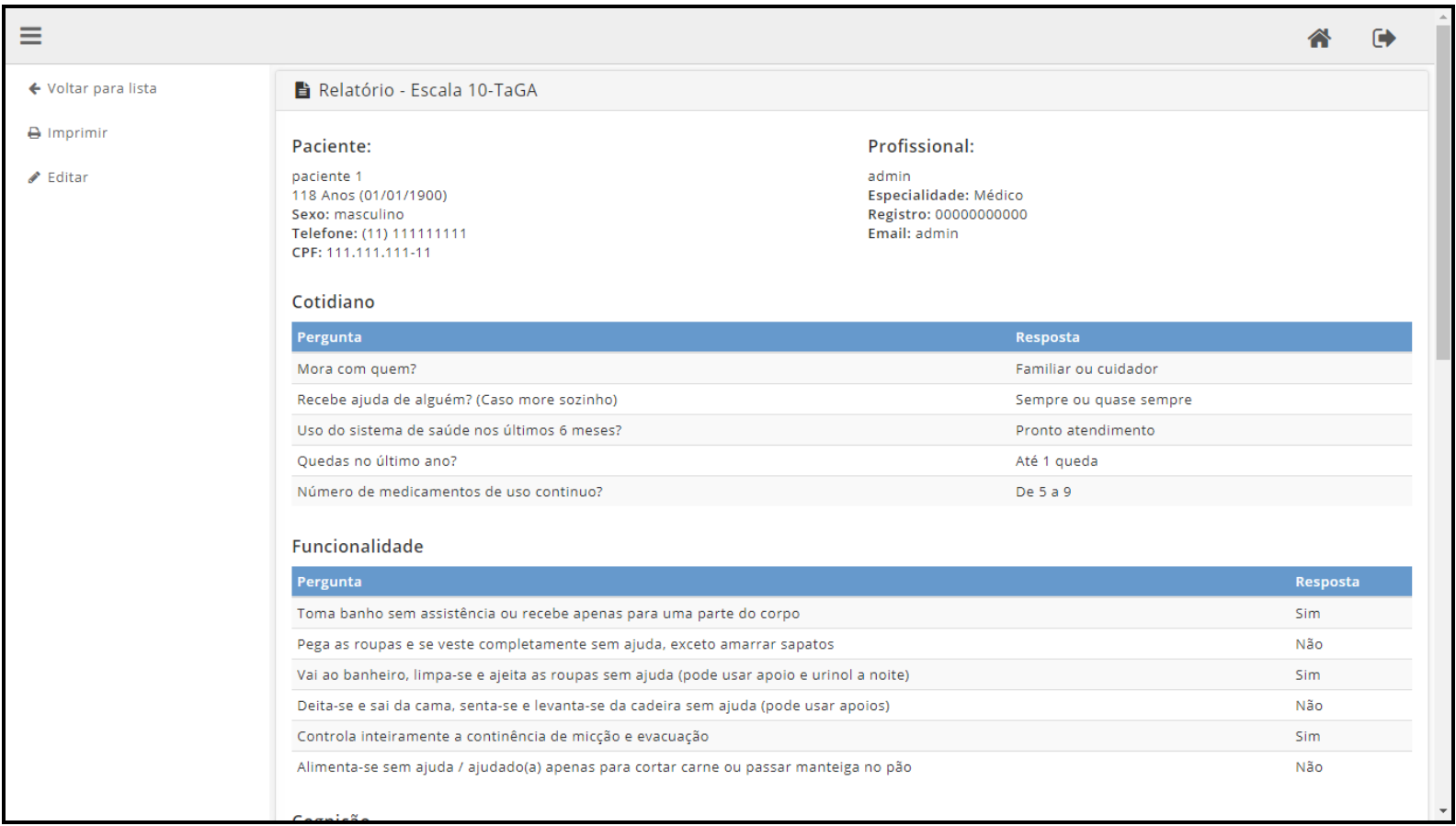

Fonte: autoria própria.

\subsubsection{Busca de avaliações}

É possível buscar avaliações de um paciente utilizando como palavra-chave: nome do profissional, nome do paciente, tipo de escala, data de criação. As chaves podem ser inseridas parcialmente e a busca retorna uma lista de resultados que contém a chave digita em seu registro (Figura 20). 
Figura 20 - Tela de atendimentos passados, busca de escala.

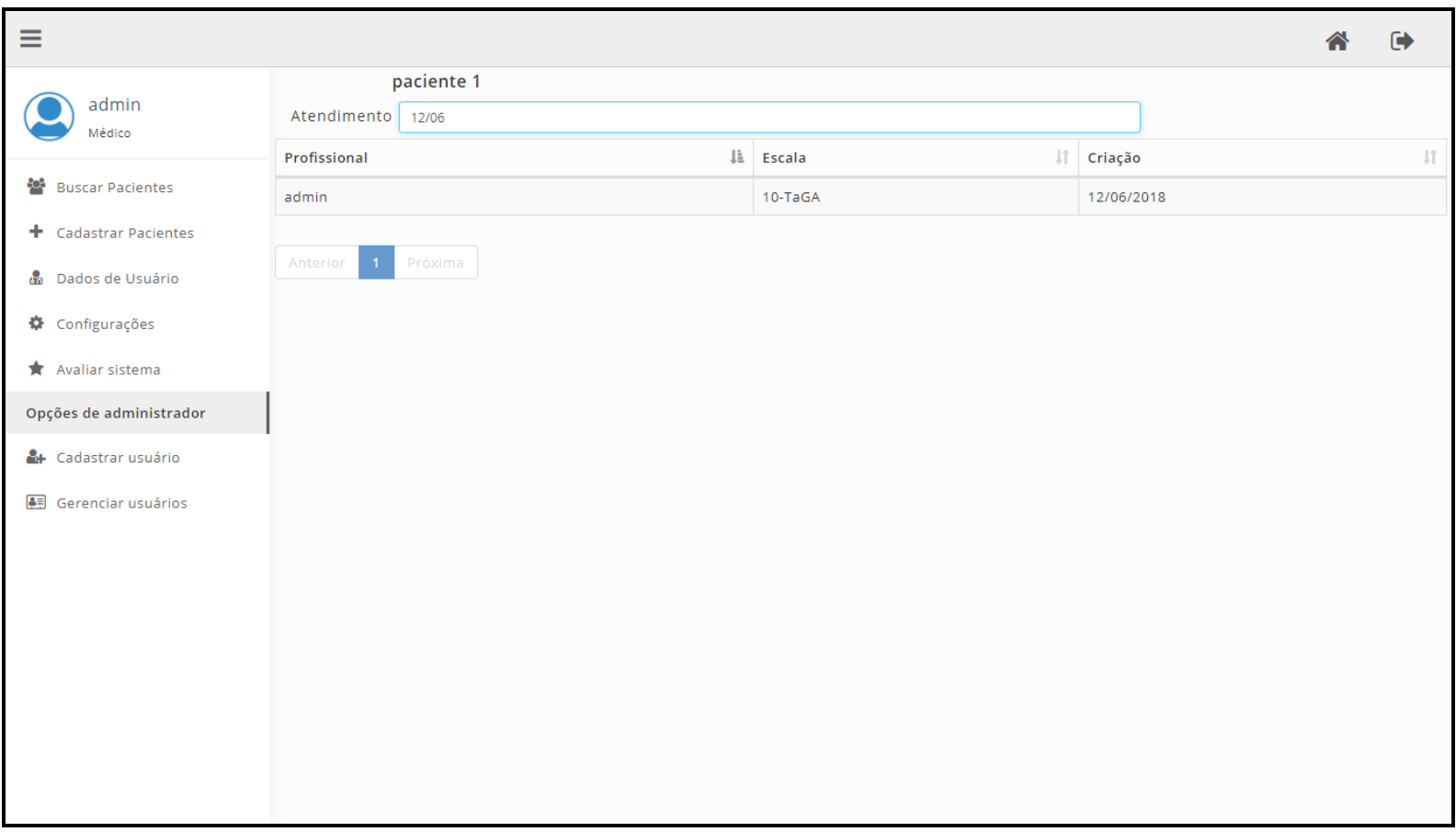

Fonte: autoria própria.

\subsection{Banco de dados}

O sistema possui um banco de dados relacional com um total de 68 Tabelas, dados sensitivos são armazenados no banco após a aplicação de criptografia. $\mathrm{Na}$ Figura 21 estão as tabelas, os campos de cada tabela e o modelo entidade relacionamento do banco.

O sistema possui algumas tabelas de informações para facilitar a inserção de dados por usuários, dentre elas: Tabela de composição de alimentos TACO, Tabela de composição de alimentos IBGE, Tabela de medicamentos da Prefeitura de Ribeirão Preto, CID-10 tabela de morbidades e base de endereços e CEP de 2014. 
Figura 21 - Modelo Entidade Relacionamento do banco de dados.

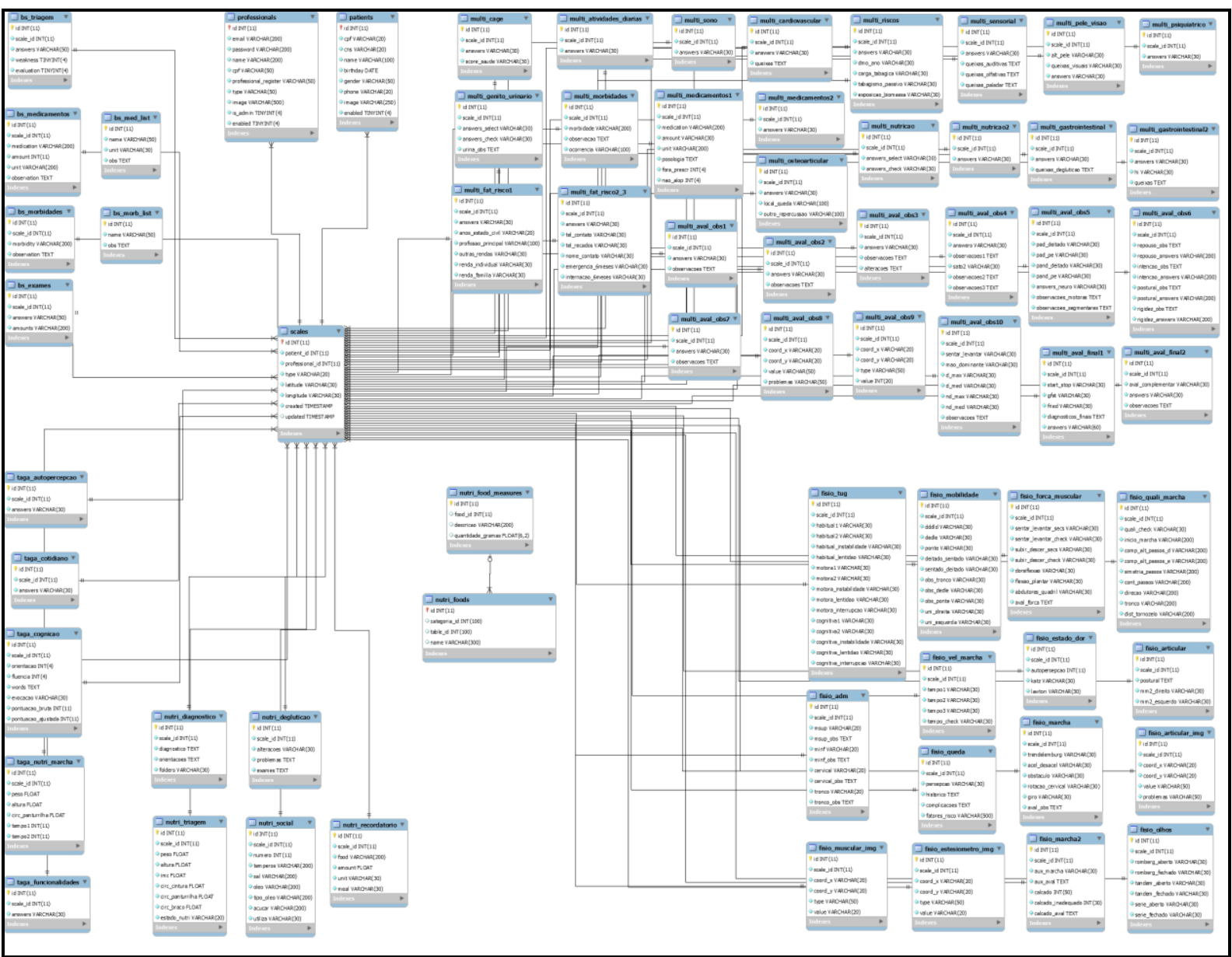

Fonte: autoria própria.

\subsection{Resultados do teste de usabilidade WAMMI}

Um total de 12 usuários realizaram o teste, dentre eles 5 residentes do curso de Medicina, 4 alunos do curso de Nutrição e Metabolismo, 1 aluno do curso de Fisioterapia e 2 profissionais responsáveis pela supervisão dos atendimentos. 0 relatório contendo os resultados do teste foi gerado no dia 19 de novembro de 2018.

O sistema teve uma avaliação no Teste Global de Usabilidade de 75 pontos de 100, todas as escalas utilizadas para compor esse resultado tiveram uma pontuação superior a 50 de 100 pontos.

A Tabela 3 mostra as médias de pontuações por escala e o desvio padrão das pontuações. Segundo o autor do teste, para este tipo de dados um valor razoável do desvio padrão é de 20,00. Desvios padrão acima de 30 sugerem que existam dois ou mais grupos de respondentes com opiniões muito diferentes sobre a 
usabilidade do site. $O$ fato dos desvios padrão serem maiores para algumas escalas do que para outras indica que existem diferenças na quantidade de concordância entre os entrevistados sobre essas escalas.

Tabela 3 - Pontuações das escalas de usabilidade

\begin{tabular}{ccc}
\hline Escala & Média & Desvio padrão \\
\hline Atratividade & 77,42 & 22,03 \\
Controlabilidade & 72,25 & 18,31 \\
Eficiência & 86,33 & 20,07 \\
Utilidade & 74,92 & 24,58 \\
Aprendizabilidade & 67,42 & 20,97 \\
Pontuação Global de & & 18,49 \\
\hline
\end{tabular}

A Tabela 4 mostra todo o conjunto de dados utilizado para os cálculos das pontuações das escalas.

Tabela 4 - Conjunto de dados das avaliações

\begin{tabular}{ccccccc}
\hline $\begin{array}{c}\text { ID do } \\
\text { usuário }\end{array}$ & Atratividade & Controlabilidade & Eficiência & Utilidade & Aprendizabilidade & $\begin{array}{c}\text { Pontuação } \\
\text { Global de } \\
\text { Usabilidade }\end{array}$ \\
\hline 1 & 83 & 94 & 91 & 92 & 81 & 88 \\
2 & 94 & 94 & 100 & 92 & 91 & 94 \\
3 & 56 & 36 & 55 & 54 & 46 & 49 \\
4 & 94 & 63 & 83 & 65 & 74 & 75 \\
5 & 22 & 72 & 37 & 7 & 27 & 33 \\
6 & 61 & 71 & 88 & 87 & 59 & 73 \\
7 & 76 & 56 & 91 & 75 & 46 & 68 \\
8 & 94 & 83 & 100 & 87 & 87 & 90 \\
9 & 73 & 55 & 91 & 75 & 81 & 75 \\
10 & 94 & 84 & 100 & 92 & 88 & 91 \\
11 & 94 & 94 & 100 & 92 & 79 & 91 \\
12 & 88 & 65 & 100 & 81 & 50 & 76 \\
\hline
\end{tabular}


Os gráficos da Figura 22 e Figura 23 mostram as dez questões nas quais os avaliadores tiveram maiores concordância e discordância entre si respectivamente, as barras representam os valores da média de todas as avaliações. Os resultados demonstram que questões possivelmente relacionadas com fatores externos têm maior variação nas respostas, a questão de lentidão está relacionada com a velocidade da rede e o gosto por utilizar o site pode ter relação com gosto pela tarefa executada. As maiores concordâncias parecer ter relação com aspectos mais objetivos e técnicos como layout e usabilidade.

Figura 22 - As dez respostas com maior divergência

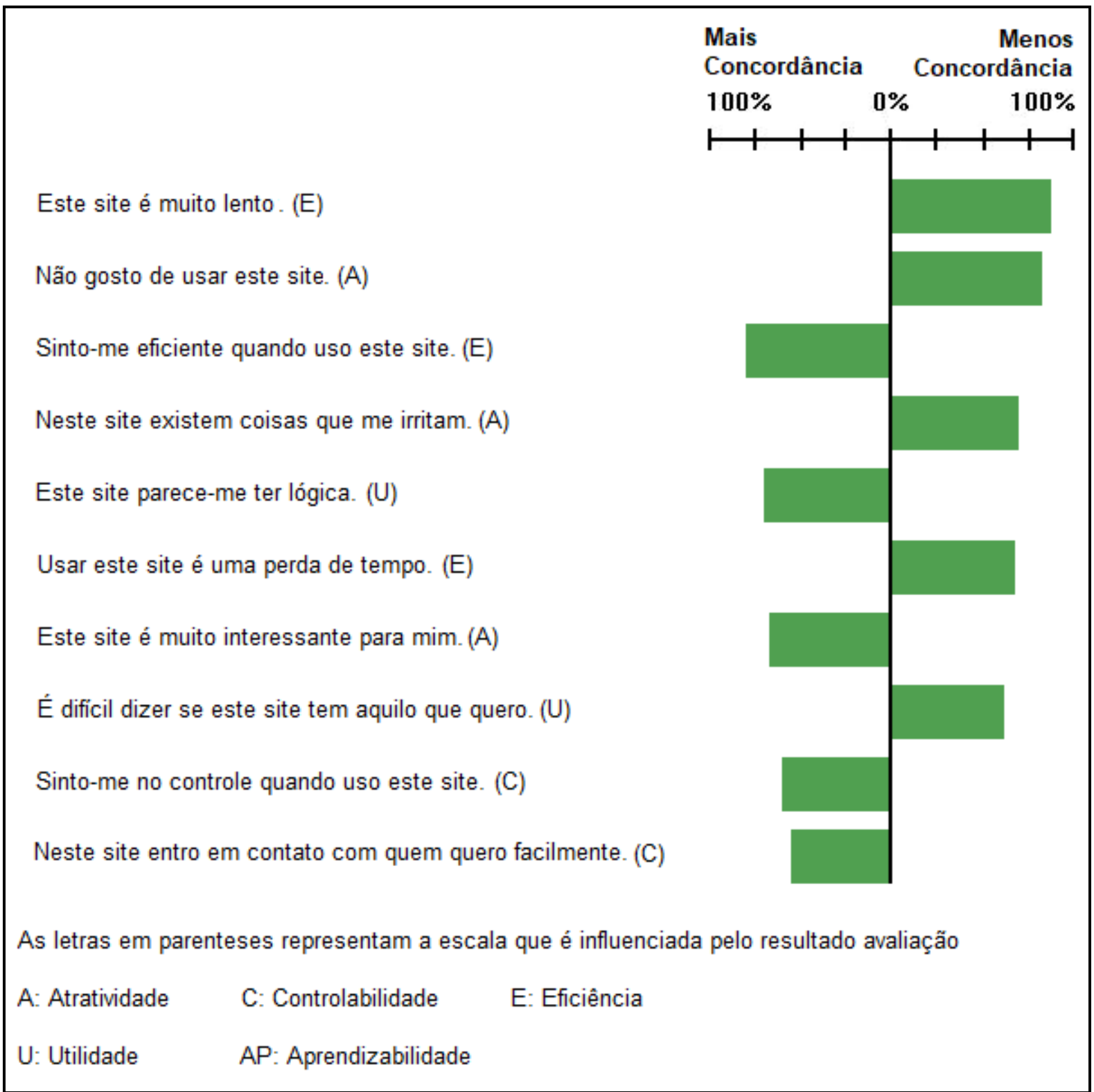

Fonte: Relatório do teste WAMMI. 
Figura 23 - As dez respostas com menor divergência

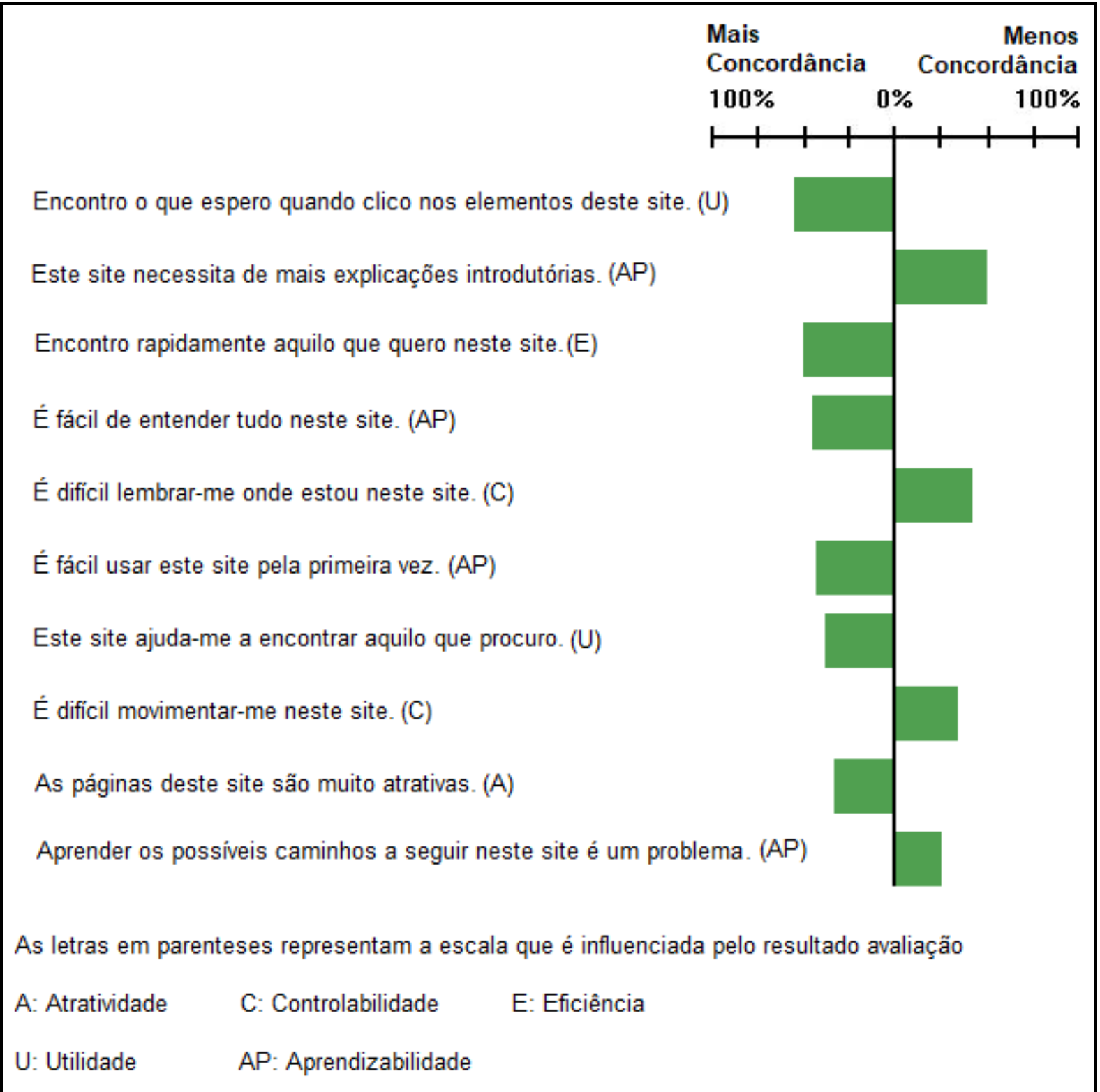

Fonte: Relatório do teste WAMMI.

Nas respostas abertas os feedbacks dados pelos usuários confirmam o layout e usabilidade como pontos fortes do sistema. Como pontos a serem melhorados destacam-se a falta de material introdutório, dentro e fora do sistema, e um canal de suporte para o usuário dentro do sistema. A Tabela 5, Tabela 6 e Tabela 7 contém o conjunto de respostas e feedbacks em texto aberto. 
Tabela 5 - Respostas de campo aberto sobre interesse ou utilidade

Qual parte deste site você considera mais interessante ou útil?

ID do usuário Comentário

1 Classificação de riscos desnutrição/sarcopenia, CMB\%, disfagia, risco nutricional;

2

O mais interessante para mim, foi a geração do relatório e a facilidade dos cálculos

3

Facilidade no atendimento

4

Aba nutrição bem completa

5

Facilidade

6

Construção de relatório sumarizado a partir dos dados registrados

7

Interação das informações

8

Menu de navegação

9

Praticidade

10

Plataforma nutrição

Que fica uma avaliação completa

12

Avaliação multiprofissional 
Tabela 6 - Respostas de campo aberto sobre melhores aspectos

\begin{tabular}{|c|c|}
\hline & Quais são os melhores aspectos desse website? Por que? \\
\hline ID do usuário & Comentário \\
\hline 1 & $\begin{array}{l}\text { Um bom protocolo de atendimento multiprofissional, com classificação de risco, fácil } \\
\text { de ser usado. }\end{array}$ \\
\hline 2 & A facilidade e a rapidez dos dados \\
\hline 3 & Facilidade de acesso aos dados e a adicionar dados dos pacientes \\
\hline 4 & Design, itens completos nutrição \\
\hline 5 & Facilita muito \\
\hline 6 & Avaliação por grupos de informações \\
\hline 7 & Visão geral. Porque integra todas as informações multiprofissionais. \\
\hline 8 & Facilidade de navegação \\
\hline 9 & Facilidade e praticidade \\
\hline 10 & Design, localização das abas, não trava, completo nas informações \\
\hline 11 & Fácil aplicabilidade, simples, objetivo e direto. \\
\hline 12 & Layout e facilidade de uso, as informações estão bem claras \\
\hline
\end{tabular}


Tabela 7 - Respostas de campo aberto sobre possíveis falhas

\begin{tabular}{|c|c|}
\hline & Tem algo que acredita estar faltando nesse website? \\
\hline ID do usuário & Comentário \\
\hline 1 & Medidas caseiras na hora de colocar o consumo alimentar do paciente. \\
\hline 2 & Nada \\
\hline 3 & Corrigir repetições de itens entre as sessões. \\
\hline 4 & - \\
\hline 5 & $\begin{array}{l}\text { Escala mais aprofundada que usamos quando o paciente atinge os pontos da } \\
\text { triagem }\end{array}$ \\
\hline 6 & $\begin{array}{l}\text { Tutoriais para novos usuários pontuações e níveis de corte explicitados apontar } \\
\text { com destaque valores abaixo de pontos de corte ou presença de fatores de risco }\end{array}$ \\
\hline 7 & Espaço para respostas \\
\hline 8 & Contato pelo site para tirar dúvidas \\
\hline 9 & Não \\
\hline 10 & Não \\
\hline 11 & Não \\
\hline 12 & Gerar relatórios estatísticos, demonstrar melhor onde o usuário está. \\
\hline
\end{tabular}

$\mathrm{Na}$ Tabela 8 os usuários avaliaram suas próprias habilidades e conhecimentos de internet, na Tabela 9 podemos observar as avaliações das escalas segmentadas pelo nível de habilidade na internet. Os resultados demonstram que as notas das escalas aumentam quanto maior for a habilidade do usuário. Uma possível maneira de equilibrar os resultados é com material introdutório das funcionalidades do sistema. 
Tabela 8 - Como o usuário classifica sua habilidade e conhecimento de Internet

\begin{tabular}{llc}
\hline Experiência & Número de respostas & Teste Global de Usabilidade \\
\hline Especialista & $2(16 \%)$ & 85.00 \\
Sou bom & $6(50 \%)$ & 76.50 \\
Mediano & $4(33 \%)$ & 68.50 \\
Fraco & $0(0 \%)$ & 0.00 \\
\hline
\end{tabular}

Tabela 9 - Pontuação das escalas por habilidade e conhecimento de Internet

\begin{tabular}{lccccc}
\hline Experiência & Atratividade & Controlabilidade & Eficiência & Utilidade & Aprendizabilidade \\
\hline Especialista & 91.00 & 79.50 & 100.00 & 86.50 & 70.50 \\
Sou bom & 77.33 & 72.33 & 87.50 & 81.17 & 66.33 \\
Mediano & 70.75 & 68.50 & 77.75 & 59.75 & 67.50 \\
Fraco & 0.00 & 0.00 & 0.00 & 0.00 & 0.00 \\
\hline
\end{tabular}

\section{DISCUSSÃO}

\subsection{Tecnologia no tema Síndrome de Fragilidade}

Observando o importante papel desempenhado pela tecnologia em nossa sociedade moderna, podemos fazer a seguinte pergunta: até que ponto a tecnologia está presente em sua relação com a fragilidade ou, que recursos tecnológicos são utilizados para lidar com a fragilidade? Para responder essa pergunta foi feita uma revisão bibliográfica com 104 artigos com o tema de tecnologia na Síndrome de Fragilidade no período do ano de 2005 a 2015 (57). A revisão dividiu os artigos em categorias de: prevenção, diagnóstico, cuidado e tratamento. O escopo das avaliações do protocolo e do acesso à plataforma fazem com que o trabalho aqui apresentado se encaixe na categoria de diagnóstico, a categoria que apresentou 
uma maior quantidade de artigos a partir do ano de 2011 até 2015 (57) como demonstra a Figura 25.

Figura 24 - Quantidade de artigos por categoria

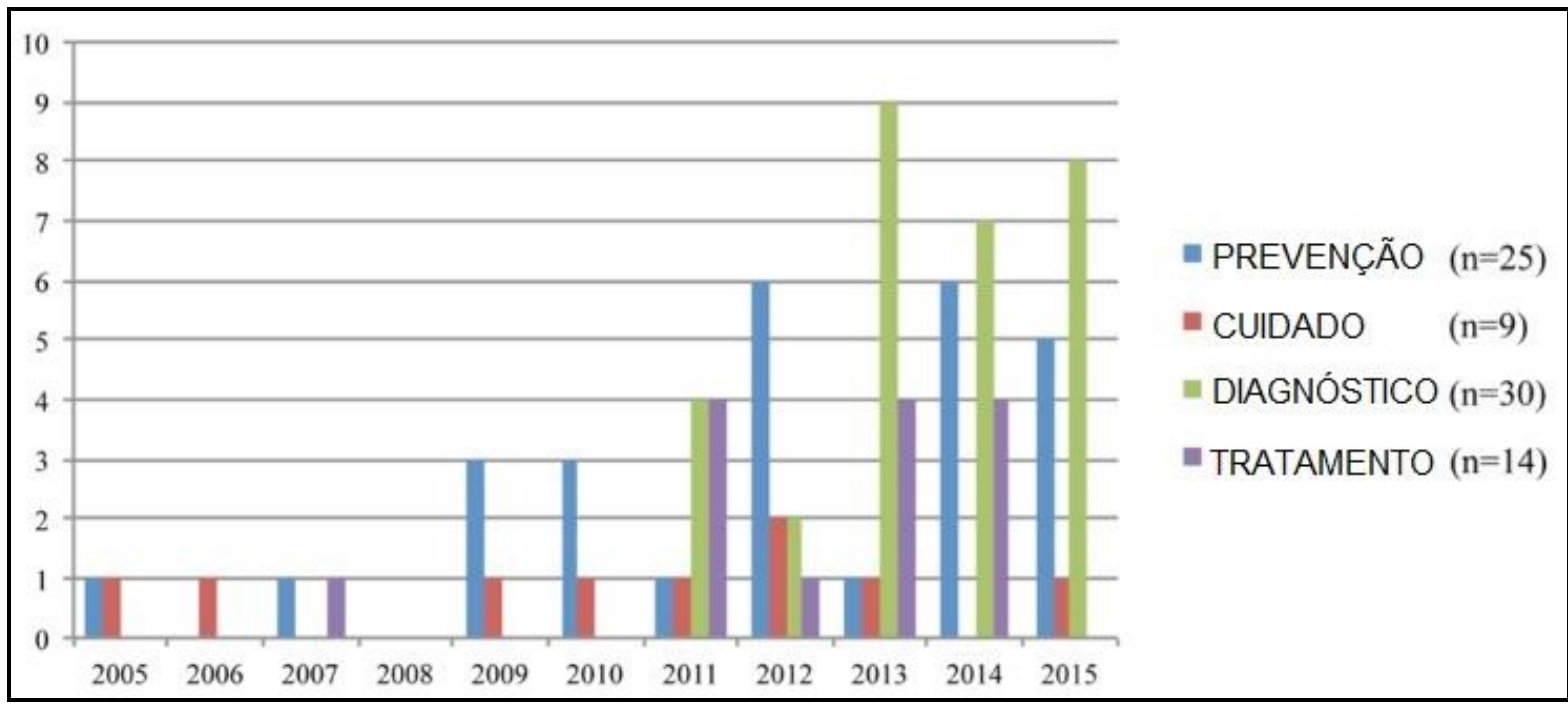

Fonte: https://www.ncbi.nlm.nih.gov/pmc/articles/PMC5362177/figure/F5-ad-8-2-176/

Os artigos da categoria de diagnóstico revistos no estudo possuem similaridades e diferenças com o presente trabalho, dentre as diferenças podemos destacar o desenvolvimento de gadgets e dispositivos de medição para coletar dados diretamente do paciente sem a necessidade de uma avaliação por um profissional, esses estudos são focados no hardware utilizado para medição e na associação de padrões de dados com a presença da síndrome de fragilidade. Um exemplo é o estudo de Chang et al., 2013 (58) que busca através de redes neurais gerar um classificador de fragilidade. O trabalho aqui apresentado não faz uso de dispositivos externos e depende da avaliação dos profissionais de saúde, uma característica que diminui sua escalabilidade, no entanto o envolvimento do profissional faz com que o processo de avaliação seja mais sensível e não dependa de um grande volume de atendimentos, sendo assim mais adequado para a realidade do CSE. 


\subsection{Normas da Sociedade Brasileira de Informática em Saúde}

Nas últimas décadas, a tecnologia afetou significativamente a área da saúde, onde profissionais e instituições vêm adotando cada vez mais os registros eletrônicos em suas atividades. A área da saúde, contudo, apresenta características e condições bastante específicas quanto à privacidade e confidencialidade dos indivíduos assistidos, à integridade e segurança das informações e aos recursos mínimos necessários para o registro dos atos praticados e das condições de saúde dos indivíduos (59).

Ciente da complexidade do assunto, o Conselho Federal de Medicina, através da Câmara Técnica de Informática em Saúde, estabeleceu convênio de cooperação técnica com a Sociedade Brasileira de Informática em Saúde para desenvolver o Manual de Certificação para Sistemas de Registro Eletrônico em Saúde (59).

No entanto, Em sua primeira versão, o sistema se adequa à 20 dos 44 dos requisitos mandatórios e 10 das 20 normas sugeridas pela Sociedade Brasileira de Informática em Saúde. As sessões nas quais o sistema melhor se adequou foram: identificação e autenticação de pessoas, autorização e controle de acesso de pessoas, controle de sessão de usuário, comunicação de componentes e segurança de dados.

$\mathrm{Na}$ Tabela 10 pode ser observada a situação de adequação do sistema à cada norma. O conteúdo de cada norma e suas condições estão disponíveis no Manual de Certificação para Sistemas de Registro Eletrônico em Saúde (59).

Tabela 10 - Adequação às normas da Sociedade Brasileira de Informática em Saúde

\begin{tabular}{|c|c|c|c|}
\hline Código da norma & Atende à norma & Obrigatoriedade & Condição de aplicabilidade \\
\hline \multicolumn{4}{|c|}{ NGS1.01 - Controle de versão do software } \\
\hline NGS1.01.01 & Não & Mandatório & Sem condição \\
\hline NGS1.01.02 & Sim & Recomendado & Sem condição \\
\hline NGS1.01.04 & Sim & Recomendado & Sem condição \\
\hline \multicolumn{4}{|c|}{ NGS1.02 - Identificação e autenticação de pessoas } \\
\hline NGS1.02.01 & Sim & Mandatório & Sem condição \\
\hline NGS1.02.02 & Sim & Mandatório & Sem condição \\
\hline NGS1.02.03 & Sim & Mandatório & Sem condição \\
\hline NGS1.02.04 & Não & Mandatório & Atinge condição \\
\hline
\end{tabular}


(Continuação)

\begin{tabular}{|c|c|c|c|}
\hline Código da norma & Atende à norma & Obrigatoriedade & Condição de aplicabilidade \\
\hline NGS1.02.05 & Não & Mandatório & Sem condição \\
\hline NGS1.02.06 & Sim & Mandatório & Sem condição \\
\hline NGS1.02.07 & Não & Recomendado & Sem condição \\
\hline NGS1.02.08 & Não & Mandatório & Sem condição \\
\hline NGS1.02.09 & Sim & Recomendado & Sem condição \\
\hline NGS1.02.10 & $\operatorname{Sim}$ & Recomendado & Atinge condição \\
\hline NGS1.02.11 & Não & Recomendado & Sem condição \\
\hline NGS1.02.12 & Não & Recomendado & Sem condição \\
\hline \multicolumn{4}{|c|}{ NGS1.03 - Controle de sessão de usuário } \\
\hline NGS1.03.01 & $\operatorname{Sim}$ & Mandatório & Sem condição \\
\hline NGS1.03.02 & $\operatorname{Sim}$ & Mandatório & Sem condição \\
\hline NGS1.03.03 & - & Recomendado & Não atinge condição \\
\hline \multicolumn{4}{|c|}{ NGS1.04 - Autorização e controle de acesso de pessoas } \\
\hline NGS1.04.01 & Sim & Mandatório & Sem condição \\
\hline NGS1.04.02 & Sim & Mandatório & Sem condição \\
\hline NGS1.04.03 & Sim & Mandatório & Sem condição \\
\hline NGS1.04.04 & Não & Mandatório & Sem condição \\
\hline NGS1.04.05 & $\operatorname{Sim}$ & Mandatório & Sem condição \\
\hline NGS1.04.06 & $\operatorname{Sim}$ & Mandatório & Sem condição \\
\hline NGS1.04.07 & - & Mandatório & Não atinge condição \\
\hline NGS1.04.08 & - & Mandatório & Não atinge condição \\
\hline NGS1.04.10 & Não & Recomendado & Sem condição \\
\hline NGS1.04.11 & Não & Mandatório & Sem condição \\
\hline NGS1.04.12 & - & Recomendado & Não atinge condição \\
\hline \multicolumn{4}{|c|}{ NGS1.05 - Disponibilidade do RES } \\
\hline NGS1.05.01 & Não & Mandatório & Sem condição \\
\hline NGS1.05.02 & Não & Mandatório & Sem condição \\
\hline NGS1.05.03 & Não & Mandatório & Sem condição \\
\hline \multicolumn{4}{|c|}{ NGS1.06 - Comunicação entre componentes do S-RES } \\
\hline NGS1.06.01 & $\operatorname{Sim}$ & Mandatório & Sem condição \\
\hline NGS1.06.02 & $\operatorname{Sim}$ & Mandatório & Sem condição \\
\hline NGS1.06.03 & $\operatorname{Sim}$ & Mandatório & Sem condição \\
\hline NGS1.06.04 & $\operatorname{Sim}$ & Mandatório & Atinge condição \\
\hline NGS1.06.05 & $\operatorname{Sim}$ & Mandatório & Atinge condição \\
\hline NGS1.06.06 & - & Mandatório & Não atinge condição \\
\hline NGS1.06.07 & - & Mandatório & Não atinge condição \\
\hline NGS1.06.08 & - & Mandatório & Não atinge condição \\
\hline NGS1.06.09 & Não & Recomendado & Sem condição \\
\hline NGS1.06.10 & Sim & Recomendado & Sem condição \\
\hline
\end{tabular}

NGS1.07 - Segurança de dados 
(Continuação)

\begin{tabular}{|c|c|c|c|}
\hline Código da norma & Atende à norma & Obrigatoriedade & Condição de aplicabilidade \\
\hline NGS1.07.01 & - & Mandatório & Não atinge condição \\
\hline NGS1.07.04 & Não & Recomendado & Sem condição \\
\hline NGS1.07.05 & Sim & Mandatório & Sem condição \\
\hline NGS1.07.06 & Sim & Mandatório & Sem condição \\
\hline NGS1.07.07 & Sim & Recomendado & Sem condição \\
\hline NGS1.07.09 & Sim & Recomendado & Sem condição \\
\hline NGS1.07.10 & $\operatorname{Sim}$ & Recomendado & Sem condição \\
\hline NGS1.07.11 & - & Recomendado & Não atinge condição \\
\hline NGS1.07.12 & - & Recomendado & Não atinge condição \\
\hline \multicolumn{4}{|c|}{ NGS1.08 - Auditoria } \\
\hline NGS1.08.01 & Não & Mandatório & Sem condição \\
\hline NGS1.08.02 & Não & Mandatório & Sem condição \\
\hline NGS1.08.04 & Não & Mandatório & Sem condição \\
\hline NGS1.08.05 & Não & Mandatório & Sem condição \\
\hline NGS1.08.06 & Não & Mandatório & Sem condição \\
\hline \multicolumn{4}{|c|}{ NGS1.09 - Documentação } \\
\hline NGS1.09.01 & Não & Mandatório & Sem condição \\
\hline NGS1.09.02 & Não & Mandatório & Sem condição \\
\hline NGS1.09.04 & Não & Mandatório & Sem condição \\
\hline NGS1.09.05 & Não & Mandatório & Sem condição \\
\hline NGS1.09.07 & - & Mandatório & Não atinge condição \\
\hline NGS1.09.08 & Não & Mandatório & Sem condição \\
\hline NGS1.09.09 & Não & Mandatório & Sem condição \\
\hline NGS1.09.10 & - & Mandatório & Não atinge condição \\
\hline NGS1.09.11 & - & Mandatório & Não atinge condição \\
\hline NGS1.09.12 & Não & Mandatório & Sem condição \\
\hline NGS1.09.13 & Não & Mandatório & Sem condição \\
\hline NGS1.09.14 & Não & Mandatório & Sem condição \\
\hline \multicolumn{4}{|l|}{ NGS1.10 - Tempo } \\
\hline NGS1.10.01 & $\operatorname{Sim}$ & Mandatório & Sem condição \\
\hline NGS1.10.03 & Sim & Mandatório & Sem condição \\
\hline \multicolumn{4}{|c|}{ NGS1.11 - Notificação de ocorrências } \\
\hline NGS1.11.01 & Não & Recomendado & Sem condição \\
\hline \multicolumn{4}{|c|}{ NGS1.12 - Privacidade } \\
\hline NGS1.12.01 & Não & Mandatório & Sem condição \\
\hline NGS1.12.02 & Sim & Recomendado & Sem condição \\
\hline NGS1.12.03 & Sim & Recomendado & Sem condição \\
\hline NGS1.12.04 & Não & Recomendado & Sem condição \\
\hline NGS1.12.05 & Não & Recomendado & Sem condição \\
\hline NGS1.12.06 & Não & Recomendado & Sem condição \\
\hline
\end{tabular}


(Continuação)

\begin{tabular}{lcll}
\hline Código da norma & Atende à norma & Obrigatoriedade & Condição de aplicabilidade \\
\hline NGS1.12.07 & - & Mandatório & Não atinge condição \\
NGS1.13 - Autenticação de usuário utilizando certificado digital \\
NGS1.13.01 & - & Recomendado & Não atinge condição \\
NGS1.13.02 & - & Recomendado & Não atinge condição \\
NGS1.13.03 & - & Mandatório & Não atinge condição \\
NGS1.13.04 & - & Mandatório & Não atinge condição \\
NGS1.13.05 & - & Recomendado & Não atinge condição \\
NGS1.13.06 & - & Mandatório & Não atinge condição \\
NGS1.13.07 & - & Mandatório & Não atinge condição \\
NGS1.13.08 & - & Mandatório & Não atinge condição \\
NGS1.13.09 & - & Mandatório & Não atinge condição \\
NGS1.13.10 & - & Mandatório & Não atinge condição \\
NGS1.13.11 & - & Mandatório & Não atinge condição \\
\hline
\end{tabular}

\subsection{Usabilidade do sistema}

Tecnologias modernas, como Internet e Web 2.0, já estão totalmente disseminadas e praticamente qualquer instituição faz uso dessas tecnologias. Em geral, a atitude positiva ou negativa do usuário afetará a aceitação de uma nova tecnologia, sendo assim avaliar a usabilidade dos sites é essencial, pois os problemas de usabilidade afetarão a aceitação dos usuários.

Comparando o desempenho do sistema desenvolvido com demais avaliações de usabilidade do questionário WAMMI encontradas na literatura, podemos concluir que os usuários do sistema tiveram uma aceitação elevada em relação à média. $\mathrm{Na}$ comparação foram levados em conta estudos que medem a usabilidade de sites acadêmicos (60), de lojas virtuais (61) e de sistemas de informação em saúde (62). A ausência de trabalhos similares impede uma avaliação comparativa segmentada, no entanto as propriedades de usabilidade avaliadas estão presentes em todos os sistemas e as boas práticas de usabilidade podem ser aplicadas independentemente do objetivo do sistema. 


\section{CONCLUSÃO}

O trabalho aqui apresentado destaca-se das demais pesquisas envolvendo a Síndrome de Fragilidade por dispensar o uso de hardwares específicos e ter um maior envolvimento do profissional no processo, adequando-se melhor à realidade do sistema de saúde pública brasileiro.

Baseando-se nos padrões da Sociedade Brasileira de Informática em Saúde, o sistema desenvolvido possui um bom controle de acesso e segurança dos dados.

Os resultados do teste de usabilidade demonstra que os usuários aprovam a estrutura da plataforma e esta demonstra ser eficiente na aplicação dos protocolos de identificação de Síndrome de Fragilidade. 


\section{REFERÊNCIAS}

1 World Health Organization. Active Ageing - A Policy Framework. A contribution of the World Health Organization to the Second United Nations World Assembly on Ageing. Madri, abril de 2002, p. 4.

2 Martins CRM. O envelhecer segundo adolescentes, adultos e idosos usuários do SESC Maringá: um estudo de Representações Sociais (dissertação). Florianópolis: Departamento de Psicologia, Universidade Federal de Santa Catarina; 2002.

3 Santosl, Silvana Sidney Costa. "Concepções teórico Concepções teóricofilosóficas sobre-filosóficas sobre envelhecimento, velhice, idoso e enfermagem ger envelhecimento, velhice, idoso e enfermagem gerontogeriátrica ontogeriátrica." Revista Brasileira de Enfermagem 63.6 (2010): 1035-1039.

4 Federal, Senado. "Estatuto do idoso." Brasília (DF): Senado Federal (2003).

5 IBGE, Instituto Brasileiro de Geografia e Estatística. Disponível em: <http://www.ibge.gov.br/apps/populacao/projecao/>. Acessado em 11/11/2015.

6 Agência IBGE de Notícias. Disponível em: $<$ https://agenciadenoticias.ibge.gov.br/agencia-noticias/2012-agencia-denoticias/noticias/20980-numero-de-idosos-cresce-18-em-5-anos-e-ultrapassa-30milhoes-em-2017.html >. Acessado em 30/05/2018.

7 Veras R. Envelhecimento populacional contemporâneo: demandas, desafios e inovações. Revista de Saúde Pública. 2009 Jun;43(3):548-54.

8 Lima-Costa MFF, Guerra HL, Barreto SM, Guimarães RM. Diagnóstico da situação de saúde da população idosa brasileira: um estudo da mortalidade e das internações hospitalares públicas. Informe Epidemiológico do SUS 2000; 9(1):23-41.

$9 \quad$ Peixoto SV, Giatti L, Elmira Afradique M, Fernanda Lima-Costa M. Custo das internações hospitalares entre idosos brasileiros no âmbito do Sistema Único de Saúde. Epidemiologia e Serviços de Saúde. 2004 Dec;13(4):239-46. 
10 Loyola Filho, Antônio Ignácio de, et al. "Causas de internações hospitalares entre idosos brasileiros no âmbito do Sistema Único de Saúde." Epidemiologia e serviços de saúde 13.4 (2004): 229-238.

11 Fabrício SCC, Rodrigues RAP. Revisão da literatura sobre fragilidade e sua relação com o Envelhecimento. Rev. RENE 2008; 9(2):113-119.

12 Ferriolli E, Morigute JC, Formighieri PF. O idoso frágil. In: Lopes AC, Neto VA, organizadores. Tratado de Clínica Médica. São Paulo: Roca Editora; 2006. p. 44544460.

13 Fried LP, Tangen CM, Walston J, Newman AB, Hirsch C, Gottdiener J, Seeman T, Tracy R, Kop WJ, Burke G, Mc Burnie MA. Frailty in older adults: evidence for a phenotype. J Gerontol A Biol Sci Med Sci 2001; 56(3):M146-M156.

14 Vieira RA, Guerra RO, Giacomin KC, Vasconcelos KSS, Andrade ACS, Pereira LSM, Dias JMD, Dias RC. Prevalência de fragilidade e fatores associados em idosos comunitários de Belo Horizonte, Minas Gerais, Brasil: dados do Estudo FIBRA. Cad Saude Publica 2013; 29(8):1631-1643

15 Fried LP, Tangen CM, Walston J, Newman AB, Hirsch C, Gottdiener J, Seeman T, Tracy R, Kop WJ, Burke G, McBurnie MA. Frailty in older adults: evidence for a phenotype. The Journals of Gerontology Series A: Biological Sciences and Medical Sciences. 2001 Mar 1;56(3):M146-57.

16 Blaum CS, Xue QL, Michelon E, Semba RD, Fried LP. The association between obesity and the frailty syndrome in older women: the Women's Health and Aging Studies. Journal of the American Geriatrics Society. 2005 Jun;53(6):927-34.

17 Hubbard RE, Lang IA, Llewellyn DJ, Rockwood K. Frailty, body mass index, and abdominal obesity in older people. Journals of Gerontology Series A: Biomedical Sciences and Medical Sciences. 2009 Nov 25;65(4):377-81.

18 Bilotta $C$, Nicolini $P$, Casè A, Pina G, Rossi S, Vergani C. Frailty syndrome diagnosed according to the Study of Osteoporotic Fractures (SOF) criteria and adverse health outcomes among community-dwelling older outpatients in Italy. A one-year prospective cohort study. Archives of gerontology and geriatrics. $2012 \mathrm{Mar}$ 1;54(2):e23-8. 
19 Beaurenaut L, Eggiman C, Gastinger F, Platzdasch H, Rasbornig F, Strasser $M$. Single-edge nibble transmission: challenges and evolutions. SAE Technical Paper; 2009 Apr 20.

20 Espinoza SE, Jung I, Hazuda $H$. Frailty transitions in the San Antonio longitudinal study of aging. Journal of the American Geriatrics Society. 2012 Apr;60(4):652-60.

21 Strandberg TE, Sirola J, Pitkälä KH, Tilvis RS, Strandberg AY, Stenholm S. Association of midlife obesity and cardiovascular risk with old age frailty: a 26-year follow-up of initially healthy men. International journal of obesity. 2012 Sep;36(9):1153.

22 Espinoza SE, Jung I, Hazuda H. Lower frailty incidence in older mexican americans than in older european americans: The san antonio longitudinal study of aging. J Am Geriatr Soc. 2010, 58: 2142-2148.

23 Kalyani RR, Varadhan R, Weiss CO, Fried LP, Cappola AR. Frailty status and altered glucose-insulin dynamics. Journals of Gerontology: Series A: Biomedical Sciences and Medical Sciences. 2011 Aug 26;67(12):1300-6.

24 Bergman H, Ferrucci L, Guralnik J, Hogan DB, Hummel S, Karunananthan S, Wolfson C. Frailty: an emerging research and clinical paradigm-issues and controversies. The Journals of Gerontology Series A: Biological Sciences and Medical Sciences. 2007 Jul 1;62(7):731-7.

25 Universidade de São Paulo - Serviço de Comunicação Social - Campus Ribeirão Preto. Disponível em: <http://ribeirao.usp.br/?p=10957>. Acessado em 30/05/2018.

26 SBIS/CFM Cartilha sobre Prontuario Eletronico, a Certificação de Sistemas de Registro Eletrônico de Saúde. Disponível em: $<$ http://portal.cfm.org.br/crmdigital/Cartilha_SBIS_CFM_Prontuario_Eletronico_fev_2 012.pdf>. Acessado em 11/11/2015.

27 Pellison, Felipe Carvalho, et al. "Análise do impacto orçamentário causado pela implantação de assina digital no Hospital das Clínicas da Faculdade de Medicina de Ribeirão Preto da Universidade de São Paulo." Medicina (Ribeirao Preto. Online) 48.1 (2015): 57-64. 
28 Vellas, B., Balardy, L., Gillette-Guyonnet, S. et al. J Nutr Health Aging (2013) 17: 629. doi:10.1007/s12603-013-0363-6.

29 Fredrick T. Sherman, THE 10 MINUTE GERIATRIC ASSESSMENT. Mount Sinai School of Medicine.

30 Podsiadlo D, Richardson S. The timed "up \& go": a test of basic functional mobility for frail elderly persons. J Am Geriatr Soc. 1991;39(2):142-148.

31 Virtuoso et al., The "Timed Up and Go" in the prediction and explanation of falls in old people practicing physical exercises. RBCDH, 2013.

32 Rikli RE, Jones CJ. Senior fitness test manual. Human Kinetics; 2013.

33 Lewis et al. One-Legged (Single Limb) Stance Test. Geriatric Function, 2006.

34 Byrd et al. Livro: O quadril. Ed.2010.

35 Pedrosa $\mathrm{CH}$. Consenso internacional sobre o pé diabético. Ministério do Estado da Saúde, Brasil. 2001.

36 Horack et al. The Balance Evaluation Systems Test (BESTest) to Differentiate Balance Deficits. Phys Ther. 2009 May; 89(5): 484-498.

37 De Castro SM, Perracini MR, Ganança FF. Versão brasileira do dynamic gait index. Revista Brasileira de Otorrinolaringologia. 2006 Dec;72(6):817-25.

38 Shopping B, Housekeeping D, Score EL. Instrumental Activities of Daily Living (IADL). Gerontologist. 1969;9(3):179-86.

39 Shelkey M, Wallace M. Katz index of independence in activities of daily living. Journal of gerontological nursing. 1999 Mar 1;25(3):8-9. 
40 Mioshi E, Dawson K, Mitchell J, Arnold R, Hodges JR. The Addenbrooke's Cognitive Examination Revised (ACE-R): a brief cognitive test battery for dementia screening. International journal of geriatric psychiatry. 2006 Nov 1;21(11):1078-85.

41 Lecrubier $\mathrm{Y}$, Weiller E, Hergueta T, Amorim P, Bonora LI, Lépine JP. Mini international neuropsychiatric interview-Brazilian version 5.0. 0. DSM-IV. 2002.

42 PRESSMAN, R. Software Engineering: A practitioner's Approach. 7aed., McGraw-Hill, 2010.

43 ELMASRI, R.; NAVATHE, S.B. Sistema de Banco de Dados. 4를ição, 2008.

44 DBDesigner 4. Disponível em: <http://www.fabforce.net/dbdesigner4/>. Acessado em 11/11/2015.

45 MySQL. Disponível em: <https://www.mysql.com/>. Acessado em 30/05/2018.

46 Pitt, Chris. Pro PHP MVC. Apress, 2012.

47 HTML 5. Disponível em: <http://www.w3.org/TR/html5/>. Acessado em $11 / 11 / 2015$.

48 JavaScript. Disponível em: <https://www.javascript.com/>. Acessado em 14/09/2017.

49 JQuery. Disponível em: <https://jquery.com/>. Acessado em 14/09/2017.

50 CSS 3. Disponível em: < http://www.w3.org/Style/CSS/Overview.en.html>. Acessado em 11/11/2015.

51 PHP. Disponível em: <https://secure.php.net/>. Acessado em 14/09/2017.

52 Codelgniter. Disponível em: <https://codeigniter.com/>. Acessado em 14/09/2017. 
53 Netbeans. Disponível em: <https://netbeans.org/features/index.html/>. Acessado em 11/11/2015.

54 Android. Disponível em: <https://www.android.com/>. Acessado em 14/09/2017.

55 Android Webview. Disponível em: $<$ https://developer.android.com/reference/android/webkit/WebView.html>. Acessado em 14/09/2017.

56 Claridge N, Kirakowski J. WAMMl: website analysis and measurement inventory questionnaire. Retrived May. 2011;20:2013.

57 Mugueta-Aguinaga I, Garcia-Zapirain B. Is technology present in frailty? Technology a back-up tool for dealing with frailty in the elderly: a systematic review. Aging and disease. $2017 \mathrm{Apr} ; 8(2): 176$.

58 Chang YC, Lin CC, Lin PH, Chen CC, Lee RG, Huang JS, et al. (2013). eFurniture for home-based frailty detection using artificial neural networks and wireless sensors. Med Eng Phys, 35(2):263-268.

59 da Silva ML, Junior LA. Manual de Certificação para Sistemas de Registro Eletrônico em Saúde.

60 Roy S, Pattnaik PK, Mall R. A quantitative approach to evaluate usability of academic websites based on human perception. Egyptian Informatics Journal. 2014 Nov 1;15(3):159-67.

61 Ahmad A, Hussain A, Flayyih OH, Abdulwahab W, Sabri Ml. Utilizing WAMMI Components to Evaluate the Usability of E-commerce Website. Journal of Telecommunication, Electronic and Computer Engineering (JTEC). 2017 Sep 15;9(211):139-43.

62 Moore A, Parr G, Logan M, Neely H, Roesner D, Dürer U. Developing a European internet and kiosk-based health information system. Journal of medical Internet research. 2001 Jan;3(1). 


\section{GLOSSÁRIO}

Back-end: Camada do sistema responsável pela regra de negócios, webservices e APIs de uma aplicação.

Backups: Cópia de arquivos, pastas ou discos inteiros (físicos ou virtuais) para sistemas de armazenamento secundários.

Check-in: Registro de entrada em determinado estabelecimento.

Criptografia: Construção e análise de protocolos que impedem terceiros, ou o público, de lerem mensagens privadas.

Design: disciplina que tem por objetivo a criação de objetos ou produtos cuja forma se adeque o mais perfeitamente possível à função para que se destinam.

Desktop: Computadores de mesa, montados para serem usados de forma fixa em um determinado local.

Feedback: Informação que o emissor obtém da reação do receptor à sua mensagem, e que serve para avaliar os resultados da transmissão.

Framework: Uma abstração que une códigos comuns entre vários projetos de software provendo uma funcionalidade genérica.

Front-end: Camada do sistema responsável pela interface de interação com o usuário.

Gadget: Equipamento tecnológico criado para facilitar uma função específica e útil no cotidiano.

Hardware: Parte física de um computador ou dispositivo eletrônico formada por componentes eletrônicos. 
Hygia: Sistema de gestão em saúde utilizado nas unidades básicas de saúde.

Interface: Elemento que proporciona uma ligação física ou lógica entre dois sistemas ou partes de um sistema que não poderiam ser conectados diretamente.

Layout: Estrutura de arranjo e propriedades dos elementos que compõe uma página web.

Login: Nome utilizado para identificar a conta de acesso à um sistema.

Mobile: Que usa dispositivos ou serviços móveis.

Smartphone: Aparelho que combina recursos de celular com recursos de computadores pessoais.

Software: conjunto de componentes lógicos de um computador ou sistema de processamento de dados; programa, rotina ou conjunto de instruções que controlam o funcionamento de um computador; suporte lógico.

Tablet: Aparelho que combina recursos de celular com recursos de computadores pessoais, possui uma tela com tamanho superior a dos smartphones.

Web: Armazenado em servidores ligados à internet e acessível pela mesma. 


\section{ANEXOS}

ANEXO A - Triagem de Fragilidade / Risco de Perda de Autonomia

\section{GÉRONTOPÔLE BRÈSIL}

EVALUATION DES FRAGILITIES ET DE PREVENTION DE LA DEPENDANCE - HÔPITAUX DE TOULOUSE DIVISÃO DE GERIATRIA - HOSPITAL DAS CLÍNICAS DE RIBEIRÃO PRETO - FMRP USP

\section{TRIAGEM DE FRAGILIDADE / RISCO DE PERDA DE AUTONOMIA}

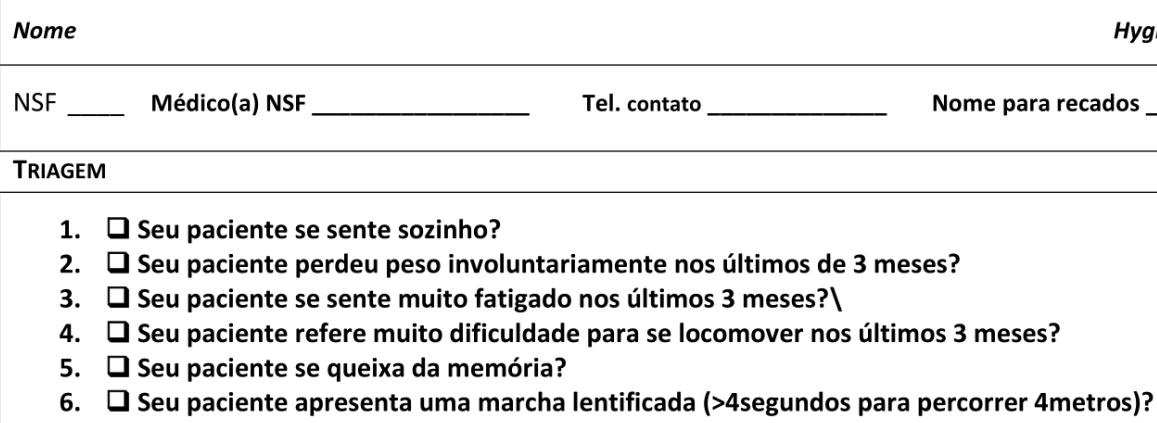

Se você respondeu SIM a uma destes perguntas $\gg$ SEU PACIENTE LHE PARECE FRÁGIL? $\square$ SIM $\square$ NÃO Se sim, ele aceitaria participar de uma avaliação de riscos de perda de autonomia em regime ambulatorial? $\square$ sIM $\square$ NÃo AgENDAR AVALIAÇÃO ATRAVÉS DO SISTEMA HYGIA - CN CSE - AMBULATÓRIO DE GERIATRIA CSE SUMAREZINHO

LISTA DE MEDICAÇõES DE USO CONTÍNUO

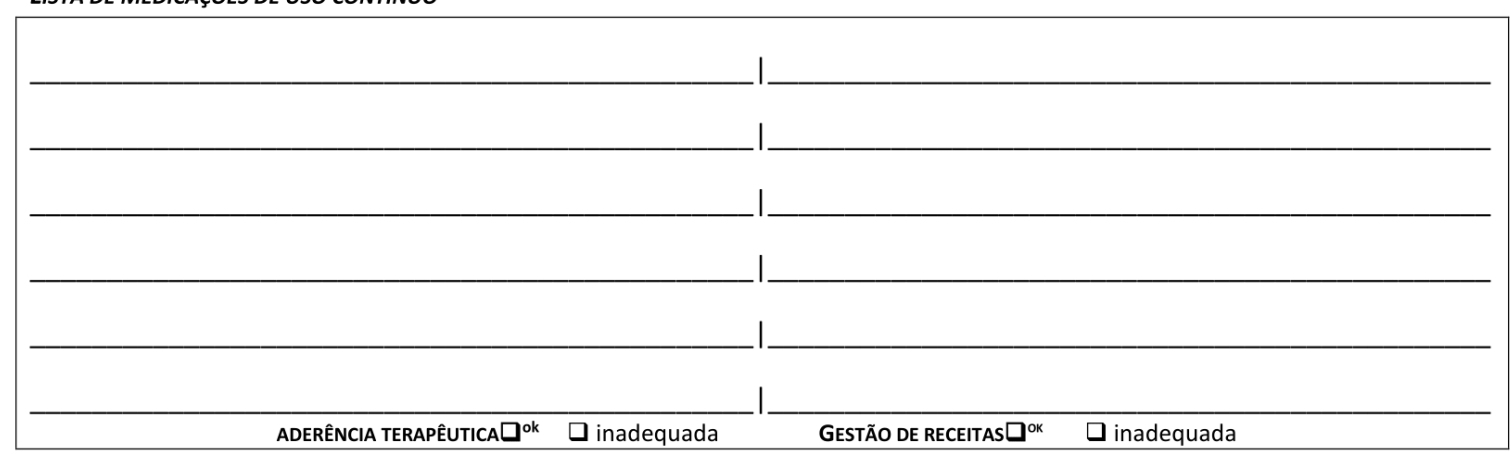
MORBIDADES CONHECIDAS

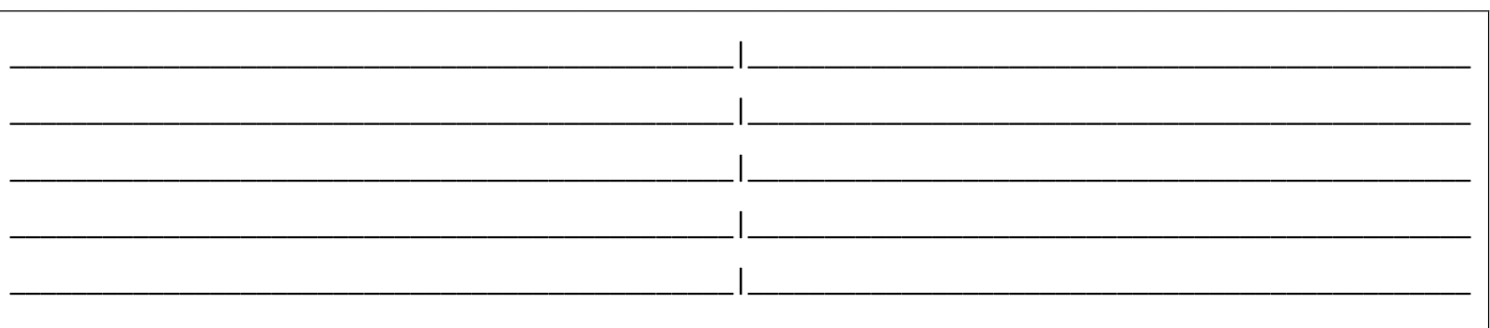

EXAMES NOS ÚLTIMOS 6MESES?

Glicemia em jejum Colesterol total
Hb glicada Triglicérides
Hemoglobina HDL col
Creatinina Albumina 
ANEXO B - TAGa10

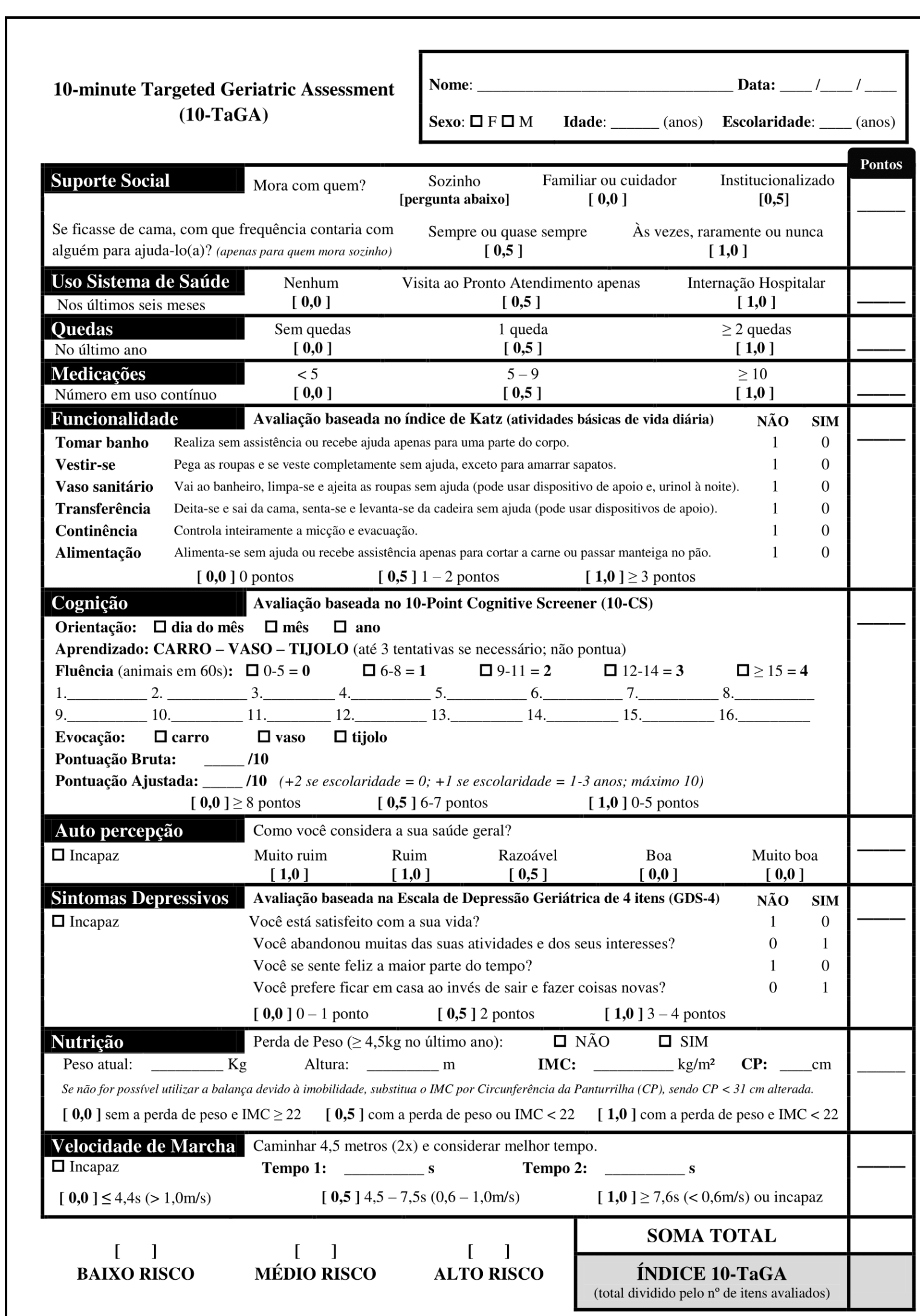


ANEXO C - Triagem Multiprofissional 


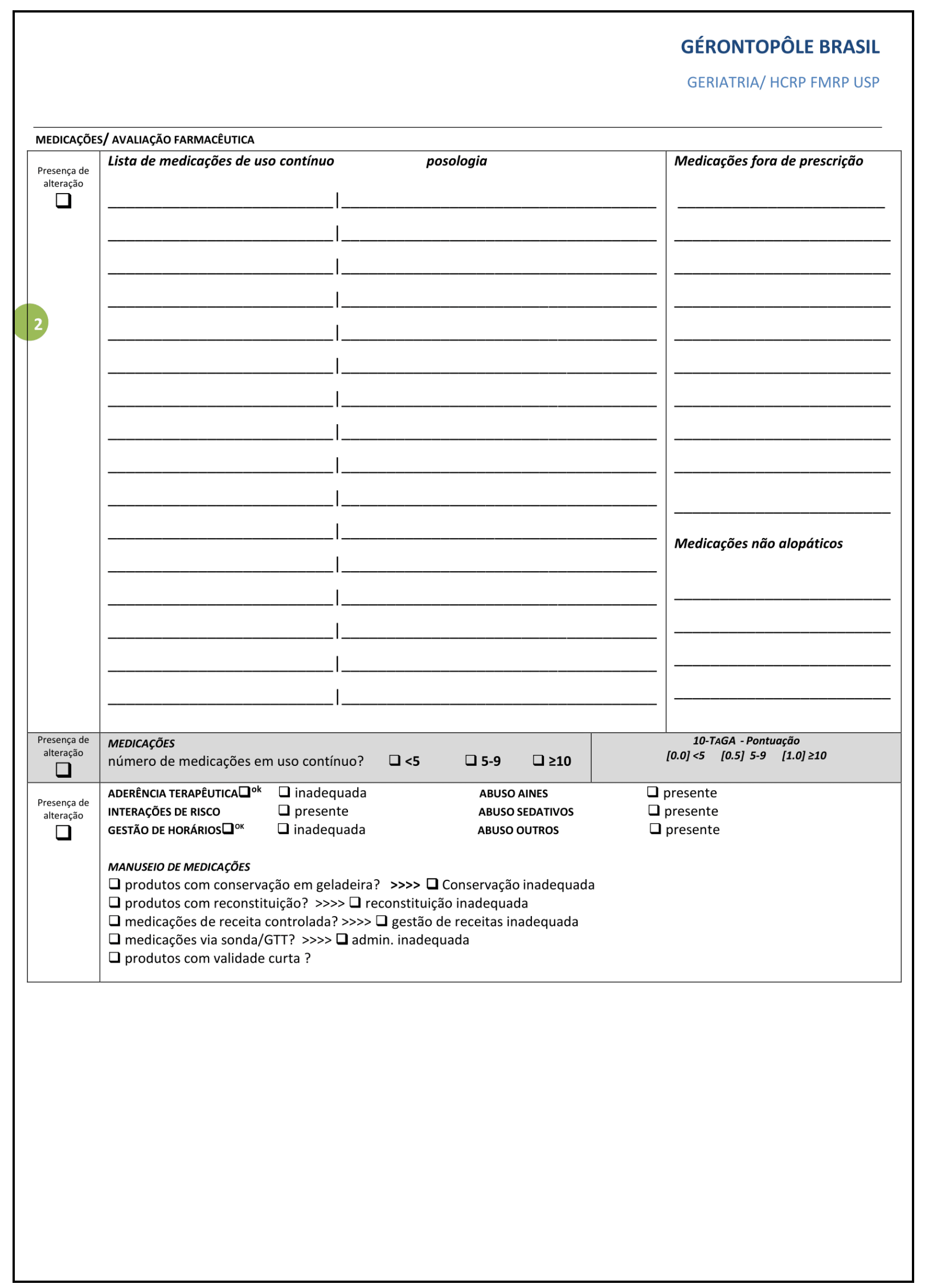




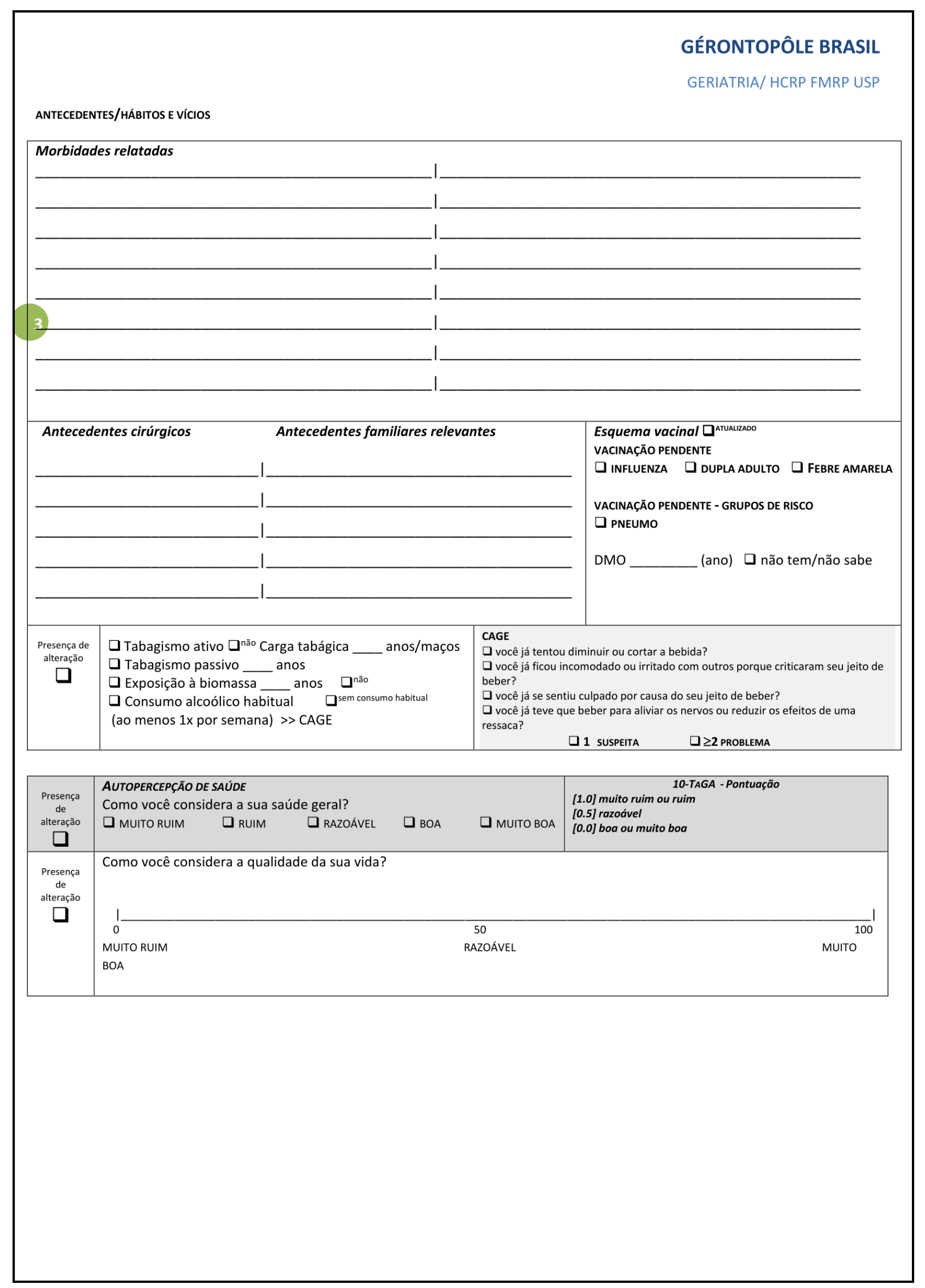




\section{GÉRONTOPÔLE BRASIL}

GERIATRIA/ HCRP FMRP USP

NUTRIÇÃO

\begin{tabular}{|c|c|c|c|}
\hline $\begin{array}{l}\text { Presença de } \\
\text { alteração }\end{array}$ & \multicolumn{2}{|c|}{ 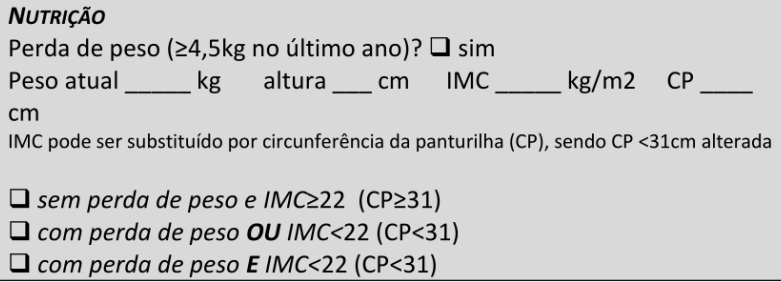 } & \\
\hline & & & \\
\hline \multirow[t]{2}{*}{$\begin{array}{l}\text { Presença de } \\
\text { alteração } \\
\text { PontUAÇão } \\
14 \text { máx }\end{array}$} & \multirow[t]{2}{*}{ 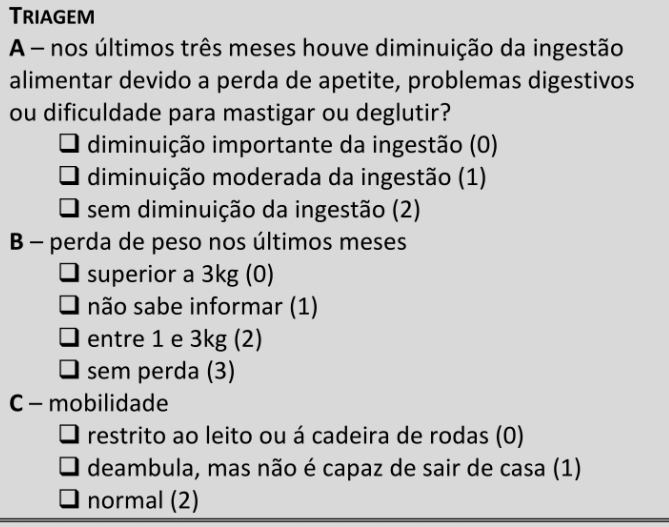 } & \multirow{2}{*}{\multicolumn{2}{|c|}{$\begin{array}{l}\text { D - passou por algum estresse psicológico ou do } \\
\text { nos últimos três meses } \\
\square \text { sim (0) } \\
\square \text { não (2) } \\
\text { E - problemas neuropsicológicos } \\
\square \text { demência ou depressão graves (0) } \\
\square \text { demência leve (1) } \\
\square \text { sem problemas psicológicos (2) } \\
\text { F - índice de massa corpórea } \\
\square \text { IMC <19 (0) } \\
\square 19 \leq \text { IMC <21 (1) } \\
\square 21 \leq \text { IMC <23 (2) } \\
\square \text { IMC } \geq 23(3) \\
\text { TRIAGEM ( }\end{array}$}} \\
\hline & & & \\
\hline $\begin{array}{l}\text { PONTUAÇão } \\
16 \text { máx }\end{array}$ & 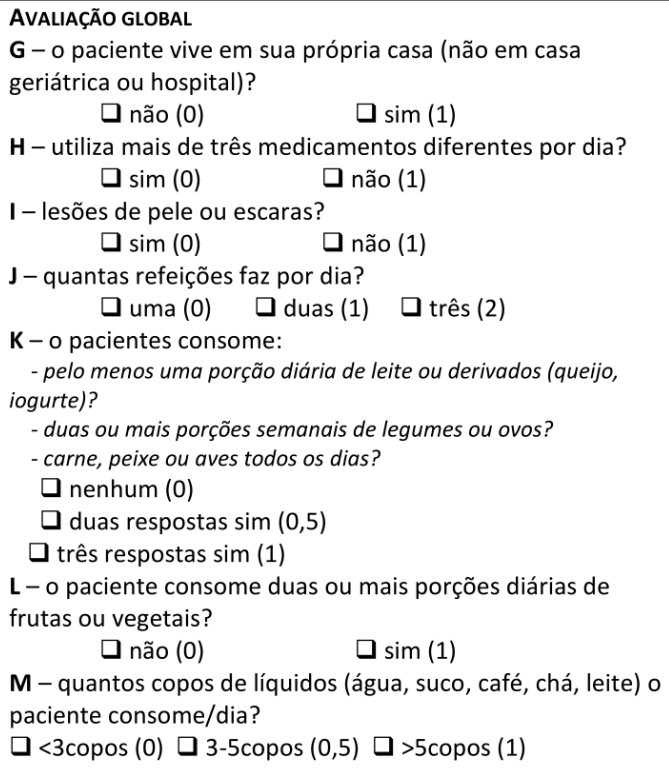 & \multicolumn{2}{|c|}{ 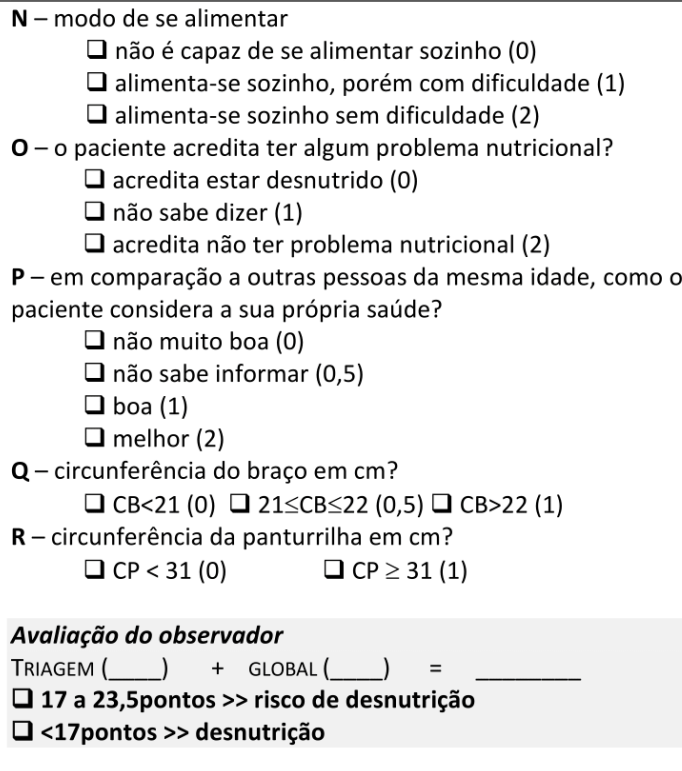 } \\
\hline
\end{tabular}




\section{GÉRONTOPÔLE BRASIL}

GERIATRIA/ HCRP FMRP USP

FUNCIONALIDADE

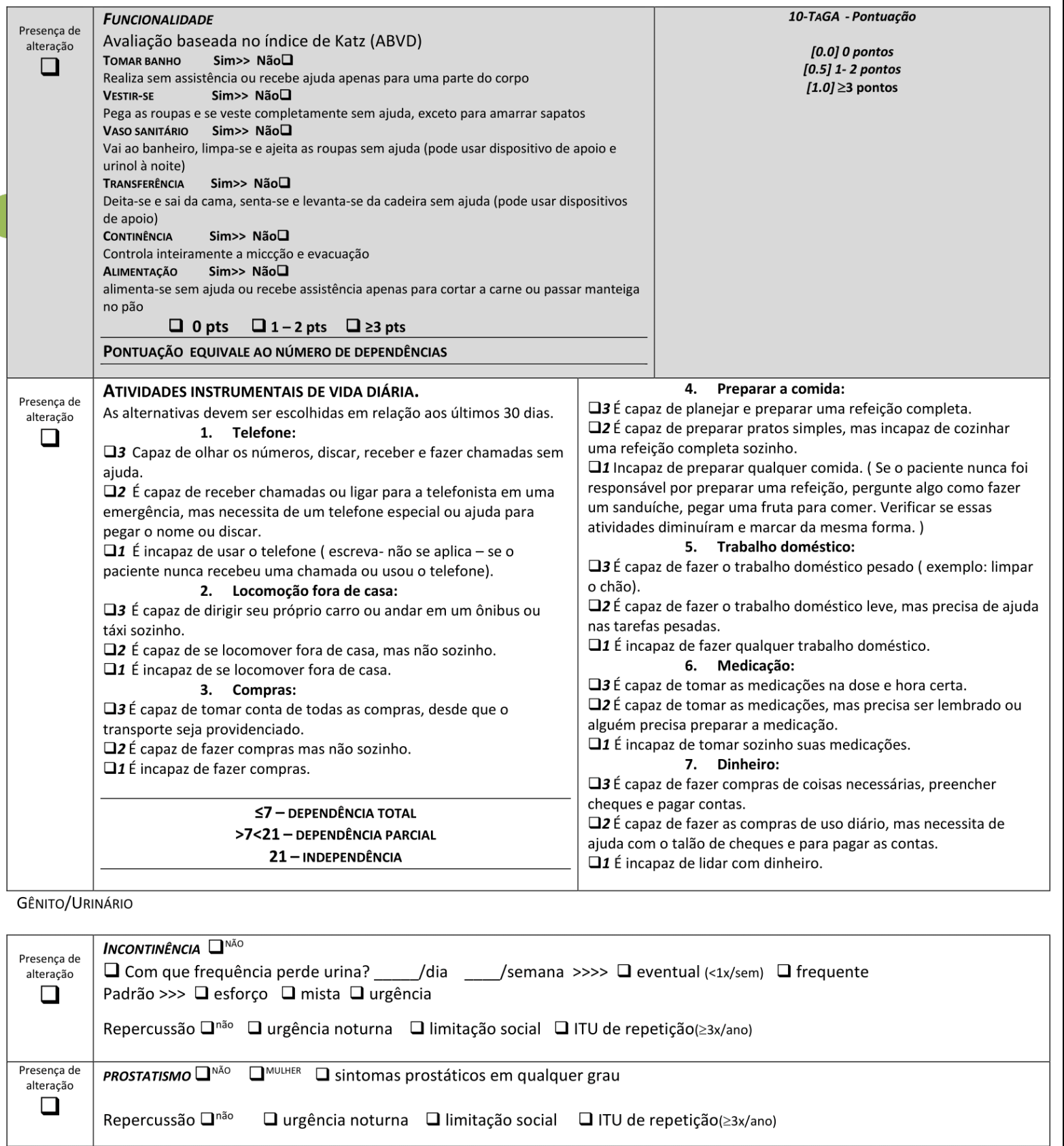




\section{GÉRONTOPÔLE BRASIL}

GERIATRIA/ HCRP FMRP USP

COGNIÇÃO

\begin{tabular}{|c|c|c|}
\hline $\begin{array}{l}\text { Presença de } \\
\text { alteração } \\
\square\end{array}$ & 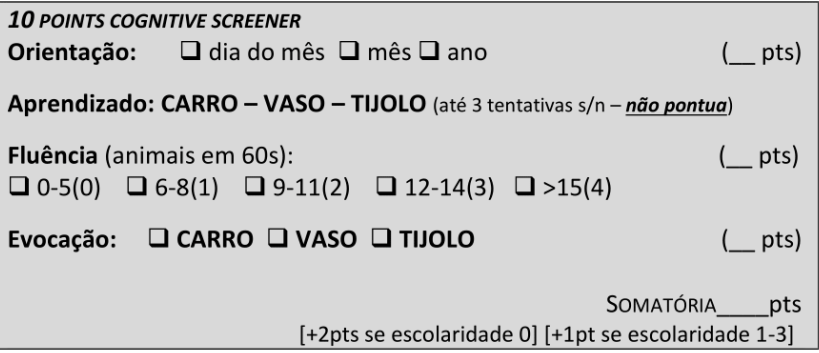 & $\begin{array}{c}\text { 10-TAGA - Pontuação } \\
{[0]>8 \mathrm{pts}} \\
{[0.5] 6-7 \mathrm{pts}} \\
{[1.0] 0-5 \mathrm{pts}}\end{array}$ \\
\hline PSIQUIÁTRI & & \\
\hline $\begin{array}{l}\text { Presença de } \\
\text { alteração }\end{array}$ & $\begin{array}{lc}\text { GDS - } 4 \text { DEPRESSÃO } & \\
\text { Você está satisfeito com a sua vida? } & \square \text { não } \\
\text { Você abandonou muito das suas atividades e dos seus interesses? } & \square \text { sim } \\
\text { Você se sente feliz a maior parte do tempo? } & \square \text { não } \\
\text { Você prefere ficar em casa ao invés de sair e fazer coisas novas? } & \square \text { sim } \\
& \text { SOMATÓRIA_pts }\end{array}$ & 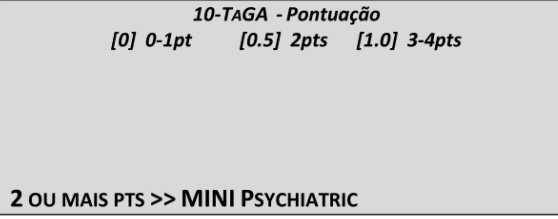 \\
\hline $\begin{array}{l}\text { Presença de } \\
\text { alteração }\end{array}$ & $\begin{array}{l}\text { FADIGA } \\
\text { Pensando na última semana, diga com que frequência as seguintes coisas } \\
\text { Sentiu que teve que fazer esforço (desproporcional) para dar conta das suas } \\
\square \text { nunca/raramente } \square \text { poucas vezes } \square \text { nas maioria das vezes* } \square \text { semp } \\
\text { Não conseguiu levar adiante suas coisas?? } \\
\square \text { nunca/raramente } \square \text { poucas vezes } \square \text { nas maioria das vezes* } \square \text { semp } \\
\text { Critério positivo se qualquer resposta com * (na maioria das vezes/sempre) }\end{array}$ & $\begin{array}{l}\text { tarefas habituais (cotidianas)?? } \\
\text { re* } \\
\text { re* }\end{array}$ \\
\hline $\begin{array}{l}\text { Presença de } \\
\text { alteração } \\
\square\end{array}$ & $\begin{array}{l}\text { ANSIEDADE GENERALIZADA } \\
\text { Durante Os últimos } 6 \text { meses, sentiu-se excessivamente preocupado(a), inqu } \\
\text { da vida cotidiana (trabalho/escola, casa, familiares/amigos), ou teve a impre } \\
\text { com tudo? } \square \operatorname{sim} \square^{\text {não } \gg>} \\
\text { NÃo COTAR SIM SE A ANSIEDADE DESCRITA CORRESPONDE A MEDO DE TER UM ATAQUE DE PÂNICO, D } \\
\text { (TOC), DE GANHAR PESO (ANOREXIA NERVOSA)... } \\
\text { Teve estas preocupações quase todos os dias? } \square \operatorname{sim} \quad \square^{\text {não }} \gg>\end{array}$ & $\begin{array}{l}\text { eto(a), ansioso(a) com relação a vários problemas } \\
\text { Ssão ou lhe disseram que se preocupava demais } \\
\text { SER HUMILHADO EM PÚBLICO (FOBIA SOCIAL), DE SER CONTAMINADO }\end{array}$ \\
\hline \multicolumn{3}{|l|}{ SONO } \\
\hline $\begin{array}{l}\text { Presença de } \\
\text { alteração } \\
\square\end{array}$ & 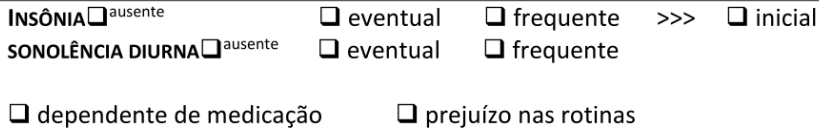 & $\square$ intermediário $\square$ final \\
\hline
\end{tabular}




\section{GÉRONTOPÔLE BRASIL}

GERIATRIA/ HCRP FMRP USP

PELE/TSC/SENSORIAL

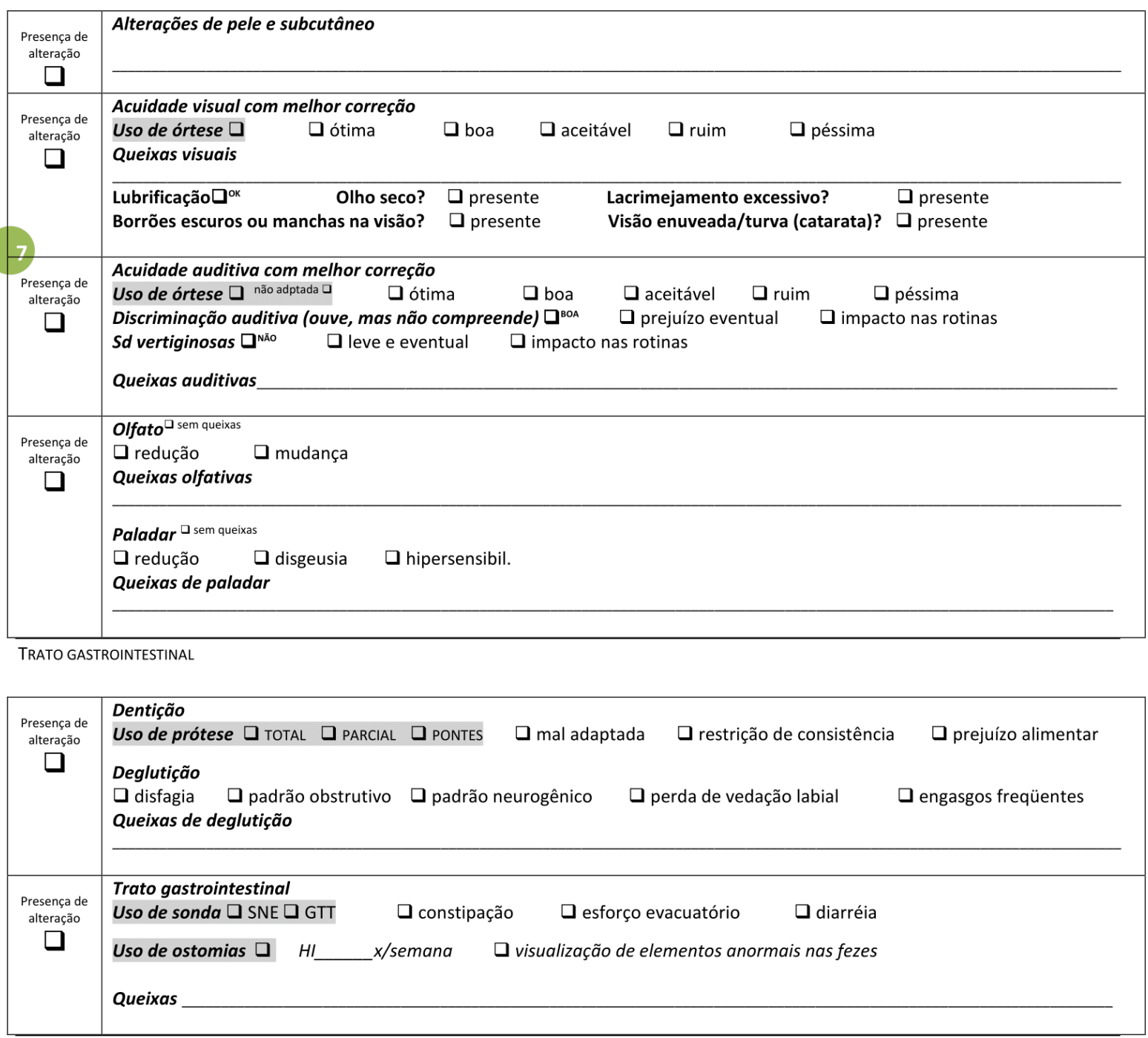


GÉRONTOPÔLE BRASIL

GERIATRIA/ HCRP FMRP USP

RESPIRATÓRIO E CARDIOVASCULAR

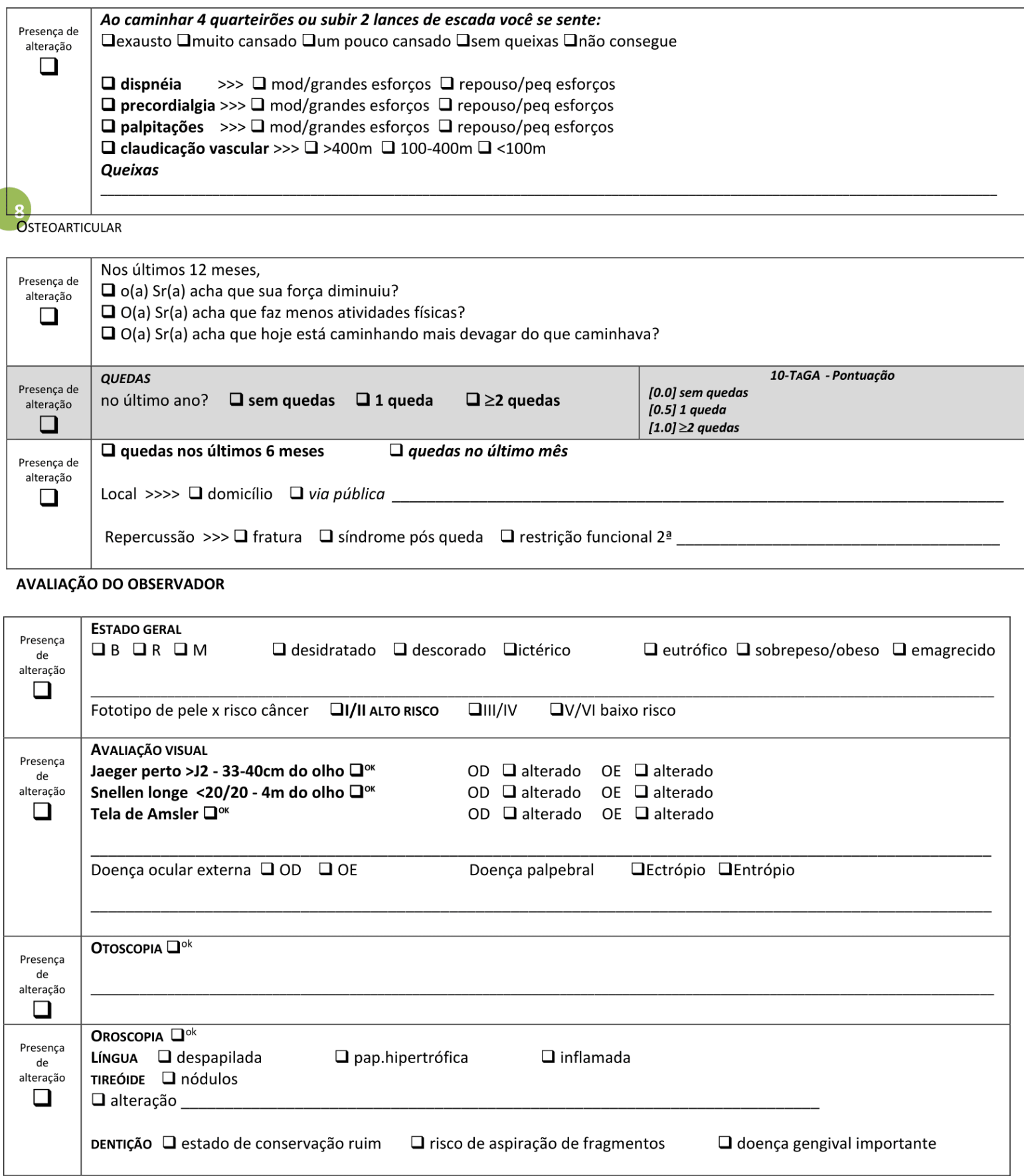




\section{GÉRONTOPÔLE BRASIL}

GERIATRIA/ HCRP FMRP USP

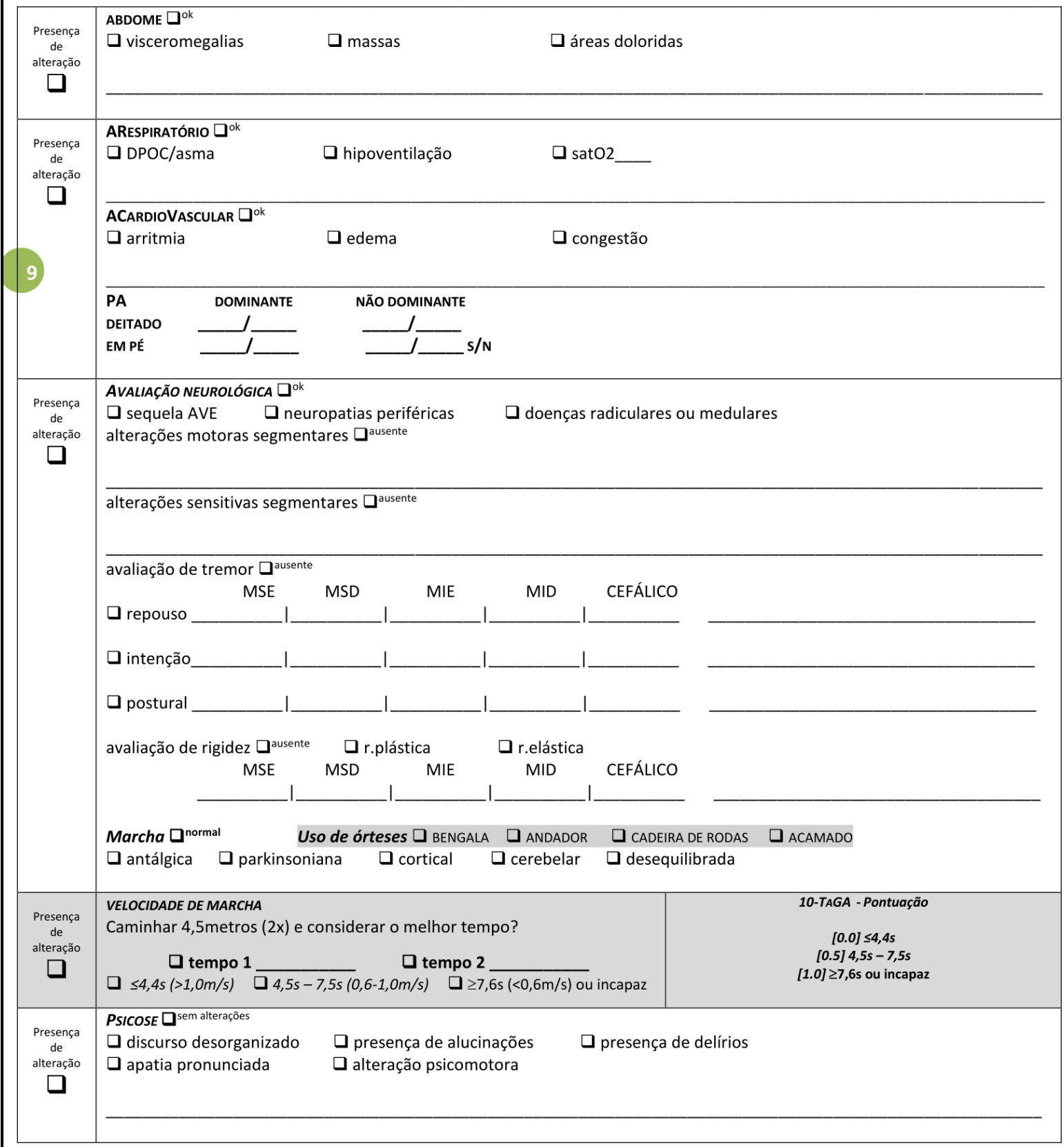




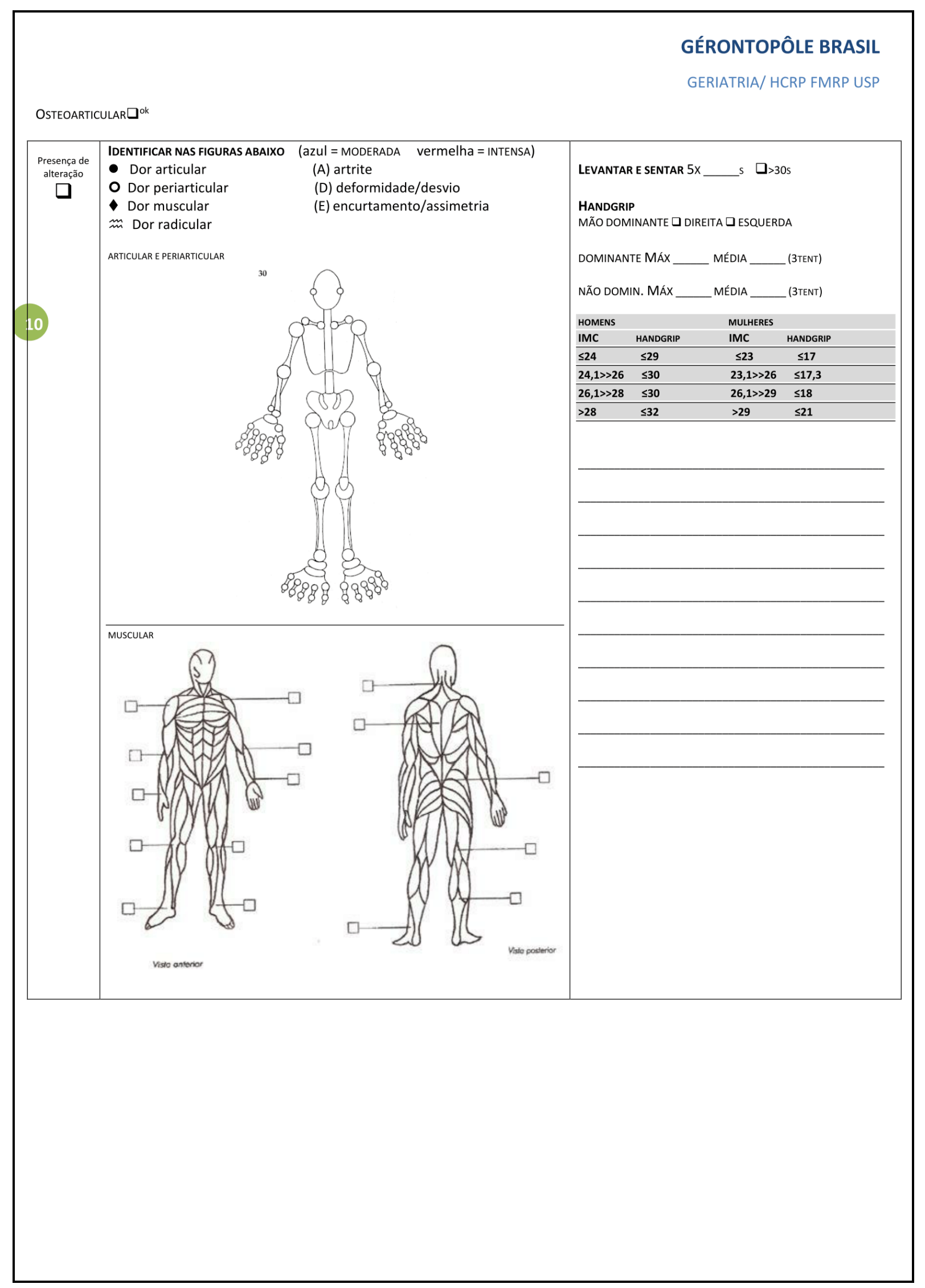




\section{GÉRONTOPÔLE BRASIL}

GERIATRIA/ HCRP FMRP USP

Avaliações finais

CRITÉRIOS START/ STOPP

Critérios de fragilidade

GFST__ critérios

Fried Upeso Dfadiga Uforça Umarcha Datividade

Diagnósticos finais

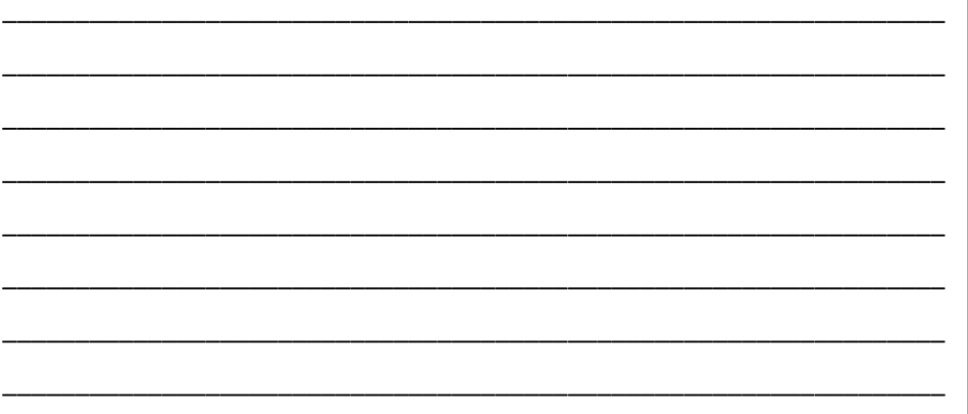

Avaliação do observador

$\square$ ALTO RISCO CARDIOVASCULAR (FRAM>20\%)

$\square$ ALTO RISCO DE SANGRAMENTO (dupla antiagregação, ACO+antiagregante, hepatopatia avançada)

ALTO RISCO FRATURA (artrite reumatóide, fraturas prévias, corticoterapia sistêmica prolongada, MM, neoplasia com metas ósseas, caidor crônico)

$\square$ ALTO RISCO TVP/TEP (neoplasia ativa, sind imobilidade, $S A F$, grande cirurgia recente)

\section{CONDUTAS}

Avaliação complementar $\gg \gg$

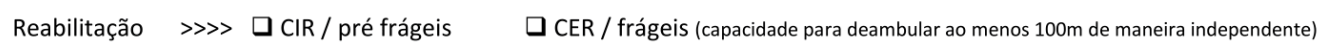

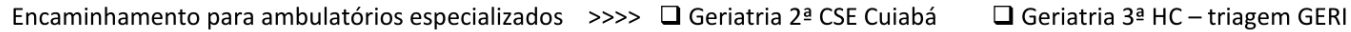


ANEXO D - Escala Auxiliar de Nutrição 


\section{GÉRONTOPÔLE BRÈSIL}

Clínica de Fragilidade - DIVISÃo DE GERIATRIA - HOSPITAL DAS CLÍNICAS DE RIBEIRÃO PRETO - FMRP USP

FluXo GÉRONTOPÔLE ESCALAS AUXILIARES NUTRIÇÃO

Questionário de triagem >> questionário de avaliação >> condutas padronizadas 


\section{GÉRONTOPÔLE BRÈSIL}

Clínica de Fragilidade - DIVISÃo dE GERIATRIA - HOSPITAL DAS CLÍNICAS DE RIBEIRÃO PRETO - FMRP USP

\begin{tabular}{|c|c|c|}
\hline Nome & data da avaliação _____ & \\
\hline $\begin{array}{l}\text { Presença de } \\
\text { alteração } \\
\square\end{array}$ & 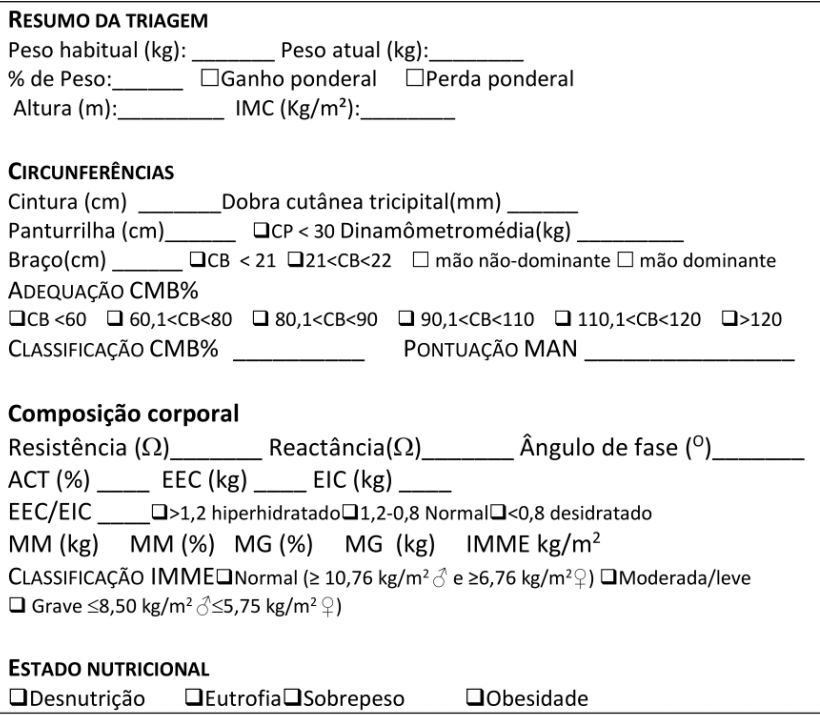 & $\begin{array}{l}\text { DISPONIBILIDADE MENSAL - PER CAPTA } \\
\text { Reside com quantas pessoas? } \\
\text { QUtiliza temperos prontos? } \\
\text { Disponibilidade de sal per capita: } \\
\text { Utiliza qual tipo de óleo? } \\
\text { Disponibilidade de óleo per capita: } \\
\text { Disponibilidade de açúcar per capita: } \\
\text { Utiliza } \square \text { açúcar ou Dadoçante? } \\
\text { Utiliza } \square \text { refrigerante } \square \text { suco industrializado } \\
\text { Disponibilidade per capita: }\end{array}$ \\
\hline
\end{tabular}

\begin{tabular}{|c|c|c|}
\hline \multirow{7}{*}{$\begin{array}{l}\text { Presençą de } \\
\text { alteração } \\
\square\end{array}$} & $\begin{array}{c}\frac{\text { REFEICÃOO }}{\text { HORÁRIO/LOCAL }} \\
\text { Hol }\end{array}$ & $\frac{\text { ALIMENTOS/BEBIDAS }}{\text { (MEDIDA CASEIRA) }}$ \\
\hline & Desjejum & \\
\hline & Lanche da manhã & \\
\hline & Almoço & \\
\hline & Lanche da tarde & \\
\hline & Jantar & \\
\hline & Ceia & \\
\hline
\end{tabular}

Erros alimentares:

Avaliação nutricional 


\section{GÉRONTOPÔLE BRÈSIL}

Clínica de Fragilidade - DIVISÃo DE GERIATRIA - HOSPITAL DAS CLÍNICAS DE RIBEIRÃO PRETO - FMRP USP

\begin{tabular}{|c|c|c|}
\hline $\begin{array}{c}\text { Presença de } \\
\text { alteração }\end{array}$ & \multicolumn{2}{|l|}{$\begin{array}{l}\text { SE ALTERAÇÕES NA DEGLUTIÇÃO } \\
\text { Fale sobre seu problema de engolir. }\end{array}$} \\
\hline & Liste todos os exames de deglutição que você fez (data e resultados). & \\
\hline $\begin{array}{l}\text { Presença de } \\
\text { alteração }\end{array}$ & $\begin{array}{l}\text { O quanto essas situações são um problema para você? Marque o melhor } \\
\text { número para o seu caso. } \\
\text { SITUAÇõEs } \\
\square 0 \square 1 \square 2 \square 3 \text { >>Meu problema para engolir me faz perder peso } \\
\square 0 \square 1 \square 2 \square 3 \text { >>Meu problema para engolir não me deixa comer fora de casa } \\
\square 0 \square 1 \square 2 \square 3 \text { >>Preciso fazer força para beber líquidos } \\
\square 0 \square 1 \square 2 \square 3 \text { >Preciso fazer força para engolir comida } \\
\square 0 \square 1 \square 2 \square 3 \text { >>Preciso fazer força para engolir remédios } \\
\square 0 \square 1 \square 2 \square 3 \text { >>Dói para engolir } \\
\square 0 \square 1 \square 2 \square 3 \text { >>Meu problema para engolir me tira o prazer de comer } \\
\square 0 \square 1 \square 2 \square 3 \text { >>Fico com comida presa/entalada na garganta } \\
\square 0 \square 1 \square 2 \square 3 \text { >>Eu tusso quando como } \\
\square 0 \square 1 \square 2 \square 3 \text { >>Engolir me deixa estressado } \\
\text { Total EAT-10 }\end{array}$ & $\begin{array}{l}\square 0 \text { - não é um problema } \\
\square 1 \text { - é um problema pequeno } \\
\square 2 \text { - é um problema razoável } \\
\square 3 \text { - é um problema muito grande }\end{array}$ \\
\hline
\end{tabular}

\begin{tabular}{|l|l|}
\hline DIAGNÓSTICO NUTRICIONAL \\
\hline \\
\hline
\end{tabular}

ORIENTAÇÕES

INDIVIDUALIZADAS

Avaliação nutricional 
ANEXO E - Escala Auxiliar de Fisioterapia 
GÉRONTOPÔLE BRÈSIL

Clínica de Fragilidade - DIVISÃo DE GERIATRIA - HOSPITAL DAS CLÍNICAS DE RIBEIRÃO PRETO - FMRP USP

FluXo GÉRONTOPÔLE

ESCALAS AUXILIARES FISIOTERAPIA

Questionário de triagem $\gg$ questionário de avaliação $\gg$ condutas padronizadas 
GÉRONTOPÔLE BRÈSIL

Clínica de Fragilidade - DIVISÃo dE GERIATRIA - HOSPITAL DAS CLÍNICAS DE RIBEIRÃO PRETO - FMRP USP

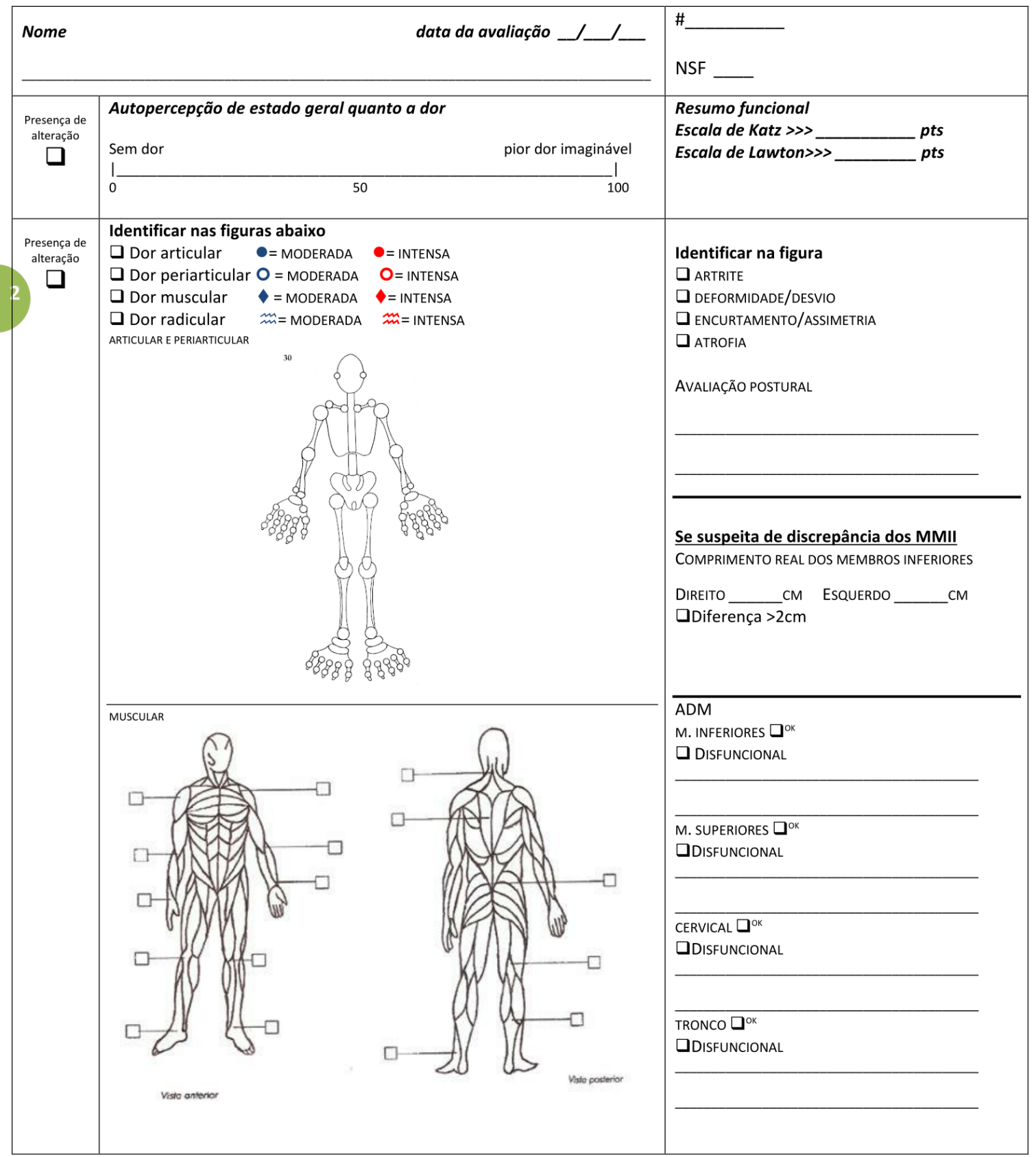




\section{GÉRONTOPÔLE BRÈSIL}

Clínica de Fragilidade - DIVISÃO DE GERIATRIA - HOSPITAL DAS CLÍNICAS DE RIBEIRÃO PRETO - FMRP USP

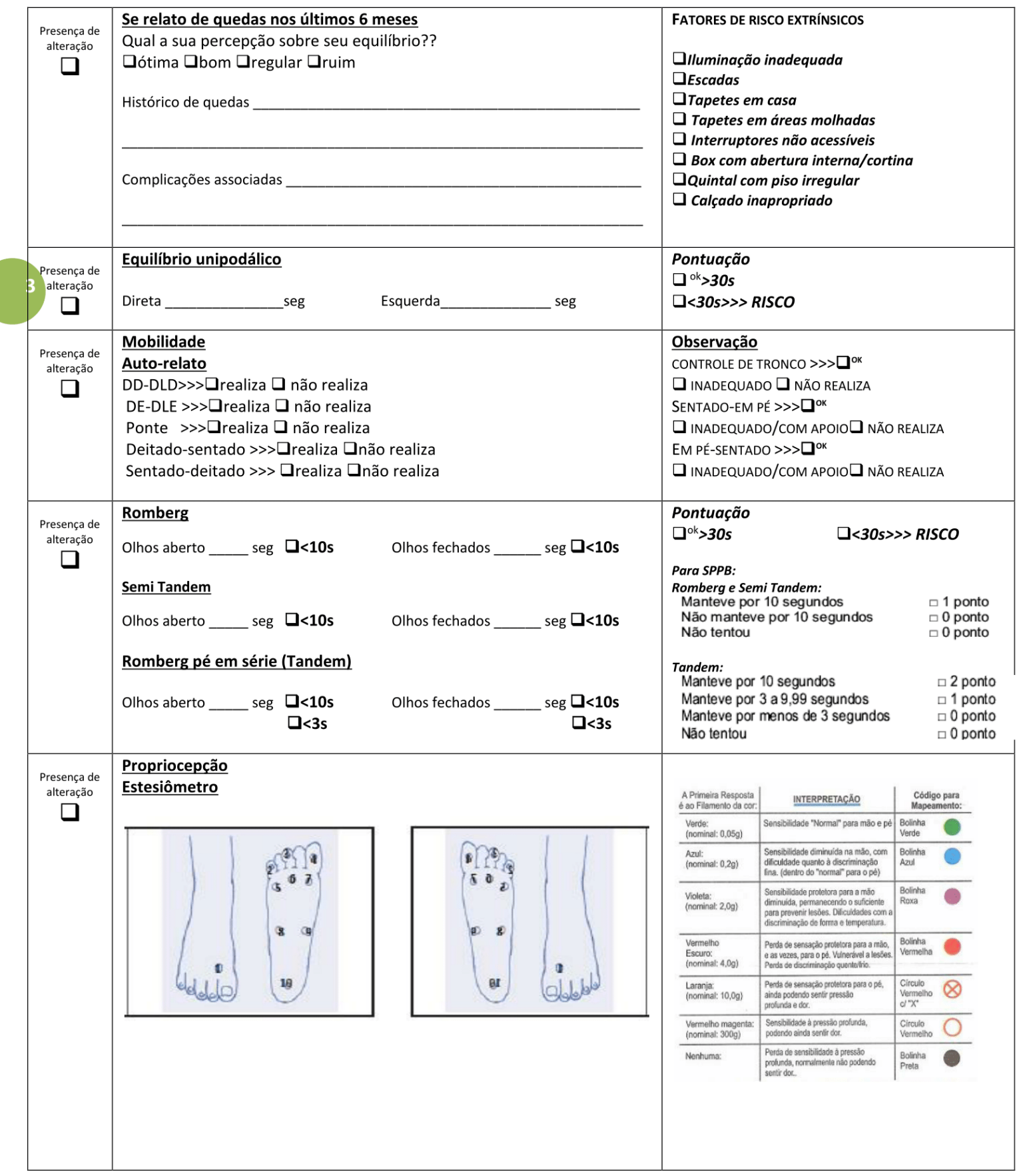


GÉRONTOPÔLE BRÈSIL

Clínica de Fragilidade - DIVISÃo DE GERIATRIA - HOSPITAL DAS CLÍNICAS DE RIBEIRÃO PRETO - FMRP USP

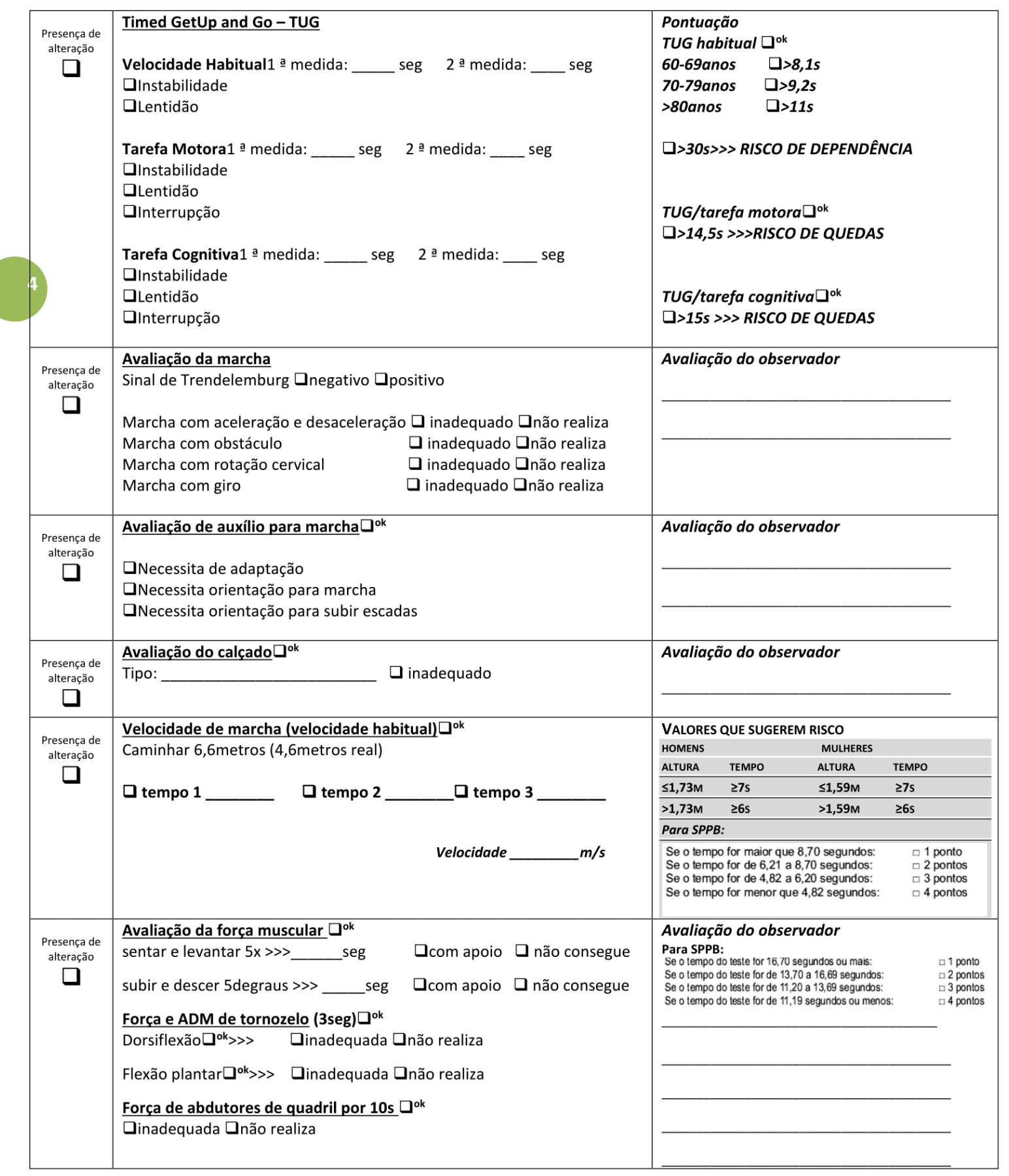


GÉRONTOPÔLE BRÈSIL

Clínica de Fragilidade - DIVISÃo DE GERIATRIA - HOSPITAL DAS CLÍNICAS DE RIBEIRÃO PRETO - FMRP USP

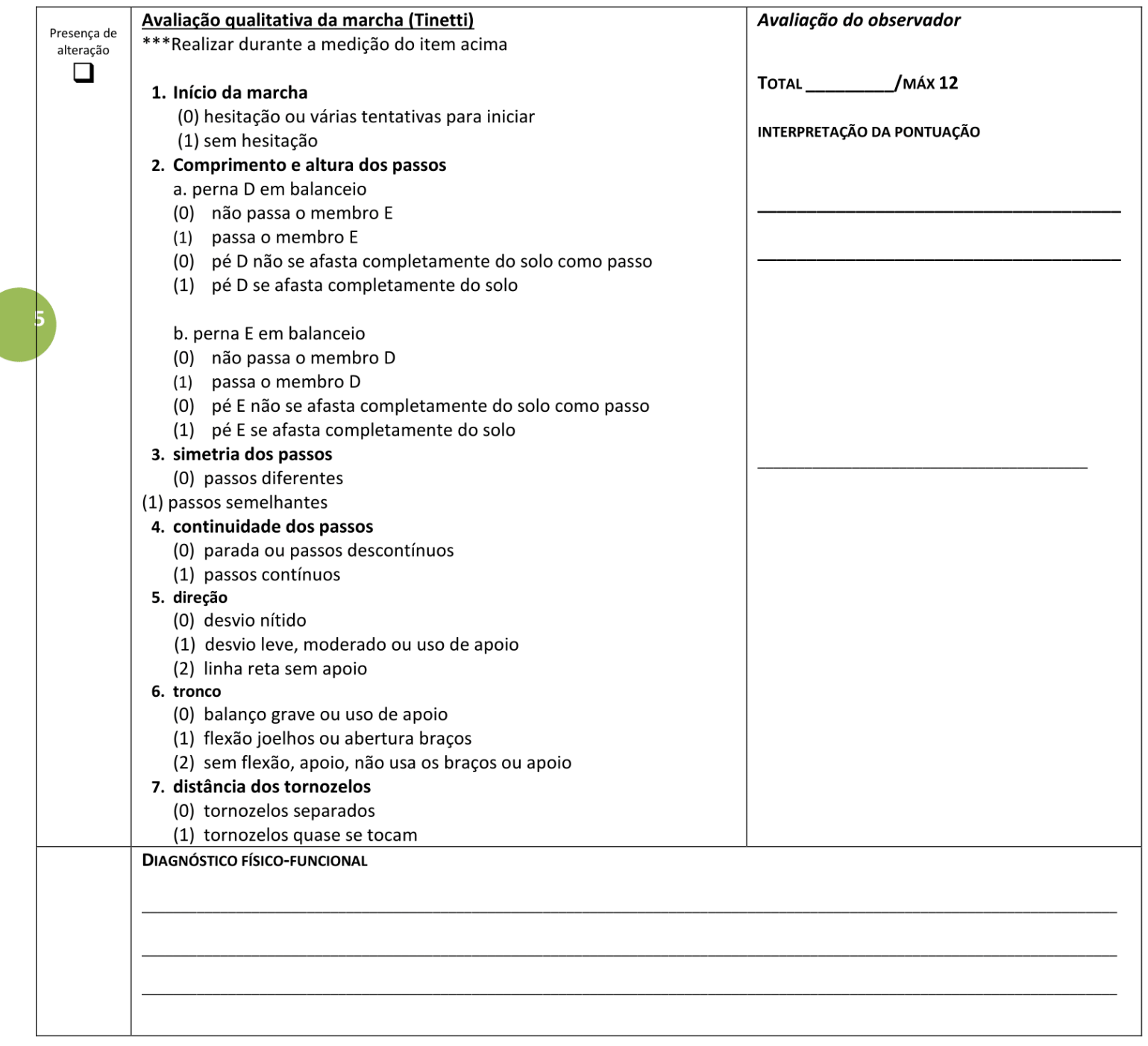

